\title{
Dietary management in COPD
}

Citation for published version (APA):

Vermeeren, M. A. P. (2004). Dietary management in COPD. [Doctoral Thesis, Maastricht University]. Universitaire Pers Maastricht. https://doi.org/10.26481/dis.20041110mv

Document status and date:

Published: 01/01/2004

DOI:

10.26481/dis.20041110mv

Document Version:

Publisher's PDF, also known as Version of record

\section{Please check the document version of this publication:}

- A submitted manuscript is the version of the article upon submission and before peer-review. There can be important differences between the submitted version and the official published version of record.

People interested in the research are advised to contact the author for the final version of the publication, or visit the DOI to the publisher's website.

- The final author version and the galley proof are versions of the publication after peer review.

- The final published version features the final layout of the paper including the volume, issue and page numbers.

Link to publication

\footnotetext{
General rights rights.

- You may freely distribute the URL identifying the publication in the public portal. please follow below link for the End User Agreement:

www.umlib.nl/taverne-license

Take down policy

If you believe that this document breaches copyright please contact us at:

repository@maastrichtuniversity.nl

providing details and we will investigate your claim.
}

Copyright and moral rights for the publications made accessible in the public portal are retained by the authors and/or other copyright owners and it is a condition of accessing publications that users recognise and abide by the legal requirements associated with these

- Users may download and print one copy of any publication from the public portal for the purpose of private study or research.

- You may not further distribute the material or use it for any profit-making activity or commercial gain

If the publication is distributed under the terms of Article $25 \mathrm{fa}$ of the Dutch Copyright Act, indicated by the "Taverne" license above, 
Dietary management in COPD 
ISBN 90-5278-427-2

(C) Copyright 2004 Marja Vermeeren, Geleen

All rights reserved. No part of this book may be reproduced or transmitted, in any form or by any means, without written permission from the author.

Cover design: Lenie en Walter Willems

Printed by: Datawyse / Universitaire Pers Maastricht

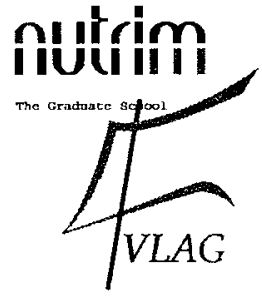

The studies presented in this thesis were performed at the Nutrition and Toxicology Research Institute Maastricht (NUTRIM), which participates in the Graduate School VLAG (Food Technology, Agrobiotechnology, Nutrition, and Health Sciences), accredited by the Royal Netherlands Academy of Arts and Sciences (KNAW). 


\title{
Dietary management in COPD
}

\author{
Proefschrift
}

ter verkrijging van de graad van doctor aan de Universiteit Maastricht, op gezag van de Rector Magnificus Prof. mr. GPMF Mols, volgens het besluit van het College van Decanen, in het openbaar te verdedigen op woensdag 10 november 2004 om 12.00 uur

door

Maria Adriana Petronella Vermeeren

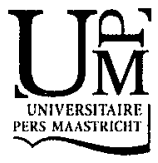


Promotores:

Prof. dr. EFM Wouters

Prof. dr. ir. AMWJ Schols

Beoordelingscommissie:

Prof. dr. R-JM Brummer (voorzitter)

Prof. dr. JJ van Binsbergen(Radboud Universiteit Nijmegen)

Prof. dr. WA van Staveren (Wageningen Universiteit)

Prof. dr. PB Soeters

Dr. MS Westerterp-Plantenga

The publication of this thesis was financially supported by: Nutricia Nederland BV, Stichting Pulmonologie, Stichting Hornerheide, GlaxoWellcome, Sorgente BV, Boehringer Ingelheim en Pfizer, AstraZeneca BV. 


\section{Contents}

$\begin{array}{lll}\text { Chapter } 1 \text { General introduction } & 7\end{array}$

$\begin{array}{lll}\text { Chapter } 2 & \text { Prevalence of nutritional depletion in a large } & 17\end{array}$ out-patient population of patients with chronic obstructive pulmonary disease

Chapter 3 Acute effects of different nutritional supplements on symptoms and functional capacity in patients with chronic obstructive pulmonary disease

Chapter $4 \quad$ Gastric emptying of different solid meals and postprandial response in patients with chronic obstructive pulmonary disease

Chapter 5 Energy balance in depleted ambulatory patients with chronic obstructive pulmonary disease; the effect of physical activity and oral nutritional supplementation

Chapter $6 \quad$ Effects of an acute exacerbation on nutritional and metabolic profile of patients with chronic obstructive pulmonary disease

Chapter $7 \quad$ Nutritional support in patients with chronic obstructive pulmonary disease during hospitalization for an acute exacerbation; a randomized controlled feasibility trial

Chapter 8 General discussion

Chapter 9 Summary

Chapter 10 Samenvatting

Abbreviations

Dankwoord 

Chapter

1

General introduction

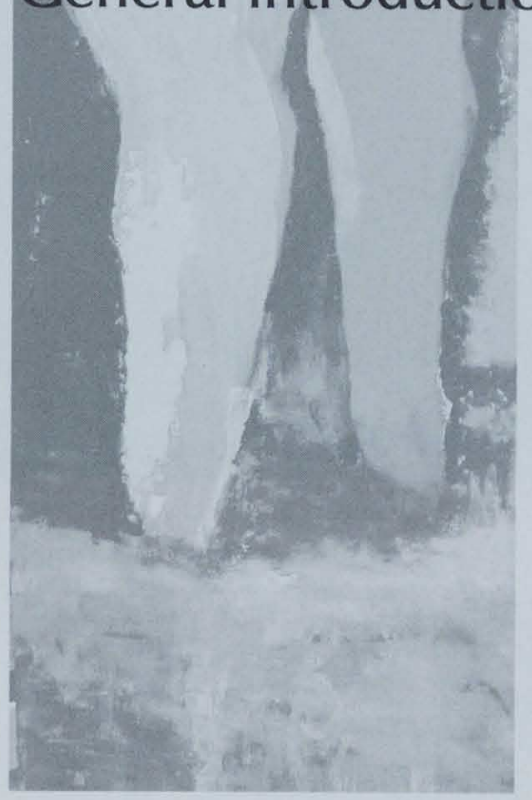


Chapter 1

8 


\section{Chronic obstructive pulmonary disease}

Chronic obstructive pulmonary disease (COPD) is a disabling condition with progressive and largely irreversible airflow limitation. The characteristic symptoms of COPD are dyspnoea, coughing and sputum production. Chronic airflow limitation characteristic of COPD is caused by a combination of small airway disease (obstructive bronchiolitis) and parenchymal destruction (emphysema). The relative contributions of these defects vary from person to person. COPD is mostly caused by a long-term smoking history. ${ }^{1}$

Recent guidelines for diagnosis and management of COPD are reported by The Global Initiative for Chronic Obstructive Lung Disease (GOLD)., ${ }^{1,2}$ GOLD is conducted in collaboration with the US National Heart, Lung, and Blood Institute (NHLBI) and the World Health Organization (WHO). The aims of GOLD are to increase awareness of COPD and decrease morbidity and mortality from the disease.

COPD causes considerable mortality and morbidity worldwide and is predicted to become the fourth leading cause of death and the fifth leading cause of disability by the year $2020 .^{3}$ In 2000 the prevalence of COPD in the Netherlands was estimated at $2.4 \%$ for men and $1.4 \%$ for women. ${ }^{4}$ The prevalence of COPD increases with age, with the highest rates seen in people 75 years and older $(16 \%$ in men and $4.4 \%$ in women). ${ }^{5}$ The future burden of COPD that was assessed by a modeling analysis predicted that the prevalence of COPD in 2015 would be increased in men by $59 \%$ and in women by $123 \%$. The higher rise in prevalence in females is predominantly due to changed smoking behavior. ${ }^{5}$

The impact of COPD in an individual patient depends largely on the severity of symptoms, especially breathlessness and decreased exercise capacity. Management of COPD is largely symptom driven, and there is an imperfect relationship between the degree of airflow limitation and the experienced symptomatology. ${ }^{6}$

\section{Exacerbations in COPD}

Exacerbations occur commonly in patients with moderate to very severe COPD. An exacerbation of COPD means a worsening of one of the common symptoms, like increased dyspnoea and/or cough and sputum volume. Unfortunately, there is no widely accepted definition of "an acute exacerbation of COPD". For the treatment of mild or moderate exacerbations in COPD antibiotics and/or corticosteroids are advised while severe exacerbations require admission to the hospital for medical treatment. Acute exacerbations of COPD are associated with an increase in health-care utilization, number of hospitalizations, and mortality. ${ }^{7}$ Furthermore, a more impaired health status was found in COPD patients with 
frequent exacerbations compared with COPD patients with infrequent exacerbations $^{8}$, indicating that the exacerbation rate has a negative influence on health status in COPD.

\section{Nutrition and COPD}

Several studies have showed that nutritional status plays an important role in patients with COPD. An increased risk in mortality was found in COPD patients with nutritional depletion. ${ }^{9,10}$ Furthermore, an increased risk of hospitalization ${ }^{11}$, an early non-elective readmission in COPD patients previously admitted for an exacerbation $^{12}$ and decreased survival time following a disease exacerbation ${ }^{13}$ have been found in depleted COPD patients. Nutritional depletion is associated with decreased muscle mass and muscle strength, in respiratory as well as in peripheral muscles, and an impaired exercise tolerance. ${ }^{14-16}$ Nutritional depletion is also related to health status ${ }^{17,18}$ in COPD patients: depleted COPD patients reported poorer health status.

Weight loss occurs frequently in COPD patients and is generally approached as an imbalance between energy expenditure and dietary intake. Altered energy and substrate metabolism and/or reduced dietary intake can cause this disturbed energy balance in COPD patients. Muscle wasting, a result of an imbalance between protein synthesis and protein breakdown, is also frequently reported in patients with COPD. ${ }^{19,20}$ The prevalence of nutritional depletion in moderate to

10 severe COPD patients was $35 \%$ in patients admitted to a pulmonary rehabilitation center ${ }^{19}$ and $20 \%$ in an out-patient COPD population. ${ }^{20}$ Unfortunately, data of the prevalence of nutritional depletion in COPD patients with mild or moderate COPD are still lacking.

Nutritional depletion is defined as a low body weight or as depletion of fat-free mass in patients with COPD. ${ }^{9,19}$ Nutritional intervention is indicated in COPD patients with nutritional depletion, with the aim to improve dietary intake resulting in gain of body weight and/or improvement of body composition.

The GOLD guidelines reported that effective management of COPD should have the following aims: prevention of disease progression, relief of symptoms, improvement of exercise tolerance, improvement of health status, prevention and treatment of complications and exacerbations and reduction of mortality. ${ }^{6}$ As described earlier, several aspects pointed as aims of the treatment, are related with nutritional status. Therefore nutritional screening and intervention should be integrated in a multi-disciplinary approach in patients with COPD. ${ }^{21}$

\section{Nutritional intervention in COPD patients}

Several studies have described the effects of nutritional intervention in COPD patients. ${ }^{22-33}$ The best effects of nutritional intervention in patients with COPD are 
reported when nutritional support was incorporated in a multi-disciplinary pulmonary rehabilitation program. ${ }^{9,22,33}$ Besides weight gain, an increase in FFM was accompanied with improvement of functional performance and better health status. ${ }^{22,33}$ When body weight increased by more than $2 \mathrm{~kg}$ during the rehabilitation program of 8 weeks, a decreased risk of mortality was found. ${ }^{9}$ The results about the effectiveness of nutritional support at home in COPD patients are less convincing. When nutritional intervention was started during a hospitalization period and continued at home, the results were better ${ }^{27,28}$ compared with nutritional support in the home setting alone. ${ }^{22-24,29,30}$

During acute exacerbations of COPD little is known concerning the effectiveness of nutritional intervention. Till now, only one study has described in a controlled design the effects of nutritional intervention during an acute exacerbation in hospitalized COPD patients. ${ }^{31}$ No significant improvement was found in body weight, inspiratory and peripheral muscle strength, but a trend was observed in improvement in well-being score. ${ }^{31}$ Besides a disturbed energy balance, COPD patients may be at increased risk for a negative nitrogen balance during an acute exacerbation, due to an enhanced systemic inflammatory response, high dose of systemic glucocorticoids, immobility and low protein intake. Only two studies have yet measured nitrogen balance in hospitalized COPD patients with an acute exacerbation. ${ }^{31,34}$ Both studies reported a negative nitrogen balance during an acute exacerbation of COPD and a negative correlation between high dose of methylprednisolone and nitrogen balance $(r=-0.73, p=0.0048)$ was found..$^{31}$ The efficacy of nutritional support during a period of negative nitrogen balance in terms of functional improvement depends on whether predominantly protein synthesis is decreased or whether there is accelerated protein breakdown. Protein supplementation will theoretically increase protein synthesis but not affect protein breakdown. During periods of acute protein breakdown this type of nutritional intervention will therefore not be able to induce a positive protein balance, but could limit the catabolic state.

Ventilation and nutrition are related since oxygen and nutrition are essential for life and participate in oxidative metabolism. Postprandial changes in $\mathrm{V}^{\prime} \mathrm{O}_{2}$ and $\mathrm{V}^{\prime} \mathrm{CO}_{2}$ appear after ingestion of nutrition ${ }^{35}$ and the composition of nutrition may influence the ventilatory load. Nutritional intervention might therefore have adverse effects in patients with COPD and since the current information is limited, further investigation is needed. 


\section{Aims of the thesis}

Although the importance of nutritional intervention is acknowledged, some important aspects concerning optimal implementation of nutritional support are still lacking in COPD patients.

The aims of the thesis addressed the current lack of dietetic information in COPD patients.

The aims of the thesis were:

1. to investigate the prevalence of nutritional depletion in an out-patient population of COPD patients.

2. to investigate the potential adverse effects of nutritional supplementation in patients with COPD and related factors accompanied with limited effectiveness of nutritional support.

3. to investigate the influence of exacerbations on nutritional profile and the feasibility of nutritional supplementation during hospitalization for an acute exacerbation of COPD.

\section{Outline of the thesis}

12 In this thesis, firstly the results of the studies during the stable phase of the disease are described (chapter 2-5). Secondly the studies during hospitalization for an acute exacerbation of COPD are presented (chapter 6 and 7).

\section{Stable disease condition}

The prevalence of nutritional depletion in COPD patients was investigated in a large multi-centre out-patient COPD population in the Netherlands (chapter 2). An important issue of nutritional supplements is the postprandial effects of supplements on exercise and symptoms in patients with COPD. For daily clinical practice, it is important to find out the optimal disease-related nutritional support strategy that improves muscle function but minimally interferes with symptoms and activity pattern. We therefore examine in chapter 3 the effects of a liquid oral nutritional supplement in different, but clinically applicable energy contents, on symptoms and exercise capacity. Furthermore the effects of a carbohydrate-rich versus a fat-rich supplement, at the most optimal energy load, on symptoms and exercise capacity in patients with COPD were investigated (chapter 3). Based on the difference in macronutrient content of the supplements described in chapter 3 , two test meals were composed to investigate the influence of different solid meals on gastric emptying. We hypothesized that delayed gastric emptying may 
occur in COPD patients with severe hyperinflation and this might be more pronounced after a fat-rich meal relative to a carbohydrate-rich meal. Besides rate of gastric emptying, several postprandial signs were measured in COPD patients and compared with a healthy control group (chapter 4).

Nutritional support in COPD patients in the community is less effective and several contributing factors can influence efficacy negatively. For instance, the influence of physical activity rate on energy balance in COPD patients at home is unknown. This issue was evaluated in COPD patients during a period of three months at home and the data are described in chapter 5 .

\section{Acute disease exacerbations}

In chapter 6 the metabolic profile of COPD patients admitted to the hospital for an acute exacerbation are described. In addition, the next step was a study to improve energy and protein intake in depleted COPD patients admitted to the hospital for an acute exacerbation. This study was performed in a randomized double-blind, placebo-controlled clinical trial in two centers and is presented in chapter 7.

In chapter $\mathbf{8}$ the results and conclusions presented in this thesis are discussed and implications for future investigations are given in the general discussion. 


\section{References}

1. Global Initiative for Chronic Obstructive Lung Disease (GOLD). NHLBI/WHO Workshop report: National Institutes of Health; April 2001. Report No.: Publication Number 2701.

2. GOLD newsletter. www.goldcopd.com August 2003.

3. Murray CJ, Lopez AD. Alternative projections of mortality and disability by cause 1990-2020: Global Burden of Disease Study. Lancet 1997;349(9064):1498-504.

4. Wouters EF. The burden of COPD in The Netherlands: results from the Confronting COPD survey. Respir Med 2003;97 Suppl C:S51-9.

5. Feenstra TL, van Genugten ML, Hoogenveen RT, Wouters EF, Rutten-van Molken MP. The impact of aging and smoking on the future burden of chronic obstructive pulmonary disease: a model analysis in the Netherlands. Am J Respir Crit Care Med $2001 ; 164(4): 590-6$.

6. Pauwels RA, Buist AS, Calverley PM, Jenkins CR, Hurd SS. Global strategy for the diagnosis, management, and prevention of chronic obstructive pulmonary disease. $\mathrm{NHLBI}$ WHO Global Initiative for Chronic Obstructive Lung Disease (GOLD) Workshop summary. Am J Respir Crit Care Med 2001;163(5):1256-76.

7. McCrory DC, Brown C, Gelfand SE, Bach PB. Management of acute exacerbations of COPD: a summary and appraisal of published evidence. Chest $2001 ; 119(4)$ : 1190-209.

8. Seemungal TA, Donaldson GC, Paul EA, Bestall JC, Jeffries DJ, Wedzicha JA. Effect of exacerbation on quality of life in patients with chronic obstructive pulmonary disease. Am J Respir Crit Care Med 1998;157(5):1418-22.

149 . Schols AM, Slangen J, Volovics L, Wouters EF. Weight loss is a reversible factor in the prognosis of chronic obstructive pulmonary disease. Am J Respir Crit Care Med 1998; 157:1791-7.

10. Landbo C, Prescott E, Lange P, Vestbo J, Almdal TP. Prognostic value of nutritional status in chronic obstructive pulmonary disease. Am J Respir Crit Care Med 1999;160(6):1856-61.

11. Kessler R, Faller M, Fourgaut G, Mennecier B, Weitzenblum E. Predictive factors of hospitalization for acute exacerbation in a series of 64 patients with chronic obstructive pulmonary disease. Am J Respir Crit Care Med 1999;159(1):158-64.

12. Pouw EM, Ten Velde GP, Croonen BH, Kester AD, Schols AM, Wouters EF. Early nonelective readmission for chronic obstructive pulmonary disease is associated with weight loss. Clin Nutr 2000;19(2):95-9.

13. Connors AF, Jr., Dawson NV, Thomas C, Harrell FE, Jr., Desbiens N, Fulkerson W], et al. Outcomes following acute exacerbation of severe chronic obstructive lung disease. The SUPPORT investigators (Study to Understand Prognoses and Preferences for Outcomes and Risks of Treatments). Am J Respir Crit Care Med 1996;154(4):959-67.

14. Nishimura $Y$, Tsutsumi $M$, Nakata $H$, Tsunenari $T$, Maeda $H$, Yokoyama $M$. Relationship between respiratory muscle strength and lean body mass in men with COPD. Chest 1995;107(5):1232-6.

15. Gosselink R, Troosters T, Decramer M. Peripheral muscle weakness contributes to exercise limitation in COPD. Am J Respir Crit Care Med 1996;153(3):976-80. 
16. Palange $P$, Forte $S$, Felli $A$, Galassetti $P$, Serra $P$, Carlone $S$. Nutritional state and exercise tolerance in patients with COPD. Chest 1995;107:1206-12.

17. Mostert R, Goris A, Weling-Scheepers C, Wouters EF, Schols AM. Tissue depletion and health related quality of life in patients with chronic obstructive pulmonary disease. Respir Med 2000;94(9):859-67.

18. Shoup $R$, Dalsky $G$, Warner $S$, Davies $M$, Connors $M$, Khan $M$, et al. Body composition and health-related quality of life in patients with obstructive airways disease. Eur Respir J 1997;10:1576-80.

19. Schols AM, Soeters PB, Dingemans AM, Mostert R, Frantzen PJ, Wouters EF. Prevalence and characteristics of nutritional depletion in patients with stable COPD eligible for pulmonary rehabilitation. Am Rev Respir Dis 1993;147(5): 1151-6.

20. Engelen MP, Schols AM, Baken WC, Wesseling G), Wouters EF. Nutritional depletion in relation to respiratory and peripheral skeletal muscle function in out-patients with COPD. Eur Respir J 1994;7(10):1793-7.

21. Celli BR, MacNee $W$ et al. Standards for the diagnosis and treatment of patients with COPD: a summary of the ATS/ERS position paper. Eur Respir J 2004;23: 932-46.

22. Schols AM, Soeters PB, Mostert R, Pluymers RJ, Wouters EF. Physiologic effects of nutritional support and anabolic steroids in patients with chronic obstructive pulmonary disease. A placebo-controlled randomized trial. Am J Respir Crit Care Med $1995 ; 152(4): 1268-74$.

23. Efthimiou J, Fleming J, Gomes C, Spiro SG. The effect of supplementary oral nutrition in poorly nourished patients with chronic obstructive pulmonary disease. Am Rev Respir Dis 1988;137(5):1075-82.

24. Lewis MI, Belman MJ, Dorr Uyemura L. Nutritional supplementation in ambulatory patients with chronic obstructive pulmonary disease. Am Rev Respir Dis 1987; 135:1062-8.

25. Knowles JB, Fairbarn MS, Wiggs BJ, Chan Yan C, Pardy RL. Dietary supplementation and respiratory muscle performance in patients with COPD. Chest 1988;93(5): 977-83.

26. Whittaker JS, Ryan CF, Buckley PA, Road JD. The effects of refeeding on peripheral and respiratory muscle function in malnourished chronic obstructive pulmonary disease patients. Am Rev Respir Dis 1990;142(2):283-8.

27. Rogers RM, Donahoe $M$, Costantino J. Physiologic effects of oral supplemental feeding in malnourished patients with chronic obstructive pulmonary disease. A randomized control study. Am Rev Respir Dis 1992;146(6):1511-7.

28. Fuenzalida CE, Petty TL, Jones ML, Jarrett S, Harbeck RJ, Terry RW, et al. The immune response to short-term nutritional intervention in advanced chronic obstructive pulmonary disease. Am Rev Respir Dis 1990;142(1):49-56.

29. Otte KE, Ahlburg P, F DA, Stellfeld M. Nutritional repletion in malnourished patients with emphysema. J Parenter Enteral Nutr 1989;13(2):152-6.

30. Sridhar MK, Galloway A, Lean ME, Banham SW. An out-patient nutritional supplementation programme in COPD patients. Eur Respir J 1994;7(4):720-4.

31. Saudny-Unterberger H, Martin JG, Gray-Donald K. Impact of nutritional support on functional status during an acute exacerbation of chronic obstructive pulmonary disease. Am J Respir Crit Care Med 1997;156:794-9. 
32. Wilson DO, Rogers RM, Sanders MH, Pennock BE, Reilly JJ. Nutritional intervention in malnourished patients with emphysema. Am Rev Respir Dis 1986;134:672-7.

33. Creutzberg EC, Wouters EF, Mostert R, Weling-Scheepers CA, Schols AM. Efficacy of nutritional supplementation therapy in depleted patients with chronic obstructive pulmonary disease. Nutrition 2003;19(2):120-7.

34. Thorsdottir I, Gunnarsdottir 1. Energy intake must be increased among recently hospitalized patients with chronic obstructive pulmonary disease to improve nutritional status. J Am Diet Assoc 2002;102(2):247-9.

35. Efthimiou J, Mounsey PJ, Benson DN, Madgwick R, Coles SJ, Benson MK. Effect of carbohydrate rich versus fat rich loads on gas exchange and walking performance in patients with chronic obstructive lung disease. Thorax 1992;47(6):451-6. 


\section{Chapter 2}

Prevalence of nutritional depletion in a large out-patient population of patients with chronic obstructive pulmonary disease

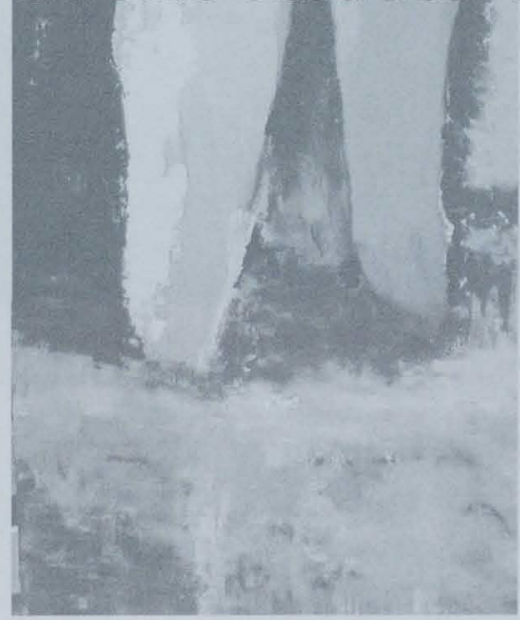

MAP Vermeeren, EC Creutzberg, AMWJ Schols, DS Postma, WR Pieters, AC Roldaan, EFM Wouters, on behalf of the COSMIC Study Group

Submitted 


\section{Abstract}

\section{Introduction}

Nutritional depletion and muscle dysfunction commonly occur in patients with chronic obstructive pulmonary disease (COPD). The present study focuses on the prevalence of nutritional depletion in relation to functional performance, airflow limitation, experienced dyspnoea and health status in a large multi-center out-patient population with moderate to severe COPD.

\section{Methods}

In 39 out-patient centers in the Netherlands, 389 patients with moderate to severe COPD (217 men) were recruited. The study evaluated baseline characteristics of the COSMIC study. Measurements included lung function by spirometry, body composition by bioelectrical impedance analysis, dysnoea by MRC-score and peripheral muscle function by isometric handgrip strength. Disease-specific health status was assessed by St. George Respiratory Questionnaire (SGRQ).

\section{Results}

The prevalence of nutritional depletion (defined as body mass index $(B M l) \leq 21 \mathrm{~kg} / \mathrm{m}^{2}$ and/or fat-free mass index (FFMI) $\leq 15$ (females) or $\leq 16$ (males) $\mathrm{kg} / \mathrm{m}^{2}$ ) was high $(27 \%$ ). Prevalence of different categories of depletion, $73 \%$ normal BMI and normal FFMI, 15\% only low FFMI, $1 \%$ only low BMI and $11 \%$ low BMI and low FFMI. The prevalence of low $\mathrm{BMI}$ as well as low FFMI was significantly higher in female than in male COPD patients, $18 \%$ and $40 \%$ versus $10 \%$ and $20 \%$ respectively (both $\mathrm{p}<0.01$ ). No differences in $\mathrm{FEV}_{1}$ \%predicted, dyspnoea score and health status were observed between depleted and nondepleted COPD patients. Multiple regression analysis in the total group, showed that handgrip strength correlated with FFMI after correction for sex distribution and age $(r=0.22, p<0.001)$, but not FEV 1 \%predicted.

\section{Conclusions}

The prevalence of nutritional depletion was high in a large out-patient COPD population in the Netherlands, especially in female COPD patients. Depletion of FFM was associated with impaired peripheral muscle strength, independently of disease severity. 


\section{Introduction}

Nutritional depletion commonly occurs in patients with chronic obstructive pulmonary disease (COPD). Its prevalence is increasing from $20 \%$ in clinically stable out-patients ${ }^{1}$ up to $35 \%$ in patients eligible for pulmonary rehabilitation. ${ }^{2}$ Whole body muscle wasting, and in particular muscle wasting of the extremities frequently occurs in patients with COPD. ${ }^{3}$ Furthermore, depletion of fat-free mass (FFM) may even occur in normal-weight COPD patients. ${ }^{2}$ Loss of FFM, as an indirect measure of muscle mass, adversely affects respiratory and peripheral muscle function ${ }^{1}$, exercise capacity ${ }^{2}$, health status $^{4}$, and even mortality rates. ${ }^{5}$ Thus nutritional depletion has an important impact on COPD.

At this moment, most studies concerning the prevalence of depletion in COPD patients have been performed in selected populations such as patients eligible for pulmonary rehabilitation, hospitalized patients, patients undergoing lung volume reduction surgery (LVRS) or treated with long-term oxygen therapy., ${ }^{2,6-11}$ Only Engelen et al has described the prevalence of depletion in an out-patient population. ${ }^{1}$ However, this study had a small sample size and was performed in a single-center.

To our knowledge, no data have been published on the prevalence of muscle wasting in COPD in a large out-patient multi-center setting. Furthermore it is yet unclear if nutritional depletion and thereby reduced muscle function are associated with the severity of airflow limitation or with other factors like gender, age and clinical symptoms or quality of life.

The present study therefore investigates the prevalence of nutritional depletion in relation to functional performance, airflow limitation, dyspnoea, and health status in a large out-patient COPD population. This study was applied on the baseline characteristics of the COSMIC (COPD and Seretide: a multi-center intervention and characterization) study; a double-blind, parallel group study on the efficacy of the salmeterol/fluticasone combination product in comparison with salmeterol alone in patients with moderate to severe COPD.

\section{Methods and materials}

\section{Patients}

In 39 out-patient centers in The Netherlands, patients were recruited to participate in the COSMIC study. Inclusion criteria were:

1. age $40-75$ years

2. an established clinical history of COPD 
3. current or ex-smokers with $\geq 10$ pack years

4. pre bronchodilator $\mathrm{FEV}_{1}$ \%predicted: 30-70\%predicted

5. reversibility after inhalation of a $\beta_{2}$-agonist ( $400 \mu \mathrm{g}$ salbutamol): $<10 \% \mathrm{FEV}_{1}$ \%predicted

6. history of at least two COPD exacerbations in the last year requiring oral corticosteroids and/or antibiotics.

Patients were excluded if they were suffering from respiratory diseases other than COPD or other disorders, if they required regular oxygen therapy or maintenance systemic corticosteroids or if there was evidence for alcohol, drug or solvent abuse.

The study was approved by a central medical ethics committee in The Netherlands and by the local medical ethics committees of the participating centers. All subjects gave written informed consent.

\section{Lung function}

Forced expiratory volume in one second $\left(\mathrm{FEV}_{1}\right)$ was calculated from the flow volume curve measured by spirometry. The highest value from at least three technically acceptable spirometric maneuvers was used and expressed as percentage of reference value. ${ }^{12}$

\section{Disease severity}

Disease severity was defined according to the currently published GOLD guideline ${ }^{13}$ and updated supplement. ${ }^{14}$ We divided our patients on base of post bronchodilator FEV $\mathrm{F}_{1}$ into stage 2, moderate COPD: FEV 1 50-80 \%predicted and with or without symptoms; and stage 3, severe COPD: FEV $130-50 \%$ predicted and with or without symptoms. According to the inclusion criteria, patients with GOLD stage 1 and 4 did not participate in the study.

\section{Body weight and body composition}

Body height was determined to the nearest $0.5 \mathrm{~cm}$ with subjects standing barefoot. Body weight was assessed with the beam scale to the nearest $0.1 \mathrm{~kg}$, with subjects standing barefoot and in light clothing. Body mass index (BMI) was calculated as body weight in $\mathrm{kg} /(\text { height in } \mathrm{m})^{2}$. Depletion of body weight was defined as $B M I \leq 21 \mathrm{~kg} / \mathrm{m}^{2}$. Body composition was estimated using single frequency $(50 \mathrm{kHz})$ bio-electrical impedance analysis (Bodystat 1500, Bodystat Ltd., Douglas, Isle of Man, Britian) while subjects were in supine position. The measurements were performed by trained personnel. FFM was calculated from COPD- and gender-specific regression equations. ${ }^{15}$ FFM depletion was defined as FFM index (FFMl: FFM in kg/(height in $\mathrm{m})^{2}$ ) $\leq 15$ (females) or $\leq 16$ (males) $\mathrm{kg} / \mathrm{m}^{2}{ }^{2}$ Fat mass (FM) was calculated by subtracting FFM from body weight. FM index (FMl) was calculated as $F M$ in $\mathrm{kg} /$ (height in $\mathrm{m})^{2}$. Patients were divided in four different categories based on BMI and FFMI: normal BMI and normal FFMl; normal BMI and low FFMI; low BMI and normal FFMI; low BMI and low FFMI. ${ }^{2}$ 
Peripheral muscle function

Peripheral muscle function was assessed by isometric handgrip strength using a hand-held dynamometer (JAMAR, Preston, Jackson, Michigan, USA). The isometric grasp was determined by measuring the maximally developed strength of the flexors of the right and left hand respectively. The highest value of three maneuvers was used. The mean of the highest value per hand was used in the analysis.

\section{Dyspnoea}

Experienced breathlessness was assessed by the Medical Research Council (MRC). The MRC dyspnoea scale is a validated and simple questionnaire (16) that consists of five statements: grade 1, "I only get breathless with strenuous exercise"; grade 2 , "I get short of breath when hurrying on the level or up a slight hill"; grade 3 , "I walk slower than people of the same age on the level because of breathlessness or have to stop for breath when walking at my own pace on the level"; grade 4, "I stop for breath after walking 100 meter or after a few minutes on the level"; grade 5, "I am too breathless to leave the house". The patients selected the grade that applied to them. MRC-score 3,4 and 5 were classified as having severe dyspnoea, corresponding with moderate to severe disability. ${ }^{16}$

\section{Disease-specific health status}

Disease-specific health status was measured by the St. George's Respiratory Questionnaire (SGRQ), with the domains: symptoms, activity, impact and total. ${ }^{17}$ The SGRQ is a broadly used and well validated questionnaire for the assessment of health status in COPD. A higher score of SGRQ means greater impairment in health status.

\section{Statistics}

To analyze possible associations between the different parameters, Pearson product moment correlation coefficients were calculated. When appropriate, partial correlation coefficients were calculated to control for the influences of gender distribution and age. ANOVA was used with age and sex as covariates to explain the differences between depleted and non-depleted COPD patients in handgrip strength and health status. A linear stepwise regression model was applied on the data to reveal which variables independently contributed to the variation in handgrip strength in the patients.

A p-value of less than 0.05 was considered statistically significant. Data were expressed as mean $\pm \mathrm{SD}$ or as median (range) in the text and tables. The statistical analyses were performed using the Statistical Product and Service Solutions (SPSS, version 11.0 for Windows, SPSS Inc., Chicago, IL, USA). 


\section{Results}

The study group consisted of 389 patients with COPD (271 men, $70 \%$ ); table 2.1 shows the characteristics of patients with COPD. According to the GOLD guidelines, the study group represented 214 patients with GOLD stage $2(55 \%)$ and 175 patients with GOLD stage 3 (45\%).

Table 2.1 Characteristics of the total out-patient COPD population

\begin{tabular}{lc}
\hline & $\mathrm{n}=389$ \\
\hline Male/female & $271 / 118$ \\
Age, years & $63 \pm 7$ \\
$\mathrm{FEV}_{1}$ \%predicted & $51 \pm 11$ \\
Body Mass Index, $\mathrm{kg} / \mathrm{m}^{2}$ & $26.1 \pm 4.3$ \\
Fat-free mass index, $\mathrm{kg} / \mathrm{m}^{2}$ & $17.2 \pm 2.2$ \\
Fat mass index, $\mathrm{kg} / \mathrm{m}^{2}$ & $8.8 \pm 2.8$ \\
\hline
\end{tabular}

Data are mean $\pm \mathrm{SD} ; \mathrm{FEV}_{1}$ : forced expiratory volume in one second post bronchodilator

\section{Prevalence of depletion}

The prevalence of nutritional depletion (defined as BMI $\leq 21 \mathrm{~kg} / \mathrm{m}^{2}$ and/or FFMI $\leq 15$ (females) or $\leq 16$ (males) $\mathrm{kg} / \mathrm{m}^{2}$ ) was $27 \%$ in the total study population. When assessing different types of depletion, $73 \%$ of the COPD population had normal $\mathrm{BMI}$ and normal FFMI, 15\% normal BMI and low FFMI, 1\% low BMI and normal FFMI and $11 \%$ low BMI and low FFMI. No differences in the prevalence of nutritional depletion between GOLD stage 2 and GOLD stage 3 were observed. The prevalence of the different nutritional depletion combinations in male and female COPD patients is presented in figure 2.1. Depletion of body weight was significantly more present in female $(18 \%)$ than in male $(10 \%)$ COPD patients, $p<0.01$. The prevalence of FFM depletion was significantly higher in female COPD patients $(40 \%)$ than in males $(20 \%), p<0.001$. In $25 \%$ of the female COPD patients FFM depletion with body weight preservation occurred, which was significantly higher than in males $(11 \%), p<0.05$.
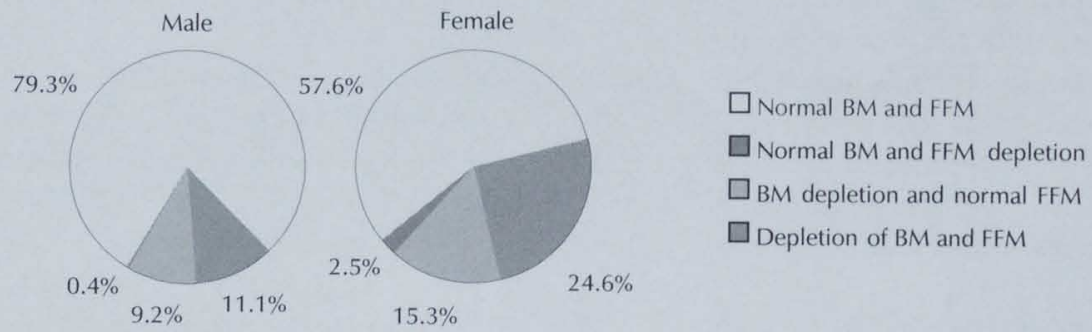

Figure 2.1 The prevalence of different depletion categories stratified by gender 
Factors related to nutritional depletion

FEV 1 \%predicted and age were similar in depleted COPD patients relative to nondepleted COPD patients. Gender distribution was significantly different between depleted and non-depleted COPD patients $(p<0.01)$. Therefore adjustment for gender distribution was applied in further analyses.

Table 2.2 Characteristics of COPD patients stratified by nutritional depletion

\begin{tabular}{lcc}
\hline & Non-depleted COPD patients & Depleted COPD patients \\
\hline Male/female & $\mathrm{n}=283$ & $\mathrm{n}=106$ \\
Age, years & $215 / 68$ & $56 / 50^{\circ}$ \\
FEV $_{1}, \%$ predicted & $63 \pm 7$ & $62 \pm 7$ \\
Handgrip strength, kg & $51 \pm 11$ & $51 \pm 12$ \\
Severe dyspnoea, \% of patients & $38 \pm 11$ & $31 \pm 9^{* *}$ \\
\hline & 40 & 41 \\
\hline SGRQ - symptoms & $\mathrm{n}=273$ & $\mathrm{n}=102$ \\
SGRQ - activity & $57(11-91)$ & $54(22-91)$ \\
SGRQ - impact & $58(0-100)$ & $59(11-100)$ \\
SGRQ - total score & $26(0-68)$ & $26(3-73)$ \\
\hline
\end{tabular}

Data are mean $\pm \mathrm{SD}$ and median (range); $\mathrm{FEV}_{1}$, forced expiratory volume in one second post bronchodilator; severe dyspnoea defined as score of 3-5 by MRC scale; $p<0.01$ for gender distribution, $" p<0.01$ after adjustment for gender distribution and age

Patients suffering from depletion were characterized by a significantly lower handgrip strength compared to non-depleted patients, as shown in table 2.2. Dyspnoea score and health status did not significantly differ between depleted and non-depleted COPD patients.

\section{Factors related to handgrip strength}

Mean handgrip strength significantly correlated with FFMI after adjustment for gender and age, $r=0.22, p<0.001$ (figure 2.2).

Stepwise regression analyses showed that gender, age and FFMI independently explained $51 \%$ of the variation in handgrip strength in the total patient group, while FMI and FEV 1 \%predicted were excluded from the model (table 2.3). 


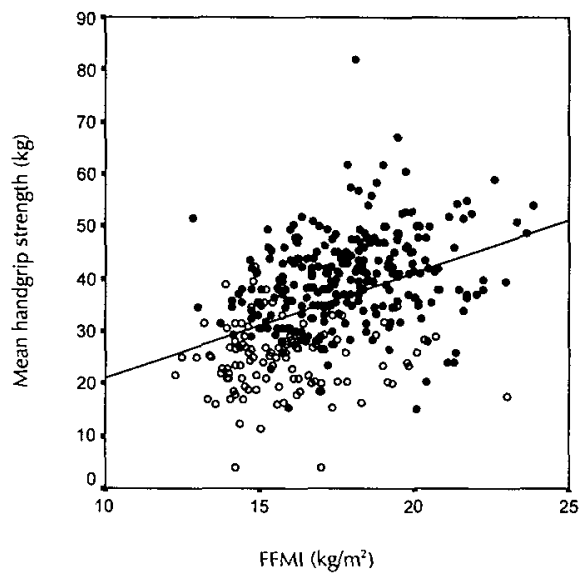

Figure 2.2 The correlation between handgrip strength and FFMI, after correction for gender distribution and age, $r=0.22, p<0.001$. Open circles, females; closed circles, males

Table 2.3 Stepwise regression analysis to assess independent variables to explain the variation in handgrip strength $(\mathrm{kg})$

\begin{tabular}{lccc}
\hline Prediction variables & Effect & Cumulative $\mathrm{R}^{2}$ & p-value \\
\hline Sex, male/female & 15.2 & 0.43 & $<0.001$ \\
Age, years & -0.35 & 0.48 & $<0.001$ \\
Fat-free mass index, $\mathrm{kg} / \mathrm{m}^{2}$ & 0.8 & 0.51 & $<0.001$ \\
Fat mass index, $\mathrm{kg} / \mathrm{m}^{2}$ & & & $\mathrm{NS}$ \\
FEV & & $\mathrm{NS}$ \\
\hline
\end{tabular}

\section{Discussion}

This study shows that the prevalence of nutritional depletion in a large out-patient COPD population in The Netherlands is high: in $27 \%$ of the COPD patients, recruited with $\mathrm{FEV}_{1}$ between 30-70 \%predicted, body mass and/or fat-free mass was depleted. Independently of disease severity, depletion of FFM was significantly correlated with impaired peripheral muscle strength. In this study, the prevalence of nutritional depletion in female patients with moderate to severe COPD was more pronounced.

The prevalence of nutritional depletion in a large out-patient COPD population by body compositional analysis has not been reported previously. Compared with the study of Engelen et al ${ }^{1}$, the prevalence of nutritional depletion was quite similar $(21 \%)$, but lower relative to the prevalence found in the study of Schols et al $(45 \%){ }^{2}$ The latter discrepancy can be due to more severe COPD being present in the study of Schols et al. Remarkably, the $26 \%$ prevalence of FFM depletion in combination with BM preservation in our study was higher than in the study of Engelen $(18 \%){ }^{1}$ This may be explained by different inclusion criteria of the 
studies. The COSMIC study population was selected by more than 2 exacerbations accompanied with corticosteroid or antibiotic treatment in the previous 12 months. It can be hypothesized that frequent treatment with systemic corticosteroid may induce protein catabolism adversely affecting skeletal muscle function. In cross sectional studies no relationship was found between depletion of FFM and systemic corticosteroid use ${ }^{18,19}$, but Bernard and coworkers showed that the ratio muscle function and muscle mass tended to be lower in COPD patients exposed to systemic corticosteroids. ${ }^{20}$ Little is known about changes in body composition due to exacerbations in COPD patients. There are two studies reporting body composition during hospitalization for an acute exacerbation in COPD patients ${ }^{21,22}$ and it seems that FFM depletion with preservation of BM occurs frequently in hospitalized COPD patients. ${ }^{21,22}$ An acute exacerbation has been shown to be accompanied with higher levels of inflammatory mediators ${ }^{22,23}$ and different reports suggested a relationship between the presence of depletion and increased systemic inflammatory status. ${ }^{24,25}$ The observed higher prevalence of nutritional depletion in our study might thus possibly be explained by the higher exacerbation rate accompanied with an impaired chronic inflammatory response and altered body composition. Otherwise, the exacerbation rate in our population is not exceptional high, since a comparable exacerbation rate of 2.4 per patient per year has been previously reported in a cohort of 101 COPD patients with mean \pm SD FEV 1 of $42 \pm 19 \%$ predicted. ${ }^{26}$ Still we cannot fully mile out that the inclusion criterion is a confounder of the reported prevalence in the current study.

Nutritional depletion has been shown to be associated with adverse effects on respiratory and peripheral muscle function, on exercise capacity and on health status. ${ }^{1,2,4,27-30}$ In the current study the association between nutritional depletion and peripheral muscle strength was confirmed and appeared to be independent of disease severity. Besides FFM depletion, age and especially gender were found to be independent predictors of muscle weakness in COPD. Further, in contrast to the studies concerning impaired health status in depleted COPD patients ${ }^{4,30}$, we found no significant or clinically relevant differences in any score of SGRQ nor in the dyspnoea score between depleted and non-depleted COPD patients. The former could be explained by the less impaired airflow limitation in the majority of our study population. A recent study in COPD showed that the threshold for worsening of health status lies at $\mathrm{FEV}_{1}<50$ \%predicted. ${ }^{31}$

Till now, COPD is predominantly considered as a "male" disease, but the prevalence of COPD will become even higher in females than in men, predominantly due to the changed smoking behavior. ${ }^{32-34}$ Given this increased prevalence of COPD in females, it is worthwhile to consider possible gender differences in COPD patients, as has been proposed by other authors. ${ }^{35,36}$ An increased risk of hospitalization has been reported previously in female COPD patients. ${ }^{37}$ We found in our study that FFM depletion occurred more frequently in female than in male COPD patients. Gender differences in body composition have been found in earlier studies. ${ }^{1,2}$ Engelen and coworkers also reported a higher prevalence of nutritional depletion in women $(35 \%)$ than in men $(16 \%)^{1}$ and values in the study of Schols et al printing in the same direction i.e. $42 \%$ and $34 \%$, 
respectively. ${ }^{2} \mathrm{~A}$ higher nutritional depletion in females could also exist if females had more severe COPD. However, in our study the female COPD patients had even a better mean FEV $_{1}$ \%predicted (54 \pm 13 \%predicted) compared to males (49 $\pm 12 \%$ predicted). Recently, several systemic effects in patients with COPD have been described. ${ }^{38}$ Nutritional depletion has been associated with lower diffusion capacity ${ }^{39}$ and with systemic inflammation in COPD patients. ${ }^{39-41}$ Therefore female COPD patients in our study might have lower diffusion capacity or increased inflammatory response, underlying the observed gender difference. Further research is required to unravel gender differences and its consequences in patients with COPD.

The prevalence of FFM depletion in our study (26\%) is higher than in the other study, reporting values of $18 \%$ in an out-patient COPD population. ${ }^{1}$ This discrepancy can be explained by differences in disease severity, but also by differences in the used formula to calculate FFM. We used a disease and gender specific formula $a^{15}$ and in earlier reported studies ${ }^{1,2}$ a disease specific formula was used. ${ }^{42}$ In comparison with reference values of FFMI in healthy female subjects ${ }^{43}$ the FFMI cut-off point in female COPD patients might be high, 15 versus $14.6 \mathrm{~kg}$ $\mathrm{FFM} / \mathrm{m}^{2}\left(10^{\text {th }}\right.$ percentile of healthy female subjects $) .^{43}$ However, using the FFMI cut-off point of healthy female subjects $\left(14.6 \mathrm{~kg} \mathrm{FFM} / \mathrm{m}^{2}\right)^{43}$, the prevalence of FFM depletion in our study population remains high, namely $30 \%$.

In conclusion, the prevalence of nutritional depletion in our COPD population is high, and especially so in female COPD patients. The presence of nutritional depletion was not associated with lower levels of FEV 1 \%predicted. Peripheral muscle weakness was associated with nutritional depletion and gender and age were also found as independent predictors of muscle weakness. Assessment of body composition additional to body weight is therefore necessary in all patients with COPD, independently of the stage of disease severity. Since depletion of FFM is an important determinant of functional capacity in COPD patients, (early) detection is essential in clinical practice.

\section{Acknowledgements}

The study was funded by GSK Research Grant from GlaxoSmithKline BV the Netherlands and United Kingdom. 


\section{References}

1. Engelen MP, Schols AM, Baken WC, Wesseling GJ, Wouters EF. Nutritional depletion in relation to respiratory and peripheral skeletal muscle function in out-patients with COPD. Eur Respir J 1994; 7:1793-7.

2. Schols AM, Soeters PB, Dingemans AM, Mostert R, Frantzen PJ, Wouters EF. Prevalence and characteristics of nutritional depletion in patients with stable COPD eligible for pulmonary rehabilitation. Am Rev Respir Dis 1993;147:1151-6.

3. Engelen MP, Schols AM, Does JD, Wouters EF. Skeletal muscle weakness is associated with wasting of extremity fat-free mass but not with airflow obstruction in patients with chronic obstructive pulmonary disease. Am J Clin Nutr 2000;71:733-8.

4. Mostert R, Goris A, Weling-Scheepers C, Wouters EF, Schols AM. Tissue depletion and health related quality of life in patients with chronic obstructive pulmonary disease. Respir Med 2000;94:859-67.

5. Schols AM, Slangen J, Volovics L, Wouters EF. Weight loss is a reversible factor in the prognosis of chronic obstructive pulmonary disease. Am J Respir Crit Care Med 1998; 157:1791-7.

6. Braun SR, Keim NL, Dixon RM, Clagnaz P, Anderegg A, Shrago ES. The prevalence and determinants of nutritional changes in chronic obstructive pulmonary disease. Chest 1984;86:558-63.

7. Openbrier DR, Irwin MM, Rogers RM, et al. Nutritional status and lung function in patients with emphysema and chronic bronchitis. Chest 1983;83:17-22.

8. Fiaccadori E, Del Canale S, Coffrini E, Vitali P, Antonucci C, Cacciani G, Mazzola I, Guariglia A. Hypercapnic-hypoxemic chronic obstructive pulmonary disease (COPD): influence of severity of COPD on nutritional status. Am J Clin Nutr 1988;48:680-5.

9. Gray Donald K, Gibbons L, Shapiro SH, Macklem PT, Martin JG. Nutritional status and mortality in chronic obstructive pulmonary disease. Am J Respir Crit Care Med 1996;153:961-6.

10. Mazolewski P, Turner JF, Baker M, Kurtz T, Little AG. The impact of nutritional status on the outcome of lung volume reduction surgery: a prospective study. Chest 1999;116:693-6.

11. Chailleux E, Laaban JP, Veale D. Prognostic Value of Nutritional Depletion in Patients With COPD Treated by Long-term Oxygen Therapy: Data From the ANTADIR Observatory. Chest 2003;123:1460-6.

12. Quanjer PH. Standardized lung function testing. Official statement of the European Respiratory Society. Eur Respir J 1993;6:1-100.

13. Pauwels RA, Buist AS, Calverley PM, Jenkins CR, Hurd SS. Global strategy for the diagnosis, management, and prevention of chronic obstructive pulmonary disease. NHLBI/WHO Global Initiative for Chronic Obstructive Lung Disease (GOLD) Workshop summary. Am J Respir Crit Care Med 2001;163:1256-76.

14. GOLD newsletter. www.goldcopd.com august 2003.

15. Steiner MC, Barton RL, Singh SJ, Morgan MD. Bedside methods versus dual energy Xray absorptiometry for body composition measurement in COPD. Eur Respir J 2002;19:626-31. 
16. Bestall JC, Paul EA, Garrod R, Garnham R, Jones PW, Wedzicha JA. Usefulness of the Medical Research Council (MRC) dyspnoea scale as a measure of disability in patients with chronic obstructive pulmonary disease. Thorax 1999;54:581-6.

17. Jones PW. Issues concerning health-related quality of life in COPD. Chest 1995;107:187S-193S.

18. Creutzberg EC, Wouters EF, Mostert R, Weling-Scheepers CA, Schols AM. Efficacy of nutritional supplementation therapy in depleted patients with chronic obstructive pulmonary disease. Nutrition 2003;19:120-7.

19. Schols AM, Soeters PB, Mostert R, Pluymers RJ, Wouters EF. Physiologic effects of nutritional support and anabolic steroids in patients with chronic obstructive pulmonary disease. A placebo-controlled randomized trial. Am J Respir Crit Care Med 1995;152:1268-74.

20. Bernard S, LeBlanc P, Whittom F, Callier G, Jobin J, Belleau R, Maltais F. Peripheral muscle weakness in patients with chronic obstructive pulmonary disease. Am J Respir Crit Care Med 1998;158:629-34.

21. Vermeeren MA, Schols AM, Wouters EF. Effects of an acute exacerbation on nutritional and metabolic profile of patients with COPD. Eur Respir J 1997;10:2264-9.

22. Creutzberg EC, Wouters EF, Vanderhoven-Aıgustin IM, Dentener MA, Schols AM. Disturbances in leptin metabolism are related to energy imbalance during acute exacerbations of chronic obstructive pulmonary disease. Am J Respir Crit Care Med 2000;162:1239-45.

23. Dentener MA, Creutzberg EC, Schols AM, Mantovani A, van het Veer $C$, Buurman WA, Wouters EF. Systemic anti-inflammatory mediators in COPD: increase in soluble interleukin 1 receptor II during treatment of exacerbations. Thorax 2001;56:721-6.

24. Takabatake N, Nakamura H, Abe S, Hino T, Saito H, Yuki H, Kato S, Tomoike H. Circulating leptin in patients with chronic obstructive pulmonary disease. Am J Respir Crit Care Med 1999;159:1215-9.

25. Schols AM, Buurman WA, Staal - van den Brekel AJ, Dentener MA, Wouters EF. Evidence for a relation between metabolic derangements and increased levels of inflammatory mediators in a subgroup of patients with chronic obstructive pulmonary disease. Thorax 1996;51:819-24.

26. Seemungal TA, Donaldson GC, Bhowmik A, Jeffries DJ, Wedzicha JA. Time course and recovery of exacerbations in patients with chronic obstructive pulmonary disease. Am J Respir Crit Care Med 2000;161:1608-13.

27. Nishimura $Y$, Tsutsumi $M$, Nakata $H$, Tsunenari T, Maeda $H$, Yokoyama $M$. Relationship between respiratory muscle strength and lean body mass in men with COPD. Chest 1995;107:1232-6.

28. Gosselink R, Troosters T, Decramer M. Peripheral muscle weakness contributes to exercise limitation in COPD. Am J Respir Crit Care Med 1996;153:976-80.

29. Palange $P$, Forte $S$, Felli $A$, Galassetti $P$, Serra $P$, Carlone $S$. Nutritional state and exercise tolerance in patients with COPD. Chest 1995;107:1206-1212.

30. Shoup R, Dalsky G, Warner S, Davies M, Connors M, Khan M, Khan F, ZuWallack R. Body composition and health-related quality of life in patients with obstructive airways disease. Eur Respir J 1997;10:1576-80. 
31. Antonelli-Incalzi R, Imperiale C, Bellia V, Catalano F, Scischilone N, Pistelli R, Rengo F. Do GOLD stages of COPD severity really correspond to differences in health status? Eur Respir J 2003;22:444-9.

32. Feenstra $\mathrm{TL}$, van Genugten $\mathrm{ML}$, Hoogenveen RT, Wouters EF, Rutten-van Molken $\mathrm{MP}$. The impact of aging and smoking on the future burden of chronic obstructive pulmonary disease: a model analysis in the Netherlands. Am J Respir Crit Care Med 2001;164:590-6.

33. Nihlen U, Nyberg P, Montnemery P, Lofdahl CG. Influence of family history and smoking habits on the incidence of self-reported physician's diagnosis of COPD. Respir Med 2004;98:263-70.

34. Watson L, Boezen HM, Postma DS. Differences between males and females in the natural history of asthma and COPD. Eur Respir Mon 2003;25:50-73.

35. Silverman EK, Weiss ST, Drazen JM, Chapman HA, Carey V, Campbell EJ, Denish P, Silverman RA, Celedon JC, Reilly JJ, Gins LC, Speizer FE. Gender-related differences in severe, early-onset chronic obstructive pulmonary disease. Am J Respir Crit Care Med 2000;162:2152-8.

36. Sunyer J, Anto JM, McFarlane D, Domingo A, Tobias A, Barcelo MA, Munoz A. Sex differences in mortality of people who visited emergency rooms for asthma and chronic obstructive pulmonary disease. Am J Respir Crit Care Med 1998;158:851-6.

37. Prescott E, Bjerg AM, Andersen PK, Lange P, Vestbo J. Gender difference in smoking effects on lung function and risk of hospitalization for COPD: results from a Danish longitudinal population study. Eur Respir J 1997;10:822-7.

38. Wouters EF, Creutzberg EC, Schols AM. Systemic effects in COPD. Chest $2002 ; 121$ : 127S-130S.

39. Engelen MP, Schols AM, Lamers RJ, Wouters EF. Different patterns of chronic tissue wasting among patients with chronic obstructive pulmonary disease. Clin Nutr 1999;18:275-80.

40. de Godoy I, Donahoe M, Calhoun WJ, Mancino J, Rogers RM. Elevated TNF-alpha production by peripheral blood monocytes of weight- losing COPD patients. Am J Respir Crit Care Med 1996;153:633-7.

41. Francia MD, Barbier D, Mege JL, Orehek J. Tumor necrosis factor-alpha levels and weight loss in chronic obstructive pulmonary disease. Am J Respir Crit Care Med 1994;150:1453-1455.

42. Schols AM, Wouters EF, Soeters PB, Westerterp KR. Body composition by bioelectrical-impedance analysis compared with deuterium dilution and skinfold anthropometry in patients with chronic obstructive pulmonary disease. Am J Clin Nutr 1991;53:421-4.

43. Schutz Y, Kyle UU, Pichard C. Fat-free mass index and fat mass index percentiles in Caucasians aged 18-98 y. Int J Obes Relat Metab Disord 2002;26:953-60. 


\section{Chapter}

Acute effects of different nutritional supplements on symptoms and functional capacity in patients with chronic obstructive pulmonary disease

MAP Vermeeren, EFM Wouters, LH Nelissen, A van Lier, Z Hofman, AMWJ Schols American Journal of Clinical Nutrition 2001;73: 295-301 


\section{Abstract}

\section{Background}

Use of nutritional supplements in depleted patients with chronic obstructive pulmonary disease (COPD) requires optimization between positive effects on outcome and potential acute adverse effects on metabolism and exercise performance.

\section{Objective}

The aim of this study was to investigate the acute effects of nutritional supplements on metabolism and exercise capacity in stable COPD patients.

\section{Design}

In part 1, the effects of 3 different energy loads (placebo, $1046 \mathrm{~kJ}$, and $2092 \mathrm{~kJ}$ ) with a normal distribution of macronutrients were investigated in 14 COPD patients. In part 2, the effects of a fat-rich compared with a carbohydrate-rich supplement (both $1046 \mathrm{~kJ}$ ) were studied in 11 COPD patients. The study was performed in a randomized, double-blind, cross-over fashion. Metabolic and ventilatory vaiables were measured postprandially and during a submaximal cycle endurance exercise test.

Results

Overall, no immediate negative effects of the supplements were found in part 1. A slight but significant postprandial increase in respiratory quotient was found after the $1046 \mathrm{~kJ}$ and 2092 kJ supplements compared with placebo. There was no significant difference in metabolism or exercise capacity after a fat-rich or carbohydrate-rich supplement. Surprisingly, the change in shortness of breath (postprandial compared with preprandial) was significantly greater after the fat-rich supplement.

\section{Conclusions}

An energy load up to $2092 \mathrm{~kJ}$ had no adverse immediate effect in COPD patients compared with placebo. The subjects who consumed the fat-rich supplement experienced more shortness of breath than did the subjects who consumed the carbohydrate-rich supplement. 


\section{Introduction}

The association between weight loss and chronic obstructive pulmonary disease (COPD) has long been recognized. In the 1960 s, several studies reported that a low body weight and weight loss were negatively associated with survival in COPD. 'Adverse effects of weight loss and, in particular, loss of the fat-free mass component on skeletal muscle function and exercise capacity were reported extensively. ${ }^{2}$ Weight loss results from an imbalance between dietary intake and energy expenditure. An elevated resting energy expenditure (REE) ${ }^{3}$ is reported in COPD, as well as an elevated total daily energy expenditure. ${ }^{4}$ The latter is related to the increased oxygen cost of breathing and possibly also to a decreased mechanical and metabolic efficiency. ${ }^{5}$ Therefore, patients with COPD can lose weight despite an apparently normal dietary intake. Besides, symptoms that occur frequently, such as dyspnoea and fatigue, as well as an elevated systemic inflammatory response, are reported in relation to a decreased appetite and dietary intake. ${ }^{6,7}$ So when optimal adaptation of dietary habits fails to improve dietary intake to preserve body weight, nutritional supplements are commonly indicated. To improve functional capacity, nutritional support should be combined with an anabolic stimulus. Indeed, nutritional support as an integrated part of a pulmonary rehabilitation program results in improvements in muscle function, exercise capacity and health status. ${ }^{8}$

In supplemented COPD patients, potential adverse effects on the ventilatory system of the nutritional support strategy also have to be considered. Nutrition and ventilation are intrinsically related because oxygen is required for optimal energy exchange. Meal-related dyspnoea and limited ventilatory reserves may restrict the quantity and composition of nutritional support in patients with respiratory disease.

It was suggested that carbohydrate-rich supplements would induce greater ventilation as a result of a higher respiratory quotient (RQ). In clinically stable patients with COPD, 3 studies $^{9-11}$ compared the acute effects of high-energy (3849 kJ) nutritional supplements with high and low carbohydrate contents, respectively, on immediate postprandial energy metabolism at rest and during exercise. For instance, Efthimiou et $\mathrm{al}^{9}$ found adverse effects of supplements on exercise performance. However, the energy content of the supplements was even higher than that of a normal meal and would therefore be difficult to incorporate into the daily pattern of meal consumption without affecting spontaneous food intake.

It is important in daily clinical practice to find out the optimal disease-related nutritional support strategy that improves muscle function but interferes minimally with symptoms and activity pattern. The first aim of the present study was therefore to examine the effects of liquid oral nutritional supplements with different, but clinically applicable, energy contents on symptoms and exercise capacity. The second aim was to compare the effects of a carbohydrate-rich with a 
fat-rich supplement, at the most optimal energy load, on symptoms and exercise capacity in patients with COPD.

\section{Subjects and methods}

\section{Study population}

The study group consisted of patients with COPD participating in an in-patient pulmonary rehabilitation program. The patients were in a clinically stable condition, patients with signs of an airway infection were excluded. Other exclusion criteria were cardiovascular, neurologic, or endocrine diseases or locomotor limitations and a resting arterial oxygen tension $<7.3 \mathrm{kPa}$ or the need for oxygen supplementation. In part 1, 14 patients (10 men) and in part 2, 11 patients $(9 \mathrm{men})$ participated in and completed the study. Patient characteristics are summarized in table 3.1. No subject participated in both studies. All subjects were fully informed of the aims and the procedures of the study and gave written informed consent. The ethical committee of Maastricht University approved the study. The procedures followed were in accord with the Helsinki Declaration of 1977, as revised in 1983.

Table 3.1 Physiological, pulmonary and metabolic characteristics of the study group

\begin{tabular}{|c|c|c|}
\hline & $\begin{array}{c}\text { Part 1 } \\
n=14\end{array}$ & $\begin{array}{c}\text { Part } 2 \\
\mathrm{n}=11\end{array}$ \\
\hline Male / female & $10 / 4$ & $9 / 2$ \\
\hline Age, years & $65 \pm 11$ & $62 \pm 8$ \\
\hline Weight, $\mathrm{kg}$ & $58.9 \pm 6.1$ & $66.5 \pm 7.2^{\circ}$ \\
\hline $\mathrm{BMI}, \mathrm{kg} / \mathrm{m}^{2}$ & $20.6 \pm 1.4$ & $22.6 \pm 2.3^{*}$ \\
\hline FFMI, $\mathrm{kg} / \mathrm{m}^{2}$ & $16.0 \pm 1.3$ & $16.6 \pm 1.8$ \\
\hline $\mathrm{FEV}_{1}, \%$ predicted & $36 \pm 7$ & $34 \pm 12$ \\
\hline IVC, \%predicted & $86 \pm 16$ & $90 \pm 16$ \\
\hline FVC, \%predicted & $82 \pm 14$ & $87 \pm 19$ \\
\hline TLC, \%predicted & $127 \pm 24$ & $125 \pm 23$ \\
\hline ITCV, \%predicted & $161 \pm 24$ & $166 \pm 44$ \\
\hline Raw, \%predicted & $225 \pm 82$ & $230 \pm 113$ \\
\hline Dlco, \%predicted & $45 \pm 13$ & $64 \pm 42$ \\
\hline $\mathrm{PaO}_{2}, \mathrm{kPa}$ & $9.5 \pm 1.4$ & $10.1 \pm 1.2$ \\
\hline $\mathrm{PaCO}_{2}, \mathrm{kPa}$ & $5.6 \pm 1.2$ & $5.5 \pm 0.5$ \\
\hline $\mathrm{SaO}_{2}, \%$ & $94.7 \pm 1.2$ & $94.8 \pm 1.7$ \\
\hline Wmax, watt & $61 \pm 20$ & $71 \pm 30$ \\
\hline
\end{tabular}

Data are mean $\pm \mathrm{SD} ; \mathrm{p}<0.01$ (independent student's t-test). $\mathrm{FEV}_{1}$, forced expiratory volume in $1 \mathrm{~s}$; IVC, inspiratory vital capacity; FVC, forced vital capacity; TLC, total lung capacity; ITGV, intrathoracaal gas volume; Raw, airways resistance; Dlco, diffusion capacity of carbon monoxide; Wmax, maximal power on cycle ergometer test 


\section{Study design}

The first aim of the study was to test the effects of 2 different clinically applicable energy loads (1046 and $2092 \mathrm{~kJ}$ compared with placebo) on symptoms, lung function, and exercise capacity (part 1). Second, the effects of a high-carbohydrate compared with a high-fat supplement on symptoms, lung function and exercise capacity were investigated at the most optimal energy load (1046 kJ) (part 2). The nutritional supplements were administered in a randomized, double-blind and cross-over fashion. The composition of the nutritional supplements, which were given as drinks with an equal volume of $200 \mathrm{~mL}$ are shown in table 3.2.

Table 3.2 Energy profile and composition of the different food supplements

\begin{tabular}{lcccc}
\hline & \multicolumn{3}{c}{ Part 1 } & \multicolumn{2}{c}{ Part 2 } \\
\hline Composition & Normal $^{\mathrm{a}}$ & Normal $^{\mathrm{b}}$ & CHO-rich $^{\mathrm{c}}$ & Fat-rich $^{\mathrm{d}}$ \\
Energy profile & $1046 \mathrm{~kJ}$ & $2092 \mathrm{~kJ}$ & $1046 \mathrm{~kJ}$ & $1046 \mathrm{~kJ}$ \\
Energy\% protein & 21 & 21 & 20 & 20 \\
Energy\% fat & 34 & 36 & 20 & 60 \\
Energy\% CHO & 45 & 43 & 60 & 20 \\
\hline
\end{tabular}

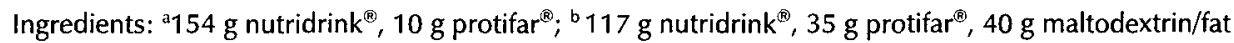

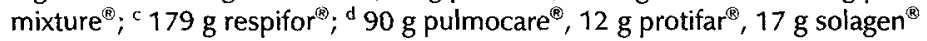

The placebo was a mixture of coffee creamer and lemon syrup with an energy load of $209 \mathrm{~kJ}$. There was no more than 1 day between the study days. The measurements were done within 2 weeks after the patients completed an incremental bicycle ergometer test. The administration of medication was standardized on the study days. Also, a breakfast with the same composition was given every study day at the same time $(07.30 \mathrm{~h})$. The study design for both studies is shown in figure 3.1.

\section{Part 1}

The experiment started 2 hours after breakfast, at 9.30h. Patients had to ingest the supplement in 15 minutes. Fifteen minutes after the supplement was consumed pulmonary function was measured and 30 minutes after the supplement was finished the exercise test began.

\section{Part 2}

The procedure followed in part 2 was exactly the same as that in part 1 , except that blood glucose was analyzed as well. Furthermore, the patients had to ingest the supplement in a 5 minutes because differences in gastric emptying might have influenced the results if patients drank teh supplements at different speeds.

\section{Pulmonary function}

The flow-volume curve was measured by using a flow screen (Masterlab, Jaeger, Wurzburg, Germany). Forced expiratory volume in 1 second $\left(\mathrm{FEV}_{1}\right)$, inspiratory 
vital capacity (IVC), forced vital capacity (FVC), mean expiratory flow (MEF), and peak expiratory flow (PEF) were calculated from the flow-volume curve. The highest value of $\geq 3$ measurements was used for analysis. The values were expressed as a percentage of the reference value. ${ }^{12}$

\section{Symptoms}

Using a visual analogue scale (VAS), the patients reported about the following symptoms: shortness of breath, satiety, and pain in the legs. The severity of the symptoms was assessed before and after administration of the supplements and before and after the exercise test. The symptom pain in the legs was scored only before and after the exercise test.

\section{Oxygen saturation}

During the study, transcutaneous oxygen saturation $\left(\mathrm{StO}_{2}\right)$ was measured with a pulse oxymeter. The electrode was placed around a finger of the left hand of the subject. Measurements were done with a $\mathrm{SaO}_{2}$ monitor (Fastrac; Sensor medics, Anaheim, California), which is attached to a printer that automatically registers the lowest measured oxygen saturation value every minute.

\section{Submaximal cycle ergometer test}

Submaximal exercise testing was performed on an electrically braked cycle ergometer (Examiner 400, Lode, Groningen, The Netherlands). Patients began to exercise at $50 \%$ of the maximal cycled load (Wmax) for 10 minutes. When the patients had performed this exercise, the workload was increased to $70 \%$ of Wmax. ${ }^{13}$ The patient cycled as long as possible but for a maximum of 30 minutes. Mechanical efficiency was calculated by using this submaximal exercise testing protocol. The maximal endurance time was also noted. The mean values of oxygen consumption $\left(\mathrm{V}^{\prime} \mathrm{O}_{2}\right)$ and carbon dioxide production $\left(\mathrm{V}^{\prime} \mathrm{CO}_{2}\right)$ during the last 3 minutes at $50 \%$ of $W \max$ were taken to calculate the net mechanical efficiency after adjustment for the individual REE. ${ }^{14}$

\section{Metabolic and ventilatory parameters and heart rate}

Metabolic and ventilatory variables were measured in expired air by using a breathing mask (Oxycon Beta, Jaeger, Wurzburg, Germany). The device was calibrated before each test. Simultaneously heart rate was registered every minute by using a sporttester (PE 3000, Polar electrocy, Kempele, Finland).

\section{Biochemical parameters}

A venous blood sample was taken to measure plasma lactate concentration. Blood was collected in a vacuum tube (Vacutainer, Becton Dickinson, New Jersey). The blood samples were stored on ice $\left(4^{\circ} \mathrm{C}\right)$ and centrifuged during 5 minutes at 3000 rpm (Sigma 2-15, Lameris, Breukelen, The Netherlands). Plasma lactate concentration was determined by an enzymatic method with use of an automated system (Cobas Mira, Roche, Bazel, Switzerland). Plasma lactate was measured at 
rest, every 2 minutes during exercise, and once during recovery ( 2 minutes after completion of the test). In part 2 , a venous catheter was placed in the forearm to obtain venous blood samples. These venous blood samples were analyzed for glucose concentration to monitor gastric emptying and lactate concentration indirectly.

\begin{tabular}{|c|c|c|c|c|c|c|c|c|}
\hline Time & 9.45 & 10.00 & 10.30 & 10.45 & 11.15 & 11.25 & 11.45 & Recovery \\
\hline Flow-volume & $x$ & \multirow[t]{2}{*}{ supplement } & $\mathrm{X}$ & & & & & \\
\hline Symptoms & $x$ & & $x$ & $x$ & & & & $x$ \\
\hline $\mathrm{StO}_{2}$ & \multicolumn{8}{|c|}{ every minute } \\
\hline $\mathrm{VO}_{2}, \mathrm{VCO}_{2}, \mathrm{~V}_{\mathrm{E}}$ & & & & \multicolumn{4}{|c|}{ every minute } & \\
\hline Heart rate & & & & \multicolumn{4}{|c|}{ every minute } & \\
\hline Glucose & & & & $x$ & \multicolumn{3}{|c|}{ every 10 minutes } & $x$ \\
\hline Lactate & & & & $x$ & \multicolumn{3}{|c|}{ every 2 minutes } & $x$ \\
\hline Peak work rate & & & & & $\begin{array}{l}50 \% \text { of } \\
W \max \end{array}$ & & $\begin{array}{l}\% \text { of } \\
\operatorname{nax}\end{array}$ & \\
\hline
\end{tabular}

Figure 3.1 Study design

\section{Statistics}

The data were analyzed to evaluate the effects of the nutritional supplements on pulmonary function and to examine the endurance and the metabolic, cardiovascular, and subjective responses to exercise. The mean response of $\mathrm{V}^{\prime} \mathrm{O}_{2}$, $V^{\prime} \mathrm{CO}_{2}, \mathrm{RQ}$, minute ventilation $\left(\mathrm{V}_{\mathrm{E}}\right)$ and heart rate was measured 30 minutes after the supplement was consumed and was calculated over 35-40, 40-50, 50-60 minutes, the last 3 minutes while cycling at $50 \%$ of Wmax, and the last minute of the exercise test. Oxygen saturation was measured before and after the supplement was consumed and the mean saturation was calculated over 0-5, 5$10,10-15,15-30,30-40,40-50,50-60$ minutes after the supplement, the last 3 minutes while cycling at $50 \%$ of Wmax, and the last minute of the exercise test. The difference in response to the 2 nutritional supplements was assessed at each time interval in every patient. For comparison between the different supplements, analysis of variance (ANOVA) was used with postprandial value as the dependent variable, with treatment and period as fixed factors, and with patient as a random factor. If appropriate, the corresponding baseline value was used as a covariate (analysis of covariance). In part 1 , if the results of treatment were significantly different, a post hoc Tukey test was performed. For comparison of the baseline characteristics of the subjects before each test an independent Student's t-test was used. A p-value of $<0.05$ was considered significant. All measured variables are expressed as mean $\pm S D$, except when mean $\pm S E M$ are used in the figures. 


\section{Results}

\section{Part 1}

Comparison of lung function before and after supplement ingestion showed no negative effects on pulmonary function (data not shown).
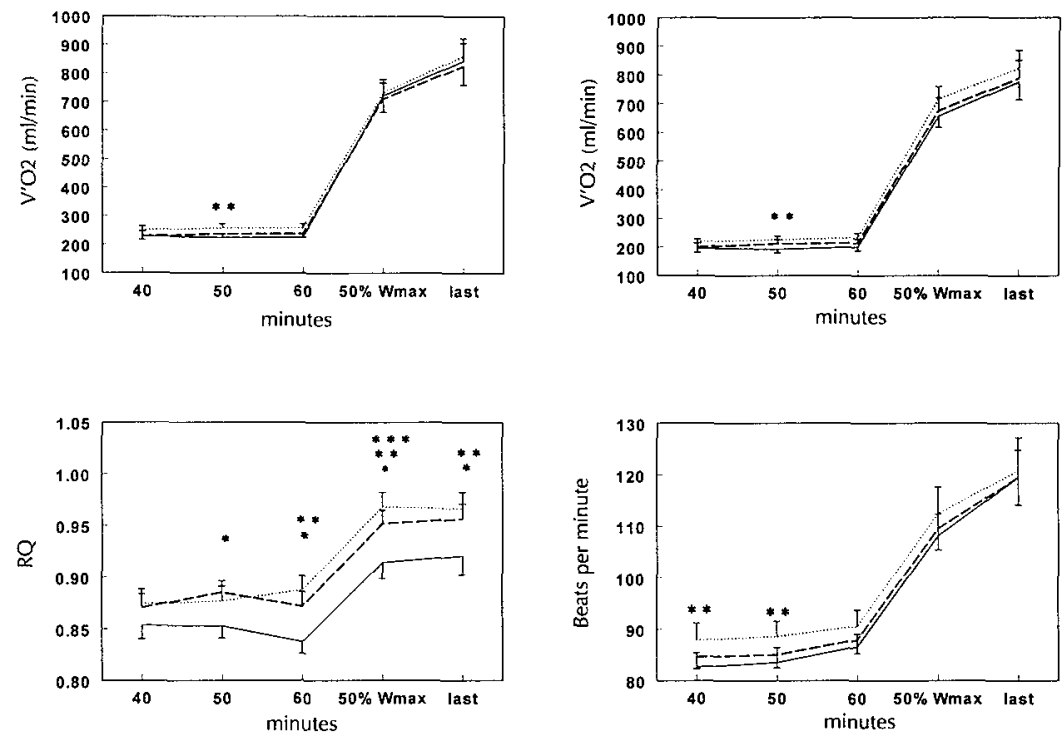

Figure 3.2 Mean ( \pm SEM) response of $\mathrm{V}^{\prime} \mathrm{O}_{2}, \mathrm{~V}^{\prime} \mathrm{CO}_{2}, \mathrm{RQ}$ and heart rate postprandially and during exercise after consumption ofplacebo (solid line), and a $1046 \mathrm{~kJ}$ supplement (dashed line), and a $2092 \mathrm{~kJ}$ supplement (dotted line). Last, the last measurement during the exercise test. $n=14 * p<0.05,1046 \mathrm{~kJ}$ versus placebo; ${ }^{* *} p<0.05,2092 \mathrm{~kJ}$ versus placebo, ${ }^{* * *} \mathrm{p}<0.05,1046 \mathrm{~kJ}$ versus $2092 \mathrm{~kJ}$ (ANOVA)

The time course of $\mathrm{V}^{\prime} \mathrm{O}_{2}$ and of $\mathrm{V}^{\prime} \mathrm{CO}_{2}$ after the different supplements were ingested is shown in figure 3.2. During the measurement period at rest, $\mathrm{V}^{\prime} \mathrm{O}_{2}$ tended to be higher after the $2092 \mathrm{~kJ}$ than after the $1046 \mathrm{~kJ}$ supplement or placebo. However, $\mathrm{V}^{\prime} \mathrm{O}_{2}$ after the $2092 \mathrm{~kJ}$ supplement was significantly higher than after the placebo only 50 minutes after the supplement was consumed. During exercise, $\mathrm{V}^{\prime} \mathrm{O}_{2}$ was not different among the 3 supplements. The value of $\mathrm{V}^{\prime} \mathrm{CO}_{2}$ was also significantly higher 50 minutes after consumption the $2092 \mathrm{~kJ}$ supplement than after the placebo. During exercise, the effects of the supplements on $\mathrm{V}^{\prime} \mathrm{CO}_{2}$ did not differ significantly.

There was a clear effect of the different energy loads on RQ. At rest at 60 minutes postingestion, RQ was significantly higher after the $1046 \mathrm{~kJ}$ and $2092 \mathrm{~kJ}$ 
supplements than after the placebo $(0.87 \pm 0.05,0.89 \pm 0.05$ and $0.84 \pm 0.04$, respectively). During exercise, RQ remained significantly elevated after the 1046 $\mathrm{kJ}$ and $2092 \mathrm{~kJ}$ supplements compared with the placebo. At 50\% of Wmax, RQ after the $2092 \mathrm{~kJ}$ supplement was significantly higher than the RQ after the 1046 kJ supplement, as shown in figure 3.2.

The effect on $V_{E}$ was less apparent, but after 50 minutes, $V_{E}$ was significantly elevated after the $2092 \mathrm{~kJ}$ supplement compared with the placebo $(14.1 \pm 2.1$ $\mathrm{L} / \mathrm{min}$ and $12.7 \pm 2.4 \mathrm{~L} / \mathrm{min}$, respectively; $\mathrm{p}=0.01$ ). During exercise, however, there was no difference in $V_{E}$ among the 3 supplements. The heart rate after the $2092 \mathrm{~kJ}$ supplement was significantly different from that after the placebo at 40 and 50 minutes postingestion, as shown in figure 3.2. There were no significant differences during the exercise test.

The changes in oxygen saturation were small, but significant, at 10 and 30 minutes after ingestion of the $1046 \mathrm{~kJ}(93.8 \pm 1.9 \%$ and $94.1 \pm 1.6 \% ; \mathrm{p}<0.05)$ and $2092 \mathrm{~kJ}(93.6 \pm 1.6 \% ; \mathrm{p}<0.01 ; 94.2 \pm 1.4 \% ; \mathrm{p}<0.05)$ supplements, respectively, compared with placebo. There were no differences in lactate concentrations during the experiment among the 3 supplements. Also, the relative increase in lactate was not significantly different among the placebo, and $1046 \mathrm{~kJ}$ and $2092 \mathrm{~kJ}$ supplements ( $107 \pm 73 \%, 104 \pm 89 \%$, and $108 \pm 95 \%$, respectively).

From the symptoms assessed by VAS, the change in satiety after the supplements was significantly different for the $2092 \mathrm{~kJ}$ supplement than after the placebo, as shown in figure 3.3. The symptoms shortness of breath, fatigue, and pain in the legs did not change during the experiment.

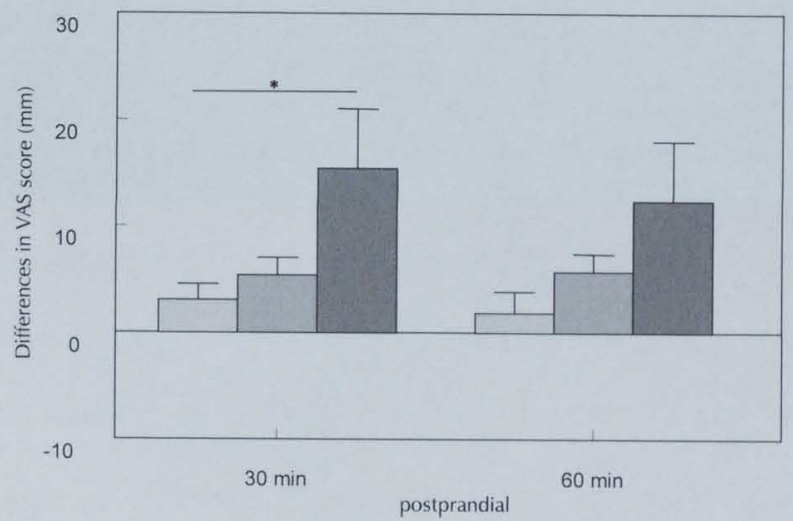

Figure 3.3 Difference between the mean ( \pm SEM) post- and preprandial satiety score on a visual analog scale 30 and 60 minutes after consumption of placebo (light grey bar), a 1046 kJ supplement (grey bar); and a $2092 \mathrm{~kJ}$ supplement (dark grey bar); ${ }^{*} \mathrm{p}<0.05$

The differences in the mean duration of the exercise test after the 3 supplements were small and insignificant. There were insignificant differences in mechanical efficiency after the 3 supplements. 
There were 3 patients who were not able to cycle 5 minutes at $50 \%$ of Wmax after the $2092 \mathrm{~kJ}$ supplement. The endurance time was dramatically lower in these outliers than in the other 11 patients, as shown in figure 3.4. A low body mass index $\left(18.9 \pm 1.7 \mathrm{~kg} / \mathrm{m}^{2}\right)$, a low fat-free mass index (fat-free mass divided by height $\left.^{2} 14.7 \pm 0.5\right)$, low maximal exercise performance $(49 \pm 3$ Watt) and low mechanical efficiency characterized these patients.
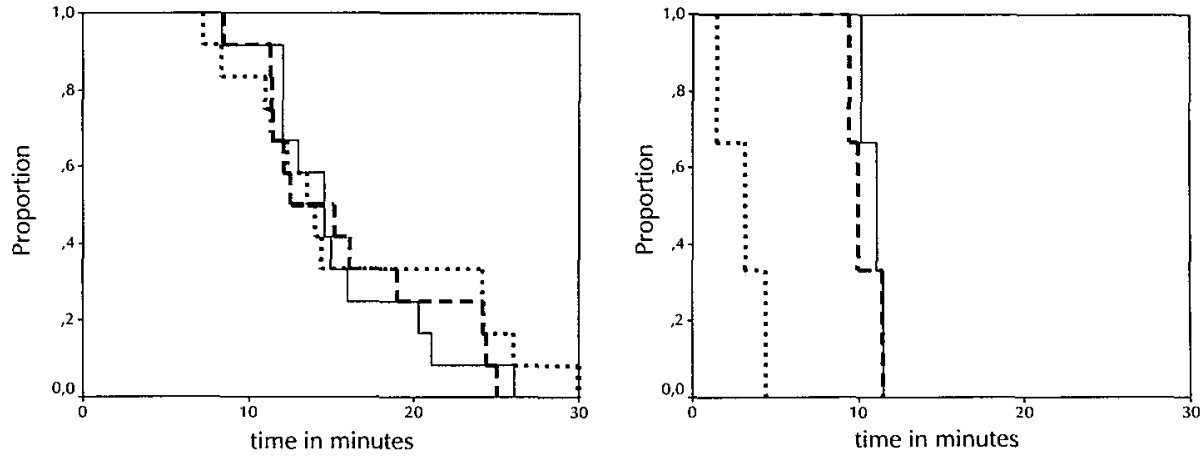

Figure 3.4 Kaplan-Meier plot of endurance time during submaximal cycle ergometry after consumption of placebo (solid line), a $1046 \mathrm{~kJ}$ supplement (dashed line); and a $2092 \mathrm{~kJ}$ supplement (dotted line). Left panel: total group - outliers ( $n=11)$; right panel: outlier $(n=3)$

\section{Part 2}

Pulmonary function before and after ingestion of the supplements is shown in table 3.3. Comparable with part 1, there were no negative effects of the supplements on pulmonary function. PEF increased significantly after the carbohydrate-rich supplement compared with baseline and compared with the fatrich supplement.

Table 3.3 Pulmonary function before and after supplements in part 2 of the study

\begin{tabular}{lcccc}
\hline & \multicolumn{2}{c}{ Carbohydrate-rich } & \multicolumn{2}{c}{ Fat-rich } \\
& Before & After & Before & After \\
\hline FVC, liter & $3.1 \pm 0.7$ & $3.5 \pm 1.3$ & $3.0 \pm 0.6$ & $3.0 \pm 0.7$ \\
FEV $_{1}$, liter & $1.1 \pm 0.3$ & $1.1 \pm 0.4$ & $1.0 \pm 0.4$ & $1.0 \pm 0.4$ \\
PEF, liter/sec & $3.1 \pm 1.0$ & $3.3 \pm 1.2^{*}$ & $3.1 \pm 0.9$ & $3.1 \pm 0.9$ \\
\hline
\end{tabular}

Data are mean $\pm \mathrm{SD} ;{ }^{*} p<0.05$ compared to before drink and compared to after fat-rich drink (ANOVA)

The courses of $\mathrm{V}^{\prime} \mathrm{O}_{2}$ and $\mathrm{V}^{\prime} \mathrm{CO}_{2}$ are shown in figure 3.5. There were no significant differences in response to the 2 supplements. After the carbohydrate-rich supplement there was a slightly lower $\mathrm{V}^{\prime} \mathrm{O}_{2}$ during the whole experiment than after the fat-rich supplement. The $R Q$ was significantly higher after the carbohydrate-rich supplement than after the fat-rich supplement during the whole 
experiment except at the last minute of the exercise trial. The higher RQ suggests a relatively higher $\mathrm{V}^{\prime} \mathrm{CO}_{2}$ after the carbohydrate-rich supplement. Although $\mathrm{V}^{\prime} \mathrm{CO}_{2}$ and $V_{E}$ are highly correlated (last minute of exercise after the carbohydrate-rich and fat-rich supplement, respectively: $r=0.87, p=0.01, r=0.96, p<0.001$ ), $V_{E}$ was not significantly different after the ingestion of the fat-rich or carbohydrate-rich supplement.
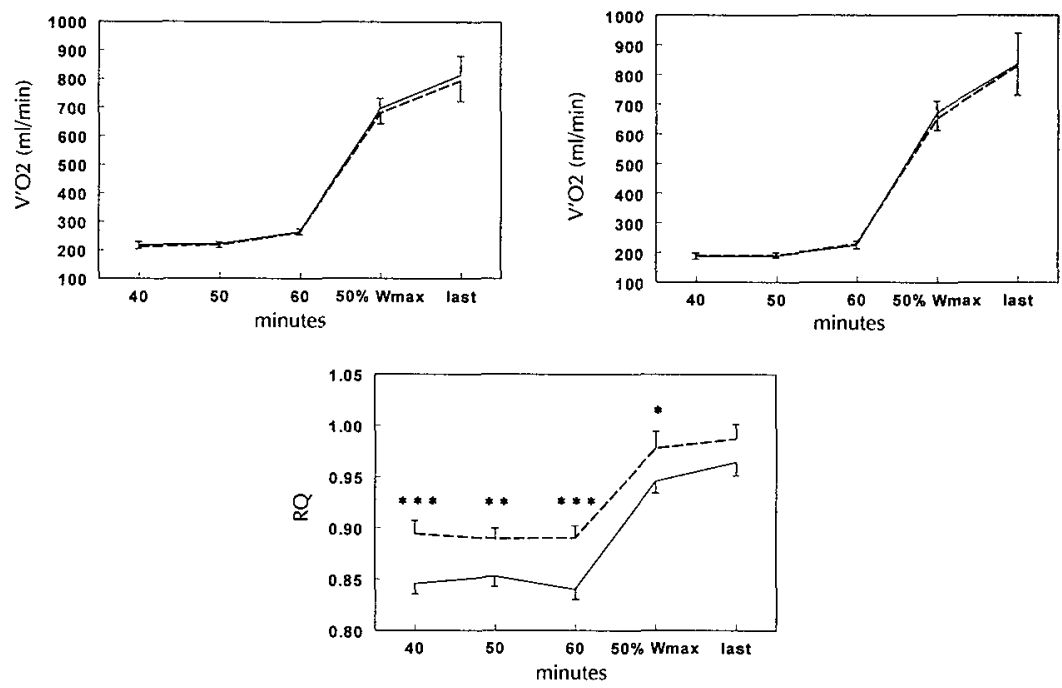

Figure 3.5 Response of $\mathrm{V}^{\prime} \mathrm{O}_{2}, \mathrm{~V}^{\prime} \mathrm{CO}_{2}$ and $\mathrm{RQ}$ postprandial and during exercise after fat-rich and carbohydrate-rich drink; solid line, fat-rich; dashed line, carbohydrate-rich; ${ }^{*} p<0.05$, ** $p=0.01,{ }^{* * *} p<0.01$

There were no significant differences in heart rate after carbohydrate-rich and fatrich supplements. Blood saturation seemed slightly lower after carbohydrate-rich supplement, and was significantly so 10 and 15 minutes after ingestion $(p<0.05)$. However, on average, the slightly lower saturation after the carbohydrate-rich supplement was not clinically significant (ie, a drop in $\mathrm{SaO}_{2}>4 \%$ ).

Lactate concentration was significantly different at the start of the exercise test between patients consuming the carbohydrate-rich and fat-rich supplements: $1.7 \pm 0.3$ and $1.3 \pm 0.2 \mathrm{mmol} / \mathrm{L}$, respectively $(p<0.05)$. The relative increase in lactate was not significantly different after the 2 supplements.

Blood glucose concentration was measured during the whole experiment. At rest, blood glucose increased significantly after ingestion of the carbohydrate-rich supplement. The highest value of blood glucose was at 30 minutes after ingestion ( $\Delta$ glucose: $2.6 \mathrm{mmol} / \mathrm{L}$, range: -0.2 to $5.5 \mathrm{mmol} / \mathrm{L}$ ). At the start of the exercise test, blood glucose was not significantly different between subjects who consumed the carbohydrate-rich and the fat-rich supplement $(5.7 \pm 1.3$ and $5.3 \pm 0.7 \mathrm{mmol} / \mathrm{L}$, respectively). During the exercise test, blood glucose concentration was not significantly different for the 2 supplements.

There were no significant differences in mean duration of the exercise test after the carbohydrate-rich and fat-rich supplement (12.6 \pm 7.2 and $13.1 \pm 7.1$ minutes, 
respectively). Also the mechanical efficiency after the 2 supplements was not significantly different $(20.0 \pm 5.8 \%$ and $19.8 \pm 5.9 \%$, respectively).

The symptoms satiety, fatigue, and pain in the legs did not change significantly during the experiment after ingestion of the supplement. Only the symptom shortness of breath changed: there was a significantly greater increase in dyspnoea after ingestion of the fat-rich supplement than after the carbohydraterich supplement, as shown in figure 3.6.

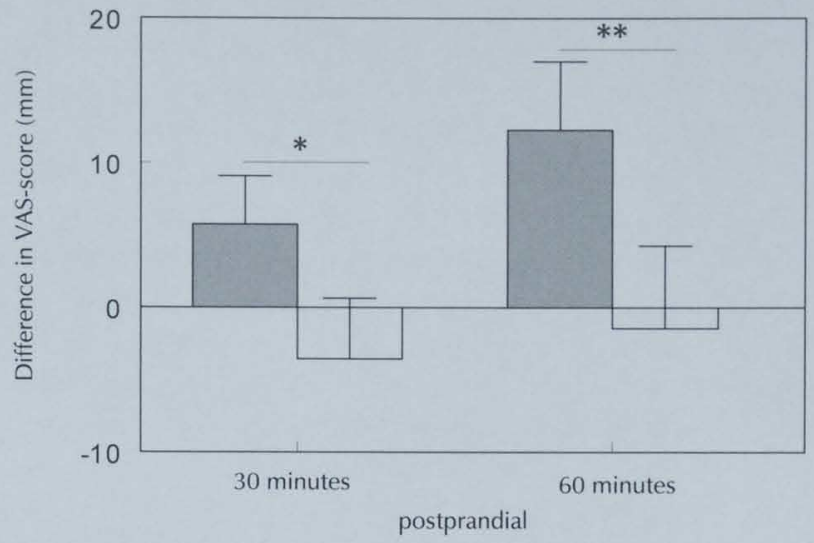

Figure 3.6 Difference between post- and preprandial of shortness of breath score on a visual analogue scale; grey bar, fat-rich; white bar, carbohydrate-rich; ${ }^{*} p=0.01,{ }^{* *} p<0.01$

\section{Discussion}

Nutritional supplements are needed in some COPD patients to reverse weight loss or to improve nutritional status. In contrast with a long-held belief, the present investigation did not show significant adverse effects of the studied nutritional supplements on the ventilatory system. Remarkably, there were even positive effects of a carbohydrate-rich supplement relative to those of a fat-rich one at a relatively low energy content, as will be discussed below.

In the first part of the study we evaluated the most optimal energy load to be given as a supplement between regular meals. As expected, relative to the $1046 \mathrm{~kJ}$ supplement, the metabolic and ventilatory response at rest was significantly higher after the $2092 \mathrm{~kJ}$ supplement. During exercise, this difference was eliminated. For the total group, there were no differences in exercise endurance capacity. Satiety, however, was clearly greater after the 2092 kJ supplement, which might interfere with a normal meal pattern. Another remarkable observation was the strikingly reduced endurance capacity of 3 patients after the $2092 \mathrm{~kJ}$ supplement, whereas no difference was seen between the placebo and the $1046 \mathrm{~kJ}$ supplement. Although this phenomenon was observed in only a few 
patients, these results are important to consider because this subgroup was characterized by a low BMI and FFMI, low maximal exercise capacity, and low mechanical efficiency. One potential cause could be an increased oxygen cost of breathing because Mannix et $\mathrm{a}^{15}$ recently reported a significant inverse relation between BMI and the oxygen cost of breathing in COPD. ${ }^{15}$ Furthermore, we showed in a previous study a significantly elevated ratio of $V_{E}$ to $V^{\prime} O_{2}$ in COPD patients with a decreased mechanical efficiency. ${ }^{5}$

Suggested positive effects of a carbohydrate-rich compared with a fat-rich $1046 \mathrm{~kJ}$ supplement are based on the following observations. A significant increase in peak expiratory flow was shown relative to baseline and relative to the fat-rich supplement. In contrast with the forced expiratory flow in 1 second, the peak expiratory flow is dependent of respiratory muscle strength. Blood glucose is a rapidly available substrate, as was indirectly observed in the insignificantly lower increase in lactate during exercise after the carbohydrate-rich supplement. Specifically, for COPD patients, this may be clinically relevant because a reduced oxidative capacity has been observed, as reflected in low muscle concentrations of oxidative enzymes such as citrate (si)-synthase and $\beta$-hydroxyacyl dehydrogenase (alone or combined with increased concentrations of the regulating glycolytic enzyme phoshofructokinase). ${ }^{16}$ One study even showed a decreased ATP-ADP ratio in resting muscle associated with an increased inosine monophosphate concentration as marker of an imbalance between ATP synthesis and production. ${ }^{17}$ Positive effects of a carbohydrate load on muscle have been described and are being used in sports medicine. The amount of carbohydrate given in this study is comparable with the recommended dose.

The RQ was indeed higher after the carbohydrate-rich supplement, but this was not due to an increased $\mathrm{V}^{\prime} \mathrm{CO}_{2}$ but to a lower $\mathrm{V}^{\prime} \mathrm{O}_{2}$. This could reflect more efficient metabolism and could be related to a lower gastric emptying time for the carbohydrate-rich supplement, when given in a fixed period, as was observed previously by Akrabawi et $\mathrm{al}^{18}$ after a moderate-fat compared with a high-fat supplement. There are clinical ramifications to delayed gastric emptying, especially in patients with COPD. Because of the disease process itself, such patients already have hyperinflation, a flattened diaphragm, and a reduction in abdominal volume, which results in feelings of bloating, abdominal discomfort, and early satiety. A significant delay in gastric emptying may lead to an extended period of abdominal distention, affecting diaphragmatic mobility and thoracic expansion.

The protein content of the supplements was high on the basis of available data showing that, in healthy subjects and in those with stable disease, protein synthesis is optimally stimulated during administration of $1.5 \mathrm{~g}$ protein $/ \mathrm{kg} /$ day. ${ }^{19}$ The effects of wasting disease on protein metabolism are characterized by net protein catabolism owing to differences between protein synthesis and breakdown rates. This is seen as a negative nitrogen balance. The pathophysiologic mechanisms of this catabolic reaction are related to disease severity. In many chronic wasting disorders, a negative nitrogen balance is associated mainly with a reduced protein synthesis rate, whereas protein breakdown is hardly affected. Morrison et $\mathrm{a}^{20}$ found a reduced protein synthesis rate in 
underweight patients with emphysema. In weight-stable COPD patients in a stable clinical condition, we recently found an increased protein turnover rate in the fasting state. ${ }^{21}$ Moreover, voluntary protein intake is important during acute exacerbations of COPD; we previously reported in hospitalized COPD patients a temporarily decreased protein intake that recovered slowly to $1.3 \mathrm{~g} / \mathrm{kg}$ at discharge from the hospital. ${ }^{7}$

The absence of adverse effects of nutritional supplements was also indirectly confirmed in previous studies that showed positive effects of 2-3 nutritional supplements $(\sim 1046 \mathrm{~kJ})$ as an integrated part of pulmonary rehabilitation on weight, fat-free mass, muscle function, and exercise capacity. Future studies using NMR or muscle biopsies might investigate the suggested specific effects of carbohydrates alone or combined with specific bioactive nutrients on oxidative muscle metabolism.

In conclusion, a liquid oral nutritional supplement with an energy content of 1046 $\mathrm{kJ}$ is preferable to an energy load of $2092 \mathrm{~kJ}$ because after the smaller load there was a better metabolic and ventilatory response and less satiety. Also the carbohydrate-rich supplement was preferable to the fat-rich supplement because lung function increased and there was less shortness of breath. 


\section{References}

1. Vanden Bergh E, Van de Woestijne KP, Gyselen A. Weight changes in the terminal stages of chronic obstructive pulmonary disease. Am Rev Respir Dis 1967;95:556-66.

2. Baarends EM, Schols AM, Mostert R, Wouters EF. Peak exercise in relation to tissue depletion in patients with chronic obstructive pulmonary disease. Eur Respir J 1997; 10:2807-13.

3. Schols AM, Fredrix EW, Soeters PB, Westerterp KR, Wouters EF. Resting energy expenditure in patients with chronic obstructive pulmonary disease. Am J Clin Nutr 1991; $54: 983-7$.

4. Baarends EM, Schols AM, Pannemans DL, Westerterp KR, Wouters EF. Total free living energy expenditure in patients with severe chronic obstructive pulmonary disease. Am J Respir Crit Care Med 1997;155:549-54.

5. Baarends EM, Schols AM, Akkermans MA, Wouters EF. Decreased mechanical efficiency in clinically stable patients with COPD. Thorax 1997;52:981-6.

6. Schols AM, Creutzberg EC, Buurman WA, Campfield LA, Saris WH, Wouters EF. Plasma leptin is related to proinflammatory status and dietary intake in patients with chronic obstructive pulmonary disease. Am J Crit Care Med 1999;160:1220-6.

7. Vermeeren MA, Schols AM, Wouters EF. Effects of an acute exacerbation on nutritional and metabolic profile of patients with COPD. Eur Respir J 1997;10:2264-9.

8. Creutzberg EC, Schols AM, Weling-Scheepers CA, Wouters EF. Functional effects of nutritional supplementation therapy incorporated in a pulmonary rehabilitation program in depleted patients with COPD. Am J Respir Crit Care Med 1998; 157:(supplement) p.A258.

9. Efthimiou J, Mounsey PJ, Benson DN, Madgwick R, Coles SJ, Benson MK. Effect of carbohydrate-rich versus fat-rich loads on gas exchange and walking performance in patients with chronic obstructive lung disease. Thorax 1992;47:451-56.

10. Brown SE, Nagendran RC, McHugh JW, Stansbury DW, Fischer CE, Light RW. Effects of a large carbohydrate load on walking performance in chronic air-flow obstruction. Am Rev Respir Dis 1985;132:960-2.

11. Frankfort JD, Fischer CE, Stansbury DW, McArthur DL, Brown SE, Light RW. Effects of high- and low-carbohydrate meals on maximum exercise performance in chronic airflow obstruction. Chest 1991;100:792-5.

12. Quanjer P, Tammeling GJ, Cotes JE, Pedersen OF, Pelsin R, Yernault JC. Standardized lung function testing. Eur Resp J 1993;6 (suppl. 16):5-40.

13. Weiner $P$, Azgad $Y$, Ganam $R$. Inspiratory muscle training combined with general exercise reconditioning in patients with COPD. Chest 1992;102:1351-6.

14. Gaesser GA, Brooks GA. Muscular efficiency during steady-rate exercise; effects of speed and work rate. Journal of Applied Physiology 1975;38:1132-9.

15. Mannix ET, Manfredi $F$, Farber $M O$. Elevated $\mathrm{O}_{2}$ cost of ventilation contributes to tissure wasting in COPD. Chest 1999;115:708-13.

16. Maltais F, Simard AA, Simard C, Jobin J. Oxidative capacity of the skeletal muscle and lactic acid kinetics during exercise in normal subjects and in patients with COPD. Am J Respir Crit Care Med 1996;153:288-93. 
17. Pouw EM, Schols AM, van der Vusse GJ, Wouters EF. Elevated iosine mono phosphate levels in resting muscle of patients with stable chronic obstructive pulmonary disease. Am J Respir Crit Care Med 1998;157:453-7.

18. Akrabawi SS, Mobahran S, Stoltz RR, Ferguson PW. Gastric emptying, pulmonary function, gas exchange, and respiratory quotient after feeding a moderate versus high fat enteral formula meal in chronic obstructive pulmonary disease patients. Nutrition 1996;12:260-5.

19. Sauerwein HP, Romijn JA. More consideration to dietary protein in the nutrition of chronically ill adults with tendency to weight loss. Ned Tijdsch Geneeskd 1999; 143:886-9.

20. Morrison WL, Gibson JN, Scrimgeour C, Rennie MJ. Muscle wasting in emphysema. Cli Sci 1988;75:415-20.

21. Engelen MP, Deutz NE, Wouters EF, Schols AM. Enhanced levels of whole body protein turnover in patients with chronic obstructive pulmonary disease. Am J Respir Crit Care Med 2000;162:1488-92. 


\section{Chapter 4}

\section{Gastric emptying of different solid meals}

and postprandial response in patients with chronic obstructive pulmonary disease

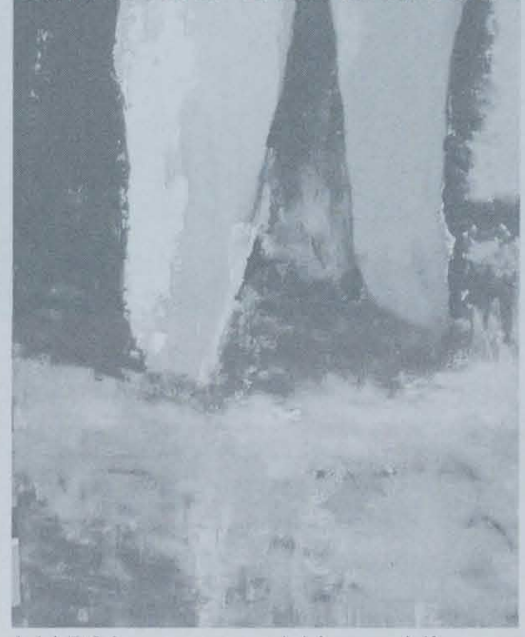

MAP Vermeeren, MA van Nieuwenhoven, RJM Brummer, PPCA Menheere, AMWJ Schols, EFM Wouters

Submitted 


\section{Abstract}

\section{Introduction}

Previously we observed adverse effects of a fat-rich meal on dyspnoea sensation and transcutaneous oxygen saturation in patients with chronic obstructive pulmonary disease (COPD). We hypothesized that this effect could be due to adverse effects of fat-rich food on gastric emptying on top of a disease-related delayed gastric emptying. The aim of the study was to investigate the effect of two isocaloric solid meals, different in fat and carbohydrate content, on gastric emptying and related parameters in 10 depleted COPD patients and 9 healthy age matched control subjects.

\section{Methods}

Patients were characterized by severe airflow limitation and lung hyperinflation (FEV $30 \pm 8 \%$ predicted, residual volume $230 \pm 49 \%$ predicted). The gastric emptying rate was measured using the ${ }^{13} \mathrm{C}$ octanoid acid breath test. Other measurements included lung function by spirometry, transcutaneous oxygen saturation, postprandial symptoms by Visual Analogue Scale (VAS) score and dietary intake. The postprandial response of glucose and insulin and the postprandial secretion pattern of gastrointestinal hormones, cholecystokinin (CCK) and glucagon-like peptide-1 (GLP-1) were measured.

\section{Results}

The gastric emptying rate did not differ between COPD patients and control subjects or between the different meals in both groups. No significant changes in lung function and symptoms were found after both meals in COPD patients and in the control group. Postprandial responses in glucose, insulin and CCK also did not differ between the groups. Despite no changes in gastric emptying rate, a significant increase in GLP- 1 after the fat-rich meal was observed relative to the carbohydrate-rich meal at 210 minutes in COPD patients $(p=0.025)$. Dietary intake at lunch time tended $(p=0.07)$ to be lower after a fat-rich test meal versus a carbohydrate-rich meal in COPD patients compared with controls.

\section{Conclusions}

In general, gastric emptying and related postprandial response after two different meals did not differ in COPD patients and control subjects. However, unrelated to gastric emptying, a postprandial increase in GLP-1 secretion and decreased dietary intake subsequently were found after a fat-rich meal in COPD patients. Therefore, a potential adverse effect of a fatrich meal may be more pronounced in perceived satiety sensation and subsequent caloric intake. 


\section{Introduction}

Chronic obstructive pulmonary disease (COPD) is defined as a disorder characterized by chronic irreversible airflow limitation. Dyspnoea and impaired exercise tolerance, largely related to ventilatory limitations and occurrence of dynamic hyperinflation are important and pronounced symptoms in these patients. Ventilatory limitation is induced by metabolic stress. Diet induced metabolic changes also induce the ventilatory response. This response depends not only on caloric load but also on substrate ingestion since per gram fat intake $\mathrm{CO}_{2}$ production is reduced in contrast with $\mathrm{CO}_{2}$ production after carbohydrate intake. ${ }^{\top}$

Little is known regarding possible differences in gastric emptying between patients with COPD and healthy control subjects regarding its effect on dietary intake. In one study the gastric emptying rate was evaluated in COPD patients after ingesting two different liquid supplements varying in fat content from high (55 energy\%) to moderate (41 energy\%). ${ }^{2}$ Gastric emptying was significantly delayed after ingesting the high fat supplement compared to the moderate fat supplement. ${ }^{2}$

Dyspnoea can also adversely affect appetite and dietary intake. Meal-related increase in dyspnoea is reported in hypoxemic patients with COPD, linked to decreased oxygen saturation. ${ }^{3,4}$ Furthermore, eating requires the recruitment of the upper extremities muscles, which may interfere with breathing, since these muscles are often used as accessory muscles for breathing in severe COPD patients with hyperinflation. ${ }^{4}$ Donahoe et al reported a high prevalence of gastrointestinal symptoms like early satiety and bloating, with prevalence of $87 \%$ and $80 \%$, respectively in a group of underweight COPD patients. ${ }^{5}$ These symptoms may also limit energy intake resulting in a disturbance of energy balance in patients with COPD.

Furthermore, after ingestion of nutrition, a cascade of processes including processes mediating satiety such as the postingestive processes occurs. ${ }^{6}$ Postingestive processes do not only include gastric emptying rate, but also gastric distension, the release of gastrointestinal hormones like cholecystokinin (CCK) and glucagon-like peptide-1 (GLP-1) and the stimulation of gastrointestinal receptors. CCK has several effects on the gastrointestinal tract, including modulation of gastric emptying and thereby also modulation of satiety. Other hormones are also involved in modulating satiety; GLP-1 has been proposed to play a role in the mediation of gastric emptying and satiety and GLP-1 is released from the intestinal mucosa of the ileum. Currently no data of those postprandial signs in patients with COPD have been described.

The present study was designed to investigate gastric emptying after two different solid meals in patients with COPD compared to healthy controls. We hypothesized that gastric emptying is more delayed in depleted COPD patients with hyperinflation compared with healthy controls. We also hypothesized that a 
fat-rich meal compared to an isocaloric carbohydrate-rich meal has more adverse effects on gastric emptying, pulmonary function and symptoms in patients with COPD. Furthermore, we hypothesized that the postprandial response of gastrointestinal hormones is more pronounced in COPD patients compared to healthy controls.

\section{Subjects and methods}

\section{Study population}

The study group consisted of 10 patients with COPD, with COPD defined according to the GOLD criteria.' All COPD patients were in a clinically stable condition; patients with a history of acute exacerbation in the last month were excluded. COPD patients were recruited from the out-patient population of the University Hospital Maastricht and from the pulmonary rehabilitation center Hornerheide, The Netherlands. Inclusion criteria for depleted patients with COPD were: Body mass index (BMI) $\leq 21 \mathrm{~kg} / \mathrm{m}^{2}$ or $>5 \%$ involuntary weight loss in 1 month or $>10 \%$ weight loss in 6 months and $\mathrm{BMI} \leq 25 \mathrm{~kg} / \mathrm{m}^{2}$. Hyperinflation in patients with COPD was defined as residual volume (RV) $>160 \%$ of predicted. Exclusion criteria in this study were a history of diabetes mellitus, previous gastrointestinal surgery or use of medication affecting gastric motility.

Ten healthy control subjects were recruited by advertisement and they were matched for age. One healthy subject was excluded because of recurrent illness. All subjects were fully informed of the aim and the procedure of the study and gave written informed consent. The study was approved by the medical ethical committee of the University Hospital Maastricht.

\section{Study design}

The two different-test meals were administered in a randomized cross-over fashion. The composition of the isocaloric meals was different in carbohydrateand in fat content and similar in protein and fibre amounts. Meal A consisted of 55 energy \% fat and 31 energy\% carbohydrate and meal B consisted of 30 energy\% fat and 55 energy\% carbohydrate. Caloric load of the both meals was $\pm 1425 \mathrm{~kJ}$. The measurements were done within 1 week; at least 1 day between the two measurements was applied for a proper washout of the isotope.

Patients with COPD were asked to abstain from medication with theophylline before and during the study, to avoid the possible influence of theophyllines on gastric emptying. Additionally all subjects were asked to register dietary intake the day before the test and to consume exactly the same diet before the other test day, to minimize the influence of the meal content of the previous day on gastric emptying.

The complete design of the study is summarized in table 4.1. 
Table 4.1 Study design

\begin{tabular}{|c|c|c|c|c|}
\hline & $\begin{array}{l}\text { Before } \\
\text { meal }\end{array}$ & \multirow{7}{*}{ 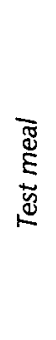 } & Directly after & $\begin{array}{l}\text { Until } 4 \text { hours after ingestion of } \\
\text { the test meal }\end{array}$ \\
\hline Gastric emptying & $x$ & & \multirow{6}{*}{$x$} & every 15 minutes \\
\hline Lung function & $x$ & & & after 90 minutes \\
\hline Oxygen saturation & $x$ & & & every 15 minutes \\
\hline Glucose, insulin & $x$ & & & $\begin{array}{l}\text { every } 15 \text { minutes during first } 2 \text { hours, } \\
\text { than every } 30 \text { minutes }\end{array}$ \\
\hline GLP-1, CCK & $x$ & & & every 30 minutes \\
\hline Symptoms & $x$ & & & every 30 minutes \\
\hline
\end{tabular}

\section{Gastric emptying}

The gastric emptying tests were performed after an overnight fast. The test meals were labeled with a stable isotope, $100 \mu l{ }^{13} \mathrm{C}$-ocatnoic acid $(99 \%$; Cambridge Isotope Laboratories, Andover, MA, USA) was mixed with the egg yolk and prepared as a baked egg. The egg was ingested with two slices of bread and margarine, followed immediately by $200 \mathrm{ml}$ of water. All test meals were ingested within 10 minutes. Breath samples for ${ }^{13} \mathrm{CO}_{2}$ enrichment analysis were drawn from a mixing chamber using Vacutainer tubes at 15-minute intervals for 4 hours after ingestion of the test meals. One breath sample was taken before administration of the meal at $t<1$ hour to determine background enrichment. The collected breath samples were analyzed for ${ }^{13} \mathrm{C}$-isotopic enrichment of the expired $\mathrm{CO}_{2}$, using Isotope Ratio Mass Spectrometry (Finnigan MAT 252, USA). Mathematical analysis of the ${ }^{13} \mathrm{CO}_{2}$ data was performed according to Ghoos et al. ${ }^{8}$ Gastric half-emptying time $\left(t_{7 / 2}\right)$ and lag phase $\left(t_{\text {lag }}\right)$ were calculated as outcome parameter.

\section{Pulmonary function}

Body weight and height were measured in a standard way before lung function testing. Lung function was assessed by flow volume curves using a portable spirometry (Jaeger, Wurzburg, Germany). Forced expiratory volume in one second $\left(\mathrm{FEV}_{1}\right)$, inspiratory vital capacity (IVC), peak expiratory flow (PEF) and inspiratory capacity (IC) were calculated from the curves. The highest value of at least three technical assessments was used for analysis. Lung function was measured before the test meal and 90 minutes after the meal.

To assess hyperinflation, total lung capacity (TLC) and residual volume (RV) were measured only in COPD patients by whole-body plethysmography (Masterlab, Jaeger, Wurzburg, Germany) during one of the study days.

All results of lung function parameters were related to a reference value and expressed as percentage of the predicted value. ${ }^{9}$

\section{Oxygen saturation}

Transcutaneous oxygen saturation $\left(\mathrm{StO}_{2}\right)$ was measured with a pulse oxymeter (Oxypleth Novametrix Medical System Inc, Wallingford CT 06492 USA). The 
electrode was placed around a finger of the left hand before the test meal was ingested. Measurements were done at baseline, directly after ingestion and at an interval of 15 minutes after ingestion for 4 hours.

\section{Biochemical parameters}

Blood was collected from an intravenous catheter in the arm. Blood collection was performed in fasting state and after ingestion of the meal during the experiment, and biochemical parameters were measured in the blood.

Glucose and Insulin

Glucose and insulin were measured in fasting state and after ingestion at 15minute intervals for 2 hours and thereafter at 30-minute interval till 4 hours after ingestion of the test meal. Blood was collected in a tube containing oxalate and sodium fluoride and centrifuged at $3500 \mathrm{rpm}$ for 15 minutes at $5^{\circ} \mathrm{C}$. Quantitative determination of glucose was done using glucose oxidase with oxygen rate detection with an oxygen electrode (Synchron $\mathrm{LX}^{\circledR}$ Systems, Beckman Coulter Inc., Fullerton, CA).

To assess insulin, blood was collected in an evacuated coagulation tube and centrifuged for 15 minutes at $3500 \mathrm{rpm}$ at $5^{\circ} \mathrm{C}$. Serum was collected and stored until measurement using an immunoassay (AutoDELFIA ${ }^{\text {TM }}$ Insulin, Wallac Oy, Turku, Finland).

\section{Cholecystokinin and glucagon-like peptide-1}

An EDTA tube (EDTA Sherwood Medical, St. Louis, MO) was used to collect blood for the measurement of CCK and GLP-1 in fasting state and after ingestion of the test meal at 30-minute intervals. Directly after collection, dipeptidyl peptidase IV (DPP IV) was added as inhibitor. Blood was centrifuged at $3500 \mathrm{rpm}$ for 15 minutes at $5^{\circ} \mathrm{C}$ within 1 hour after collection. Plasma samples were stored at $70^{\circ} \mathrm{C}$ until analyzed.

CCK has been assayed using the commercially available EURIA-CCK assay of EuroDiagnostica $A B$, Malmö, Sweden. This is a competitive radioimmunoassay in which an antibody is used raised in rabbit against the eight $\mathrm{C}$-terminal amino acids of CCK-33-sulphate (commonly named CCK-8). ${ }^{125}$ Iodinated CCK-8 is equally used as tracer. The separation between the bound and the free fractions is performed by means of an anti-rabbit IgG antiserum coupled to cellulose particles. The assay is calibrated against known solutions of CCK-8. EDTA-Samples with added trasylol have been ethanol extracted. The lowest sensitivity of the assay is $0.3 \mathrm{pmol} / \mathrm{l}$. The inter assay coefficient of variation is between 5 and $10 \%$. Cross reactivity with CCK (26-33), sulphate is $100 \%$, with CCK-33, sulphate is $134 \%$ and with gastrin-17 sulphate $0.5 \%$. With all other molecules of interest no cross reactivity has been found. Normal fasting levels of CCK are $\leq 1.12 \mathrm{pmol} / \mathrm{I}^{10}$

GLP-1 has been assayed using the commercially available GLP-1 (active) RIA from Linco, StCharles, MO, USA. This is a radioimmunoassay in which the GLP-1 from the samples is in competition with $\mathrm{a}^{125}$ J GLP (7-36) amide for the binding sites on 
a guinea pig anti GLP (7-36) amide antibody. The separation between the bound and the free fractions is performed using a goat anti-guinea-pig $\operatorname{lgG}$ antibody with $3 \%$ PEG added. The assay is calibrated against known solutions of GLP-1 (7-36) amide. In order to preserve the active GLP-1 in the samples DPP-IV inhibitor has been added immediately after the withdrawal of the blood. The lowest detectable concentration is $3 \mathrm{pmol} / \mathrm{l}$. The inter assay coefficient of variation is about $6-8 \%$ in the concentration range of 40 to $300 \mathrm{pmol} / \mathrm{l}$. Cross reactivity with GLP-1 (7-36) amide, with GLP-1 (7-37) is $100 \%$ and with glucagon $16 \%$. Cross reactivity is undetectable with GLP-1 (1-36)amide, GLP-1 (1-37), GLP-1 (9-36) amide and GLP-1 (9-37). ${ }^{11}$

\section{Subjective symptoms}

Symptoms were measured before the test, 5 minutes after ingestion and with an interval of 30 minutes after ingestion of the test meals using a visual analogue scale (VAS-score) of $10 \mathrm{~cm}$ length. The following symptoms were assessed: shortness of breath, satiety, hunger, fullness, thirst and appetite and expressed in $\mathrm{cm}$, ranging from 0 to $10 \mathrm{~cm}$.

\section{Dietary intake}

Dietary intake was assessed on the two study days of the test, using food records, with the aim to investigate the influence of the test meals on spontaneous dietary intake during the same day. Since dietary intake was recorded on the previous day for standardization of dietary intake, we also compared the energy content of that breakfast with the energy content of the two test meals.

\section{Statistics}

It was predicted that the inclusion of 9 participants per group would permit detection of a difference of 25 minutes in gastric emptying rates and a 0.05 difference between the groups at $\alpha=0.05$ and Power $=0.90$.

Differences in the baseline characteristics between the patients with COPD and the healthy control group were compared using a Student's t-test for independent samples. The data were analyzed to evaluate the effect of the different meals on gastric emptying, pulmonary function, biochemical parameters and symptoms. Differences in the outcome parameters among the two study groups were compared by an analysis of variance (ANOVA) method and period, sequence and treatment were included. All analyzes were performed using the SPSS 11 for Windows statistical package. Values of $p<0.05$ were accepted as statistically significant. Data were expressed as mean $( \pm S D)$ in the text and tables and as mean $( \pm$ SEM) in the graphs. 


\section{Results}

The baseline characteristics of the study population are shown in table 4.2. All COPD patients were ex-smokers and 2 of 9 healthy subjects had a history of smoking cigarettes. The COPD patients had severe airflow limitation (GOLD stage III-IV, FEV $130 \pm 8 \%$ predicted), with severe static hyperinflation under resting conditions (RV: $230 \pm 49 \%$ predicted). In the control group, all lung function values were within normal range.

Table 4.2 The baseline characteristics of the study population

\begin{tabular}{lcc}
\hline & $\begin{array}{c}\text { COPD patients } \\
\mathbf{n}=10\end{array}$ & $\begin{array}{c}\text { Control group } \\
\mathbf{n}=9\end{array}$ \\
\hline Male / female & $8 / 2$ & $6 / 3$ \\
Age, years & $59 \pm 10$ & $60 \pm 6$ \\
Weight, $\mathrm{kg}$ & $56.2 \pm 9$ & $64.9 \pm 14$ \\
Height, cm & $170 \pm 9$ & $169 \pm 12$ \\
$\mathrm{BMI}, \mathrm{kg} / \mathrm{m}^{2}$ & $19.1 \pm 2.1^{*}$ & $22.4 \pm 2.1$ \\
$\mathrm{FEV}$ & 30 predicted & $104 \pm 14$ \\
IVC, \%predicted & $82 \pm 15^{*}$ & $113 \pm 14$ \\
RV, \%predicted & $230 \pm 49$ & - \\
\hline
\end{tabular}

Data are mean $\pm \mathrm{SD} ; \mathrm{BMI}$, Body Mass Index; $\mathrm{FEV}_{1}$, forced expiratory volume in one second; IVC, inspiratory vital capacity; RV, residual volume; " $p<0.05$ compared between COPD patients and control group

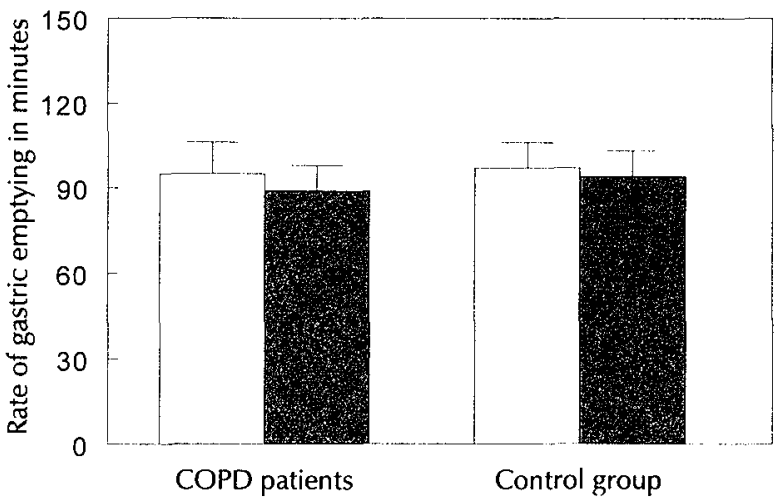

Figure 4.1 The gastric emptying rate after both meals in COPD patients and control group Open bars, after fat-rich meal; grey bars, after carbohydrate-rich meal

\section{Gastric emptying}

In COPD patients gastric emptying half-time of the fat-rich meal $\left(\mathrm{t}_{1 / 2}\right)$ was $95 \pm 35$ minutes and of the carbohydrate-rich meal $89 \pm 27$ minutes. In the control group 
$(n=9) t_{1 / 2}$ was $96 \pm 26$ versus $94 \pm 28$ minutes, respectively. The gastric emptying rate was not different between COPD patients and healthy controls, as shown in figure 4.1. In both COPD patients and controls, there were no significant differences in the gastric emptying rate between the two different meals. The lag phase $\left(t_{\mathrm{lag}}\right)$ of the fat-rich meal was $52 \pm 19$ minutes in COPD patients and of the carbohydrate-rich meal it was $50 \pm 22$ minutes. In the control subjects $t_{\text {lag }}$ of the fat-rich meal was $55 \pm 20$ minutes and of the carbohydrate-rich meal it was $54 \pm 21$ minutes. Between both groups and within groups no significant differences in $t_{\text {lag }}$ after the test meals were observed.

Table 4.3 Pulmonary function before and after supplements of the different meals in COPD patients

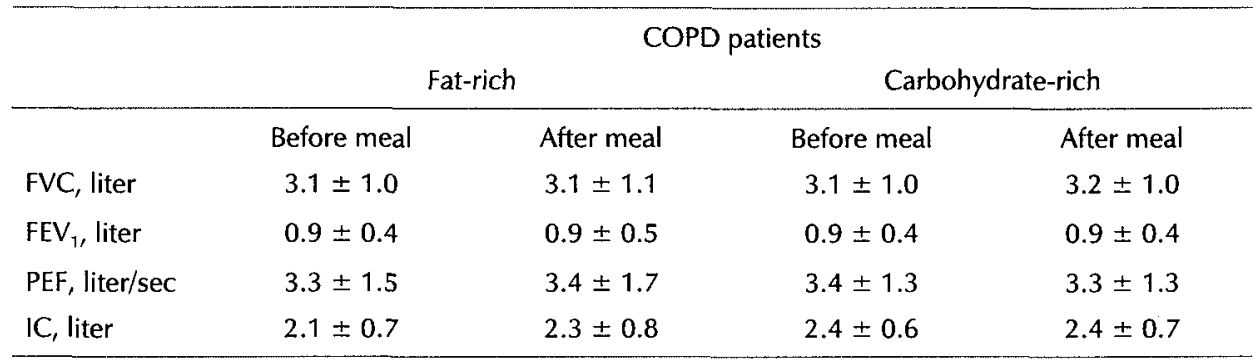

Data are mean $\pm \mathrm{SD} ; \mathrm{FVC}$, forced vital capacity; $\mathrm{FEV}_{1}$, forced expiratory volume in one second, $\mathrm{PEF}$, peak expiratory flow; IC, inspiratory capacity

\section{Lung function and oxygen saturation}

Pulmonary function in patients with COPD is shown in table 4.3. No significant changes were found after ingestion of the test meals. Also in the control group there were no differences after both meals, data not shown.

Figure 4.2 shows the slight changes in oxygen saturation in COPD patients after both meals. Directly after ingestion, there was a significant drop in oxygen saturation and this was similar after both meals in COPD patients, $p=0.048$, but not clinically significant, as defined by a drop of $>4 \%$ in $\mathrm{SaO}_{2}$. In the postprandial pattern of oxygen saturation after the two different meals in COPD patients, there were significant differences, as shown in figure 4.2. After 15 minutes the mean oxygen saturation after the carbohydrate-rich meal was above the level of baseline in COPD patients. From 60 until 195 minutes postprandial, the change in oxygen saturation after the carbohydrate-rich meal was significantly different in patients with COPD, compared to the change in oxygen saturation after the fat-rich meal. There were no changes in oxygen saturation in healthy controls after the two different meals, data not shown. 


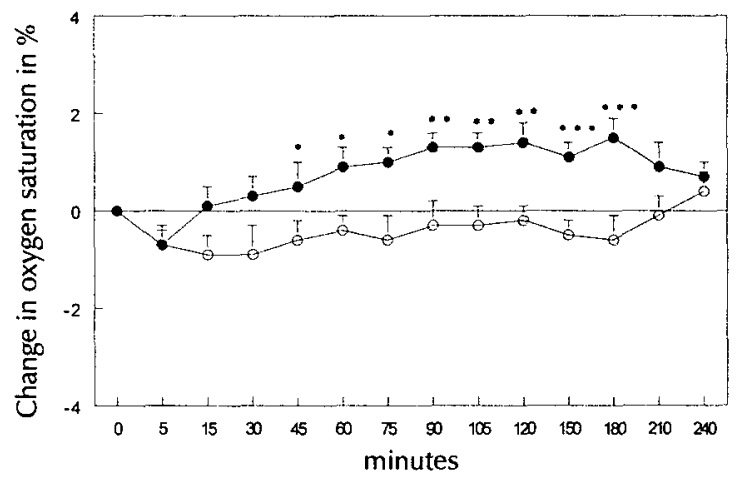

Figure 4.2 Change in oxygen saturation after both meals in patients with COPD Open circles, after fat-rich meal; closed circles, after carbohydrate-rich meal ${ }^{*} \mathrm{p}<0.05,{ }^{* *} \mathrm{p}=0.01,{ }^{* * *} \mathrm{p}<0.01$

\section{Biochemical parameters}

The postprandial glucose response in COPD patients was significantly higher after the carbohydrate-rich meal compared to the response after the fat-rich meal for the first 60 minutes $(p<0.05)$. After 60 minutes the postprandial differences were no longer significant between the meals. For insulin, the postprandial response was also significantly higher for the first 60 minutes after the carbohydrate-rich meal compared to the fat-rich meal in patients with COPD $(p<0.05)$. The postprandial patterns of glucose and insulin after both meals in COPD patients are shown in figure $4.3 \mathrm{a}$ and $4.3 \mathrm{~b}$, respectively.

In the control group, there was also a significant increase in glucose at 30 and 60 minutes postprandial, but there were no significant differences in insulin response between the two meals in this group, shown in figure 4.3e and 4.3f.

The pattern of GLP-1 secretion at baseline and postprandially is shown for both groups in figure $4.4 \mathrm{a}$ and $4.4 \mathrm{~b}$. There were no significant changes in GLP-1 between both meals in the control group. At 210 minutes postprandially, there was a significant difference in GLP-1 response after the carbohydrate-rich meal compared with the response after the fat-rich meal in patients with COPD, $p=0.025$.

The postprandial pattern of CCK was not significant different between COPD patients and control subjects and not after both meals in the groups, shown in figure $4.5 \mathrm{a}$ and $4.5 \mathrm{~b}$.

\section{Symptoms}

Changes in symptom score were not different between COPD patients and healthy controls. In COPD patients, the change in satiety was similar after both meals, as shown in figure 4.3c. No significant differences in postprandial change in shortness of breath were observed after both meals in COPD patients, as shown in figure $4.3 \mathrm{~d}$. The other symptoms hunger, fullness, thirst and appetite were also not different between the two isocaloric meals in patients with COPD 
(data not shown). The pattern of satiety and shortness of breath during the experiment in the control group are presented in figure $4.3 \mathrm{~g}$ and $4.3 \mathrm{~h}$. There were no significant changes in symptoms in the control group between the test meals.

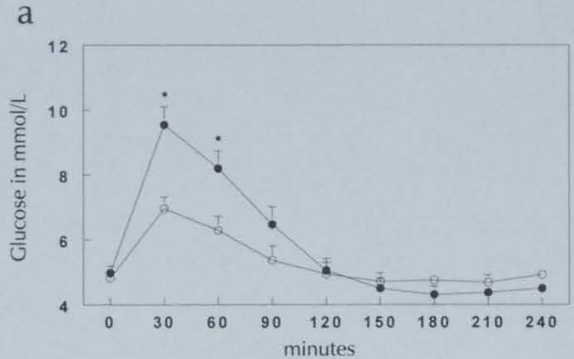

b

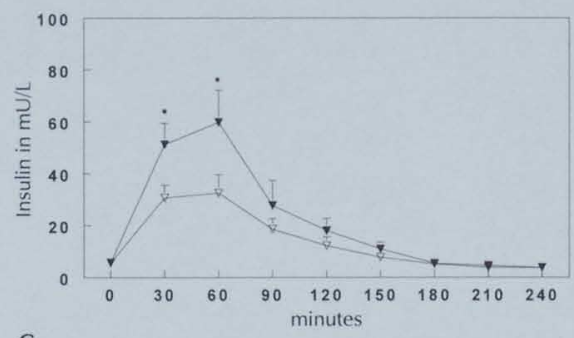

C

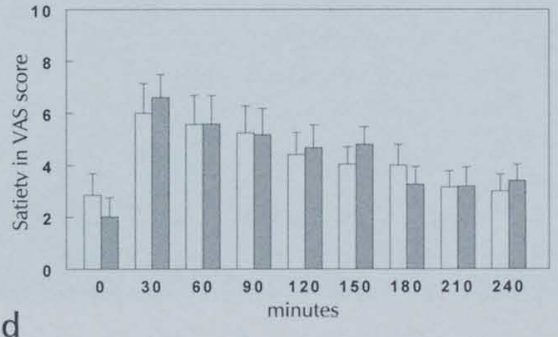

d

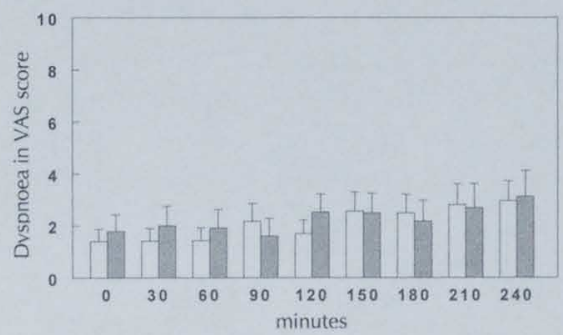

$\mathrm{e}$

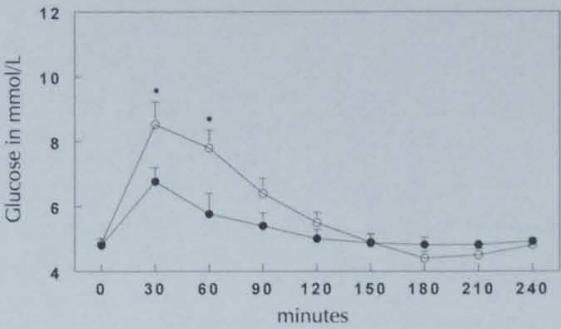

f

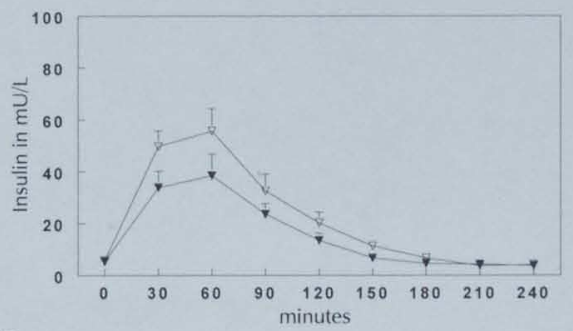

g

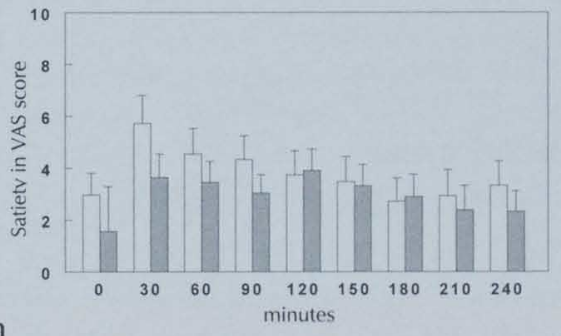

h

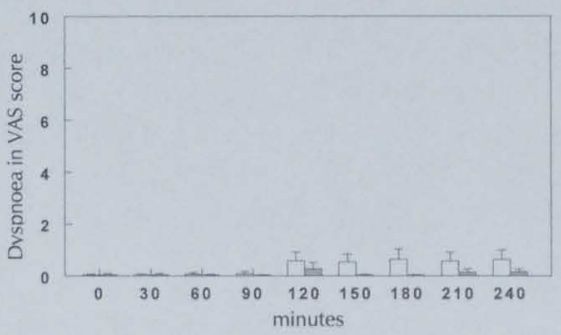

Figure 4.3 Pattern of glucose, insulin, satiety and dyspnoea during both tests in COPD patients, 4.3a, $4.3 \mathrm{~b}, 4.3 \mathrm{c}, 4.3 \mathrm{~d}$; in healthy controls, $4.3 \mathrm{e}, 4.3 \mathrm{f}, 4.3 \mathrm{~g}$, 4.3h. Open circles, open triangles, open bars, fat-rich meal; closed circles, closed triangles and grey bars, carbohydrate-rich meal; ${ }^{*} p<0.05$ carbohydrate-rich meal compared with fat-rich meal 
a

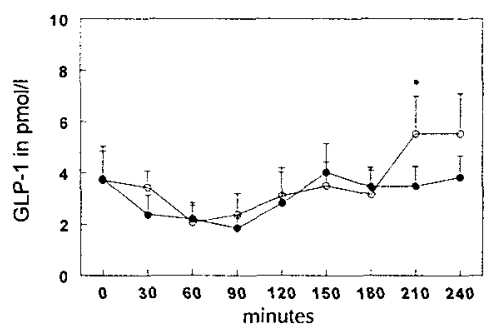

b

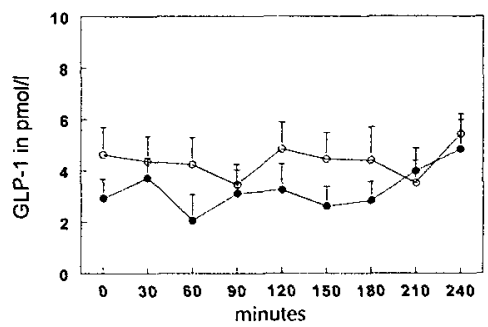

Figure 4.4 Pattern of GLP-1 during both meals in patients with COPD,4.4a and in control subjects,4.4b. Open circles, after fat-rich meal; closed circles, after carbohydrate-rich meal

a

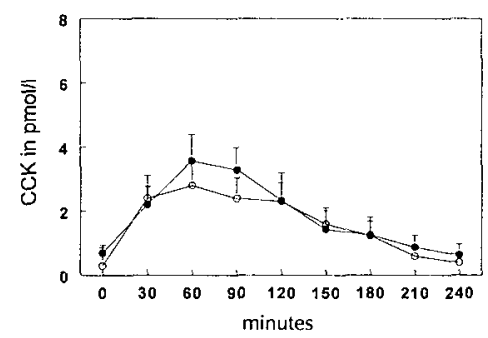

b

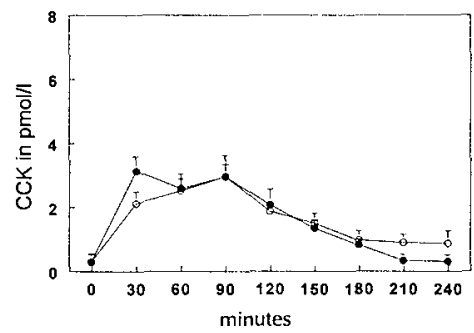

Figure 4.5 Pattern of CCK after both meals in COPD patients, 4.5a and in control subject, 4.5b. Open circles, after fat-rich meal, closed circles, after carbohydrate-rich meal

\section{Dietary intake}

In $70 \%$ of the patients versus $40 \%$ in healthy controls, energy content of the test meal was higher than their reported breakfast on the previous day. The energy intake during the test days was $5620 \pm 1877 \mathrm{~kJ}$ after the fat-rich meal compared to $6619 \pm 2465 \mathrm{~kJ}$ after the carbohydrate-rich meal in patients with COPD (ns). In the control group, energy intake during the test days was similar after both meals, $5787 \pm 1587 \mathrm{~kJ}$ after fat-rich meal versus $5665 \pm 2074 \mathrm{~kJ}$ after carbohydrate-rich meal. In figure 4.6 the energy intake at lunch time after completion of the tests tended to be lower after fat-rich meal compared to carbohydrate-rich meal in COPD patients, $p=0.07$. In healthy control subjects energy intake at lunch time was similar after both meals, shown in figure 4.6. 


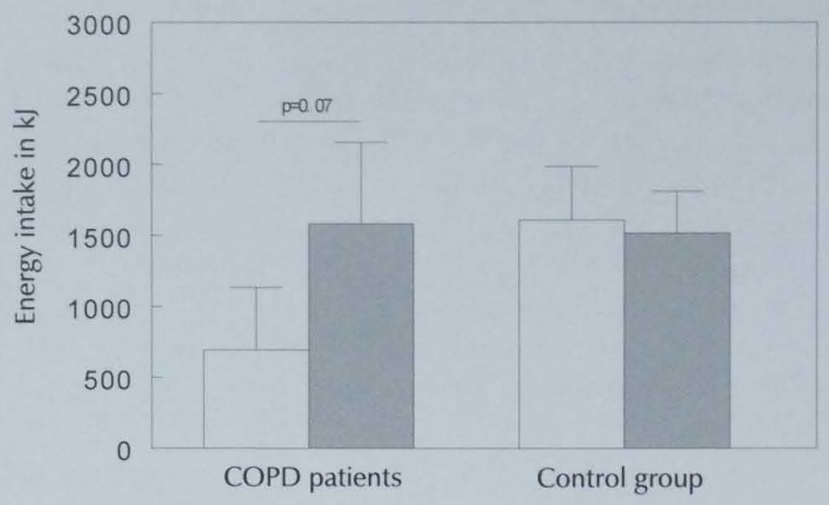

Figure 4.6 Energy intake at lunch time after completion of the tests in COPD patients and control group. Open bars, after fat-rich meal; grey bars, after carbohydrate-rich meal

\section{Discussion}

This is the first study describing the gastric emptying rate in COPD patients compared with healthy control subjects. In contrast to our hypothesis, no differences in the gastric emptying rate in COPD patients and in controls were found and also no differences in the gastric emptying rate between meals in both study groups. Despite no differences in the primary outcome, differences were found in the secondary outcome parameters, namely postprandial GLP-1 secretion and dietary intake at lunch time in COPD patients. A significant higher postprandial increase of GLP-1 secretion was found after the fat-rich meal in COPD patients and this may be related to dietary intake at lunch time in COPD patients which tended to be lower after the fat-rich meal. A potential adverse effect of a fat-rich meal may therefore be more pronounced in perceived satiety sensation and subsequent caloric intake in patients with COPD.

Patients with marked hyperinflation were selected for this study as it can be expected that particularly in this subgroup the possible mechanical disadvantages due to changes in pulmonary mechanics will be more manifested. Hyperinflation in these patients is associated with important alterations in the geometry of the chest wall, particularly at the level of the diaphragm: hyperinflation is associated with a marked flattening of the diaphragm with a dramatic decrease in the zone of apposition height. ${ }^{12}$ Furthermore, respiratory cycle-related gastric pressure changes are largely related to the level of lung inflation. In case of resistive and restrictive impediment as in COPD patients with static hyperinflation, positive gastric pressure swings will be more pronounced. Indeed, patients with COPD are able to develop greater maximal inspiratory pressure than normal subjects at a given lung volume possibly due to length adaptation of the diaphragm to the 
chronic hyperinflation resulting in a preservation of ventilatory pump capacity. ${ }^{13}$ In addition, studies indicate that in many patients with stable but severe COPD the expiration is a mechanically active process at least in part determined by the active contraction of the transversal abdominal muscle. ${ }^{14}$ In the same study a close relationship was found between the rise in gastric pressure during expiration and end-expiratory alveolar pressure, indicating a transmission through the relaxed diaphragm of this rise in abdominal pressure produced by the contraction of the transversus abdominis. Furthermore, dynamic hyperinflation during periods of increased minute ventilation will pronounce these pressure variations. Therefore, despite these more pronounced mechanical effects during in and expiration in this selected group of hyperinflated COPD patients, no differences in gastric emptying could be demonstrated.

In contrast to our study, Akrabawi et al found a significantly lower gastric emptying rate, measured by scintigraphy, after a supplement with high-fat compared with a supplement with moderate-fat content. ${ }^{2}$ Remarkably the difference in fat content between the supplements used in that study was lower compared to the current study (resp. $7.6 \mathrm{~g}$ and $9.6 \mathrm{~g}$ fat). However, the caloric load of the supplements was higher in the study of Akrabawi (2310 kJ versus 1425 $\mathrm{kJ})$ and that could be the explanation of the conflicting results. ${ }^{2}$

A significant different response of oxygen saturation after the two meals was observed in COPD patients. However, the change of oxygen saturation after the fat-rich meal was not clinically significant. In line with a previous study ${ }^{3}$, we found a more distinct decrease in $\mathrm{SaO}_{2}$ after fat-rich meal compared to carbohydraterich meal. The decrease in $\mathrm{SaO}_{2}$ in our study was less pronounced, probably due to the fact that the COPD patients who participated in the study of Schols were more hypoxemic. ${ }^{3}$ Furthermore, the higher energy content of the fat-rich warm meal $(1870 \mathrm{~kJ})$ and the different meal temperature ${ }^{3}$ may further explain why we did not detect a difference in meal related dyspnoea in our study.

No correlation between subjective perception of satiety by VAS score and satiety mediating hormones (CCK and GLP-1) are found in the current study. We hypothesized that a fat-rich meal would induce more satiety as result of a delayed gastric emptying and due to a different pattern of gastrointestinal hormone response, compared to the carbohydrate-rich meal. However no differences in satiety perception were reported during the tests, in both COPD patients and controls. In a recently published study of Raben et $\mathrm{al}^{15}$, no differences in subjectively reported satiety after 4 isocaloric meals with different macronutrient compositions in healthy subjects were observed. In that study the proposed relation between the satiety hierarchy and the oxidation hierarchy of the four macronutrients was not confirmed. ${ }^{15}$ The suggestion has been made that satiety is influenced more by protein. ${ }^{16}$ In our study we used test meals similar in energy and protein content and that may explain the lack of differences in satiety in our study, in accordance with the study of Raben. ${ }^{15}$

Furthermore, the influence of the different meal contents on satiety may be more extended with respect to time. Dietary intake after the test meals showed that energy intake after fat-rich meal was lower at lunch time compared to a previous carbohydrate-rich meal in COPD patients. Spontaneous energy intake at an ad 
libitum lunch after intravenously infused GLP-1 has been described in healthy young men. ${ }^{17}$ We proposed that decreased dietary intake at lunch time after fatrich meal in COPD patients was due to the increased GLP-1 secretion. So the role of GLP-1 is more attributed to the inter-meal satiety in patients with COPD.

The secretion pattern of CCK was not different between the meals. Comparing our results with studies describing GLP-1 and CCK secretion patterns is difficult concerning the different used experimental designs. ${ }^{17-23}$ For instance, an endogenous load may reveal another secretion pattern of GLP-1 and CCK compared to the response after a pharmacological load. In some of our study population, the postprandial changes in CCK or GLP-1 secretion was less pronounced and we suggested that this may be related to their habitual dietary intake. After ingestion of a higher dietary intake relative to habitual dietary intake, a more pronounced postprandial response in CCK or GLP-1 secretion may occur. Recently an effect of habitual dietary protein intake on appetite and satiety has been described in healthy subjects. ${ }^{24}$ We hypothesized that besides appetite and satiety, secretion of gastrointestinal hormones varies with habitual dietary intake. Loss of appetite and early satiety may contribute to decreased dietary intake resulting in weight loss. In COPD patients, decreased dietary intake has been described in both stable condition and during acute exacerbation ${ }^{25,26}$ which was associated with loss of appetite and early satiety. Anorexia, defined as loss of appetite and early satiety, was related to higher inflammatory response and nonresponse of nutritional intervention in COPD patients. ${ }^{27}$ So, inflammation influences appetite negatively and became a predictor for response to nutritional therapy. Still, it is not clear how to interfere in the inflammatory process resulting in improvement of the altered appetite regulation. Recently an appetite stimulant, megestrol acetate, was prescribed in underweight stable COPD patients ${ }^{28}$ in a randomized double-blind placebo-controlled study. Megestrol acetate induced an improved appetite and weight gain in COPD patients after 8 weeks, mainly fat mass. However despite these improvements, there was no progression in health status or functional performance found.

In summary, gastric emptying and postprandial response in COPD patients was not different compared to healthy controls after two isocaloric solid meals. Subsequent dietary intake was more negatively influenced by the fat-rich meal in COPD patients and satiety sensation may be more extended. Further research concerning the regulation of satiety and appetite likewise by inflammatory markers in COPD patients will be needed to unravel the altered regulation. 


\section{References}

1. Efthimiou J, Mounsey PJ, Benson DN, Madgwick R, Coles SJ, Benson MK. Effect of carbohydrate rich versus fat rich loads on gas exchange and walking performance in patients with chronic obstructive lung disease. Thorax 1992;47:451-6.

2. Akrabawi SS, Mobarhan S, Stoltz RR, Ferguson PW. Gastric emptying, pulmonary function, gas exchange, and respiratory quotient after feeding a moderate versus high fat enteral formula meal in chronic obstructive pulmonary disease patients. Nutrition 1996;12:260-5.

3. Schols AM, Mostert R, Cobben N, Soeters PB, Wouters EF. Transcutaneous oxygen saturation and carbon dioxide tension during meals in patients with chronic obstructive pulmonary disease. Chest 1991;100:1287-92.

4. Wolkove N, Fu LY, Purohit A, Colacone A, Kreisman H. Meal-induced oxygen desaturation and dyspnea in chronic obstructive pulmonary disease. Can Respir J 1998;5:361-5.

5. Donahoe $M$, Rogers RM. Nutritional assessment and support in chronic obstructive pulmonary disease. Clin Chest Med 1990;11:487-504.

6. Blundell JE, Hill AJ, Rogers PJ. Hunger and the satiety cascade - their importance for food acceptance in the late 20th century. Food acceptability 1988;D.M.H. Thompson (ed.), Elsevier:233-50.

7. Pauwels RA, Buist AS, Calverley PM, Jenkins CR, Hurd SS. Global strategy for the diagnosis, management, and prevention of chronic obstructive pulmonary disease. NHLBI/WHO Global Initiative for Chronic Obstructive Lung Disease (GOLD) Workshop summary. Am J Respir Crit Care Med 2001;163:1256-76.

62 8. Ghoos YF, Maes BD, Geypens BJ, Mys G, Hiele MI, Rutgeerts PJ, Vantrappen G. Measurement of gastric emptying rate of solids by means of a carbon-labeled octanoic acid breath test. Gastroenterology 1993;104:1640-7.

9. Quanjer PH. Standardized lung function testing. Official statement of the European Respiratory Society. Eur Respir J 1993;6(Suppl 16):1-100.

10. Cantor P. Evaluation of a radioimmunoassay for cholecystokinin in human plasma. Clin Chem 1998;44:991-1001.

11. Holst JJ, Orskov C, Hartmann B, Deacon CF. Posttranslational processing of proglucagon and postsecretory fate of proglucagon products. Basel: Front Diabetes. Karger; 1997.

12. Gauthier AP, Verbanck S, Estenne M, Segebarth C, Macklem PT, Paiva M. Threedimensional reconstruction of the in vivo human diaphragm shape at different lung volumes. J Appl Physiol 1994;76:495-506.

13. Similowski T, Yan S, Gauthier AP, Macklem PT, Bellemare F. Contractile properties of the human diaphragm during chronic hyperinflation. $N$ Engl J Med 1991;325:917-23.

14. Ninane V, Yernault JC, de Troyer A. Intrinsic PEEP in patients with chronic obstructive pulmonary disease. Role of expiratory muscles. Am Rev Respir Dis 1993;148: 1037-42.

15. Raben A, Agerholm-Larsen L, Flint A, Holst J), Astrup A. Meals with similar energy densities but rich in protein, fat, carbohydrate, or alcohol have different effects on energy expenditure and substrate metabolism but not on appetite and energy intake. Am J Clin Nutr 2003;77:91-100. 
16. Westerterp-Plantenga MS. The significance of protein in food intake and body weight regulation. Curr Opin Clin Nutr Metab Care 2003;6:635-8.

17. Flint A, Raben A, Astrup A, Holst JJ. Glucagon-like peptide 1 promotes satiety and suppresses energy intake in humans. J Clin Invest 1998;101:515-20.

18. Elliott RM, Morgan LM, Tredger JA, Deacon S, Wright J, Marks V. Glucagon-like peptide-1 (7-36)amide and glucose-dependent insulinotropic polypeptide secretion in response to nutrient ingestion in man: acute post-prandial and 24-h secretion patterns. J Endocrinol 1993;138:159-66.

19. Maclntosh CG, Morley JE, Wishart J, Morris H, Jansen JB, Horowitz M, Chapman IM. Effect of exogenous cholecystokinin (CCK)-8 on food intake and plasma CCK, leptin, and insulin concentrations in older and young adults: evidence for increased CCK activity as a cause of the anorexia of aging. J Clin Endocrinol Metab 2001;86:5830-7.

20. Gutzwiller JP, Drewe J, Goke B, Schmidt H, Rohrer B, Lareida J, Beglinger C. Glucagon-like peptide-1 promotes satiety and reduces food intake in patients with diabetes mellitus type 2. Am J Physiol 1999;276:R1541-4.

21. Long SJ, Sutton JA, Amaee WB, Giouvanoudi A, Spyrou NM, Rogers PJ, Morgan LM. No effect of glucagon-like peptide-1 on short-term satiety and energy intake in man. $\mathrm{Br}$ J Nutr 1999;81:273-9.

22. Naslund E, Bogefors J, Gryback P, Bjellerup P, Jacobsson H, Holst J, Hellstrom PM. GLP-1 inhibits gastric emptying of water but does not influence plasma. Scand J Gastroenterol 2001;36:156-62.

23. Verdich C, Flint A, Gutzwiller JP, Naslund E, Beglinger C, Hellstrom PM, Long SJ, Morgan LM, Holst JJ, Astrup A. A meta-analysis of the effect of glucagon-like peptide1 (7-36) amide on ad libitum energy intake in humans. J Clin Endocrinol Metab 2001;86:4382-9.

24. Long SJ, Jeffcoat AR, Millward DJ. Effect of habitual dietary-protein intake on appetite and satiety. Appetite 2000;35:79-88.

25. Schols AM, Mostert R, Soeters PB, Saris WH, Wouters EF. Energy balance in patients with chronic obstructive pulmonary disease. Am Rev Respir Dis 1991;143:1248-52.

26. Vermeeren MA, Schols AM, Wouters EF. Effects of an acute exacerbation on nutritional and metabolic profile of patients with COPD. Eur Respir J 1997;10:2264-9.

27. Creutzberg EC, Schols AM, Weling-Scheepers CA, Buurman WA, Wouters EF. Characterization of nonresponse to high caloric oral nutritional therapy in depleted patients with chronic obstructive pulmonary disease. Am J Respir Crit Care Med $2000 ; 161: 745-52$.

28. Weisberg J, Wanger J, Olson J, Streit B, Fogarty C, Martin T, Casaburi R. Megestrol acetate stimulates weight gain and ventilation in underweight COPD patients. Chest $2002 ; 121: 1070-8$. 
Chapter 5

Energy balance in depleted ambulatory patients with chronic obstructive pulmonary disease; the effect of physical activity and oral nutritional supplementation

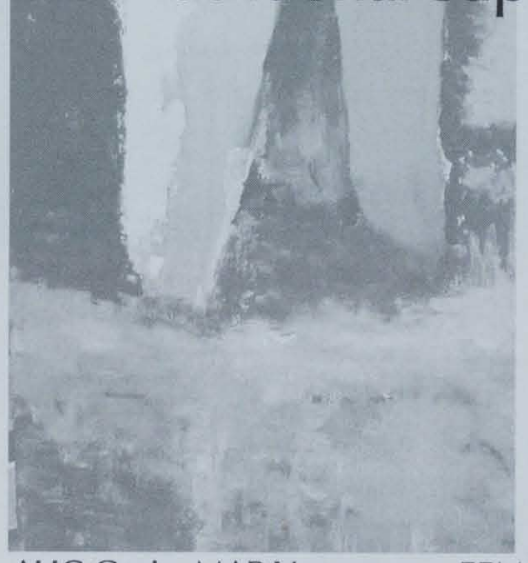

AHC Goris, MAP Vermeeren, EFM Wouters, AMWJ Schols, KR Westerterp

British Journal of Nutrition 2003; 89: 725-729 


\section{Abstract}

\section{Background}

Patients with chronic obstructive pulmonary disease (COPD) often suffer from weight loss.

\section{Objective}

The aim of the present study was to gain insight into the energy balance of depleted ambulatory COPD patients, in relation to their habitual level of physical activity and consumption of oral nutritional supplements.

\section{Design}

Clinically stable and weight-stable patients ( $n=20$, body mass index $19.8 \pm 2.0 \mathrm{~kg} / \mathrm{m}^{2}$ ) were studied 1 and 3 months after pulmonary rehabilitation or recovery in the clinic and were at random assigned to a control or intervention group with regard to nutritional supplementation. Energy intake was measured with a 7-day food record. Energy expenditure was estimated from a simultaneous 7-day assessment of physical activity with a tri-axial accelerometer for movement registration in combination with measured basal metabolic rate. Body mass was measured at several time points.

\section{Results}

The body mass remained stable in both groups after 1 or 3 months and mean energy balances were comparable for both groups. The mean body mass change between month 1 and 3 was negatively related to the mean physical activity level $(r=-0.49, p=0.03)$.

\section{Conclusions}

Weight change over the 3 months was negatively associated with the physical activity level. These results suggest that knowledge about the individual physical activity level is necessary for the estimation of the energy need of the COPD patient. 


\section{Introduction}

Patients with chronic obstructive pulmonary disease (COPD) often suffer from weight loss, due to an inadequate dietary intake combined with an increased energy expenditure. ${ }^{1}$ Nutritional depletion in COPD patients influences functional status and health related quality of life. ${ }^{2.5}$ Insight into factors related to the energy balance of depleted COPD patients at home helps to optimize the nutritional status of patients at home.

Nutritional therapy in a rehabilitation setting improves physical condition of depleted COPD patients, especially when it is combined with exercise or another anabolic stimulus such as anabolic steroids. ${ }^{2,6}$ The success of nutritional therapy in ambulatory depleted COPD patients varies and probably depends partly on compliance and appropriate incorporation of the supplements, as there is less control on the food intake of the patients than in a clinical situation. ${ }^{7,8}$

An increase in energy intake by supplementation does not necessarily imply a positive energy balance. The energy balance of ambulatory depleted COPD patients is also a function of the energy requirement of the patients. Physical activity, as the main determinant of variation in energy requirement, may play an important role. In particular because previous studies by our group have demonstrated an increased energy requirement for physical activity in severe COPD patients. ${ }^{9}$

The aim of the present study was to get insight into the energy balance of ambulatory, depleted COPD patients in relation to their habitual physical activity. A secondary aim of the study was to look at the effect of the consumption of nutritional supplements on the energy balance. Energy expenditure and energy intake were estimated at 1 and 3 months after discharge from the clinic (after recovery of an exacerbation or after rehabilitation in a pulmonary rehabilitation center). Reported food intake was controlled for misreporting or a change in diet while food recording. ${ }^{10,11}$

\section{Subjects and methods}

\section{Protocol}

Twenty depleted COPD patients were studied 1 and 3 months after discharge from the university hospital in Maastricht or from the pulmonary rehabilitation center in Horn, The Netherlands. At discharge all patients were in a clinically and weight-stable condition. The patients were then at random assigned (with a randomization table) to the intervention group, who received $3 \times 125 \mathrm{ml}$ Respifor ${ }^{(1)}$ (sip-feed, Nutricia, The Netherlands, nutritional supplement $375 \mathrm{ml}=2.38 \mathrm{MJ} /$ day, 
composition 20 energy\% protein, 20 energy\% fat and 60 energy\% carbohydrate) or to the control group. Patients were advised to take the supplements in the morning, the afternoon and in the evening respectively. All patients received nutritional advices from a dietician on how to increase the energy intake. Patients from the hospital and rehabilitation center were equally distributed between the intervention group and control group. Food intake, energy expenditure and water loss (to check for misreporting, see also discussion) were measured together over a 1-week period. Measurements of body mass gave insight into whether subjects were in energy balance while food recording. None of the patients participated in an out-patient or home based pulmonary rehabilitation program.

\section{Subjects}

Inclusion criteria were a body mass index (BMI) $\leq 22 \mathrm{~kg} / \mathrm{m}^{2}$ or $\mathrm{BMl} \leq 25 \mathrm{~kg} / \mathrm{m}^{2}$ in combination with recent weight loss ( $>5 \%$ of usual body mass). Exclusion criteria were severe cardiovascular disease, gastrointestinal abnormalities or endocrine disease, malignancies or dementia. Patients were informed about the aim and procedures of the study and they gave written consent. The medical ethics committee of the university and the hospital approved the protocol. The characteristics of the subjects at discharge are described in table 5.1. Patients had a moderate to severe airflow limitation in combination with normal blood gasses.

Table 5.1 Characteristics of patients with COPD at discharge

\begin{tabular}{|c|c|c|c|}
\hline & $\begin{array}{l}\text { Intervention group } \\
\qquad \mathrm{n}=\mathbf{1 1}\end{array}$ & $\begin{array}{c}\text { Control group } \\
n=9\end{array}$ & $\begin{array}{c}\text { Total group } \\
n=20\end{array}$ \\
\hline Male/female & $6 / 5$ & $5 / 4$ & $11 / 9$ \\
\hline Age, years & $61 \pm 12$ & $62 \pm 10$ & $62 \pm 11$ \\
\hline $\mathrm{BMI}, \mathrm{kg} / \mathrm{m}^{2}$ & $19.6 \pm 2.4$ & $20.0 \pm 1.5$ & $19.8 \pm 2.0$ \\
\hline $\mathrm{FEV}_{1}, \%$ predicted & $40 \pm 13$ & $41 \pm 19$ & $40 \pm 16$ \\
\hline IVC, \%predicted & $94 \pm 12$ & $83 \pm 18$ & $89 \pm 16$ \\
\hline $\mathrm{PaO}_{2}, \mathrm{kPa}$ & $9.4 \pm 1.4$ & $9.5 \pm 1.1$ & $9.5 \pm 1.3$ \\
\hline $\mathrm{PaCO}_{2}, \mathrm{kPa}$ & $5.5 \pm \mathbf{0 . 9}$ & $5.8 \pm 0.7$ & $5.6 \pm 0.8$ \\
\hline
\end{tabular}

Data are mean $\pm \mathrm{SD} ; \mathrm{FEV}_{1}$, forced expiratory volume in 1 second; IVC, inspiratory vital capacity; $\mathrm{PaO}_{2}$, arterial $\mathrm{O}_{2}$ tension; $\mathrm{PaCO}_{2}$, arterial $\mathrm{CO}_{2}$ tension. No baseline differences were found between the intervention and control group.

\section{Body mass}

Body mass measurements were performed at month 1 and month 3 after discharge and were measured three times, with 7-day intervals, 1 week before the start of the recording week, at the start and at the end of the recording week. Thus, possible weight changes due to a change of diet while food recording can be compared with normal body mass fluctuations. Patients were weighed in indoor clothing and without shoes, in the morning before any drink or beverage consumption and after voiding, on a digital balance accurate to $\pm 0.1 \mathrm{~kg}$ (Seca, Almere, The Netherlands). The balances used in the hospital and in the rehabilitation center were calibrated. 


\section{Food and water intake}

A 7-day food record was used to measure total food and water intake (at month 1 and month 3 together with the measurement of energy expenditure and water loss). Subjects received instructions from a dietician on how to fill in the food record. The food records were converted into intakes of total energy, macronutrients and water with a computer program based on food tables (Becel Nutrition Program, Nederlandse Unilever Bedrijven B.V., Rotterdam, The Netherlands). The amount of metabolic water was calculated by multiplying energy expenditure by the percentages of energy from protein, fat, and carbohydrate from the 7-day food record. Oxidation of protein yields $0.41 \mathrm{ml}$ water $/ \mathrm{g}$, fat yields $1.07 \mathrm{ml}$ water $/ \mathrm{g}$ and carbohydrate yields $0.60 \mathrm{ml}$ water/g. ${ }^{12}$

\section{Energy expenditure}

Energy expenditure was estimated from measured basal metabolic rate (BMR) and physical activity (PA) assessed with a tri-axial accelerometer for movement registration. BMR was measured at the start of the recording week after an overnight fast, while lying for 30 minutes in a supine position, with a ventilated hood system (Oxycon-ß; Mijnhardt, Bunnik, The Netherlands).

PA was estimated with a tri-axial accelerometer for movement registration (Tracmor) during the recording week. The Tracmor is a small device $(7 \times 2 \times 0.8$ $\mathrm{cm}, 30 \mathrm{~g}$ ), which measures accelerations in the anteroposterior, mediolateral and vertical directions of the trunk. Subjects wore the Tracmor during waking hours for 7 days in a belt at the back of the waist. The Tracmor has been validated against doubly labeled water, in a group of men and women between 55 and 74 years, which gave the following formula using Tracmor counts and BMR for the calculation of total energy expenditure (TEE): TEE $(\mathrm{MJ} / \mathrm{d})=-2.289+1.777^{*} \mathrm{BMR}$ $(\mathrm{MJ} / \mathrm{d})+0.063^{*}$ counts/minute (regression analysis $r^{2}=0.82, \mathrm{p}<0.0001 ; \mathrm{n}=26$ healthy elderly). ${ }^{11}$ The physical activity level was calculated by expressing energy expenditure as a multiple of basal metabolic rate (PAL $=$ TEE/BMR).

\section{Water loss}

Water loss was measured with the deuterium elimination method. The evening before the start of the recording week subjects drank a weighed dose of a deuterium dilution, $70 \mathrm{~g}$ water with an enrichment of 5 atom $\%$ excess ${ }^{2} \mathrm{H}$, after voiding (background sample). Subjects collected urine samples in the morning and evening of day 1 , at the start of the recording week, the evening of day 7 and the morning of day 8 . Water loss was calculated from ${ }^{2} \mathrm{H}$ elimination with the equation of Fjeld et $\mathrm{al}^{12}$, as described before. ${ }^{13}$

\section{Statistics}

Mean and standard deviations were calculated. Differences between groups were tested with the Wilcoxon rank-sum test and differences between measurements within groups were tested with paired sign tests. A paired t-test was used to test differences between the two periods within the total group. Correlation coefficients were calculated to describe relations between parameters. 
Body mass changes and mean physical activity levels of month 1 and 3 were calculated for 19 subjects, because 1 subject went to rehabilitation center at month 2.

The calculation of the power of the study was not based on expected changes in body mass between the control and the supplemented group, as the main focus of the present study was to elucidate the influence of physical activity on energy balance. Significance was set on $p<0.05$.

\section{Results}

The body mass change between discharge and month 1 was $-0.1 \pm 1.0(-1.6$ to 2.3) $\mathrm{kg}$ and $0.3 \pm 2.3(-2.3$ to 5.1$) \mathrm{kg}$ for the intervention group and for the control group, respectively (Wilcoxon rank-sum test $p=0.6$ ). Between month 1 and month 3 the body mass change was $0.3 \pm 1.4(-1.8$ to 2.9$) \mathrm{kg}$ and $-0.0 \pm 2.4(-4.4$ to 3.4$) \mathrm{kg}$ for the intervention group and for the control group, respectively (Wilcoxon rank-sum test $\mathrm{p}=0.9$ ).

Table 5.2 Energy intake, basal metabolic rate, physical activity level and total energy expenditure of the intervention-, control- and total group at 1 and 3 months after discharge

\begin{tabular}{lcccccc}
\hline & \multicolumn{2}{c}{ Intervention group } & \multicolumn{2}{c}{ Control group } & \multicolumn{2}{c}{ Total group } \\
& $\begin{array}{c}\text { Month 1 } \\
\mathrm{n}=11\end{array}$ & $\begin{array}{c}\text { Month 3 } \\
\mathrm{n}=11\end{array}$ & $\begin{array}{c}\text { Month 1 } \\
\mathrm{n}=9\end{array}$ & $\begin{array}{c}\text { Month 3 } \\
\mathrm{n}=8\end{array}$ & $\begin{array}{c}\text { Month 1 } \\
\mathrm{n}=20\end{array}$ & $\begin{array}{c}\text { Month 3 } \\
\mathrm{n}=19\end{array}$ \\
\hline $\mathrm{BMR}$, & $5.9 \pm 1.1$ & $5.6 \pm 1.3$ & $5.9 \pm 0.6$ & $5.5 \pm 1.1$ & $5.8 \pm 0.1$ & $5.6 \pm 1.2$ \\
$\mathrm{M} / \mathrm{d}$ & $(4.5-7.7)$ & $(3.9-8.0)$ & $(4.8-6.5)$ & $(3.8-6.9)$ & & \\
$\mathrm{PAL}$ & $1.58 \pm 0.07$ & $1.60 \pm 0.29$ & $1.56 \pm 0.07$ & $1.54 \pm 0.08$ & $1.56 \pm 0.08$ & $1.57 \pm 0.22$ \\
& $(1.47-1.66)$ & $(1.40-2.44)$ & $(1.46-1.67)$ & $(1.46-1.70)$ & & \\
$\mathrm{TEE}$, & $8.8 \pm 1.6$ & $9.0 \pm 2.5$ & $9.4 \pm 1.9$ & $8.5 \pm 1.7$ & $9.1 \pm 1.7$ & $8.8 \pm 2.2$ \\
$\mathrm{MJ} / \mathrm{d}$ & $(5.3-11.1)$ & $(5.6-12.7)$ & $(7.2-12.4)$ & $(6.4-10.6)$ & & \\
$\mathrm{EI}$, & $9.7 \pm 2.0$ & $8.9 \pm 1.9$ & $8.7 \pm 2.4$ & $9.1 \pm 2.4$ & $9.2 \pm 2.2$ & $9.0 \pm 2.1$ \\
$\mathrm{M} / / \mathrm{d}$ & $(6.9-12.7)$ & $(7.4-12.1)$ & $(4.9-12.6)$ & $(6.3-13.2)$ & & \\
\hline
\end{tabular}

Data are mean \pm SD and (range); $B M R$, basal metabolic rate; $P A L$, physical activity level; TEE, total energy expenditure; $\mathrm{El}$, energy intake.

Results on energy intake and expenditure at month 1 and month 3 are presented in table 5.2. Energy intake was not significantly different from energy expenditure, neither for the intervention group, nor for the control group. There was no statistical significant difference in energy balance between the two groups (month 1 Wilcoxon rank-sum test; $p=0.50$, month 3 Wilcoxon rank-sum test; $p=0.49$ ). The intervention group had a positive energy balance of $0.8 \pm 2.3 \mathrm{MJ} / \mathrm{d}$ and the control group had a negative energy balance of $-0.7 \pm 2.5 \mathrm{MJ} / \mathrm{d}$ in the first month. In the third month the intervention group had a small negative energy balance of $-0.1 \pm 2.2 \mathrm{MJ} / \mathrm{d}$ and the control group had a positive energy balance of $0.6 \pm 1.9 \mathrm{MJ} / \mathrm{d}$. 
The body mass changes over both recording weeks were not different from the body mass changes over the non-recording weeks (see table 5.3). The patients did not change their diet while food recording, nor did they incorrectly record their food intake; there was also no difference in reported water intake and measured water loss (see table 5.3).

Table 5.3 Total water intake (recorded and metabolic water), water loss and body mass changes over the recording week and a non-recording week for the total group at 1 and 3 months after discharge

\begin{tabular}{lcccc}
\hline Water intake $(\mathrm{l} / \mathrm{d})$ & Water loss $(\mathrm{l} / \mathrm{d})$ & $\begin{array}{c}\text { BM change over } \\
\text { recording week } \\
(\mathrm{kg})\end{array}$ & $\begin{array}{c}\text { BM change over } \\
\text { non-recording } \\
\text { week }(\mathrm{kg})\end{array}$ \\
\hline Month 1 & $2.7 \pm 0.7$ & $2.8 \pm 0.7^{\circ}$ & $0.08 \pm 0.51$ & $0.09 \pm 0.51^{*}$ \\
Month 3 & $2.5 \pm 0.7$ & $2.6 \pm 0.7^{\circ}$ & $0.09 \pm 0.68$ & $-0.16 \pm 0.73^{*}$ \\
\hline
\end{tabular}

Data are mean $\pm S D$; ${ }^{\circ}$ paired t-test water intake and water loss $p=0.3, p=0.1$ for month 1 and 3 , respectively; " paired t-test body mass change recording week and non-recording week $p=0.95$, $p=0.4$ for month 1 and 3, respectively

The differences in body mass (BM) change over time between patients could not be explained by the reported energy intakes $(p=0.32)$. The mean body mass change from month 1 to month 3 was negatively correlated with the mean physical activity level (figure 5.1 ; correlation $r=-0.49, p=0.03$ ). The physical activity level was not related to the body composition (results not shown) of the patients and was not different between months 1 and 3 .

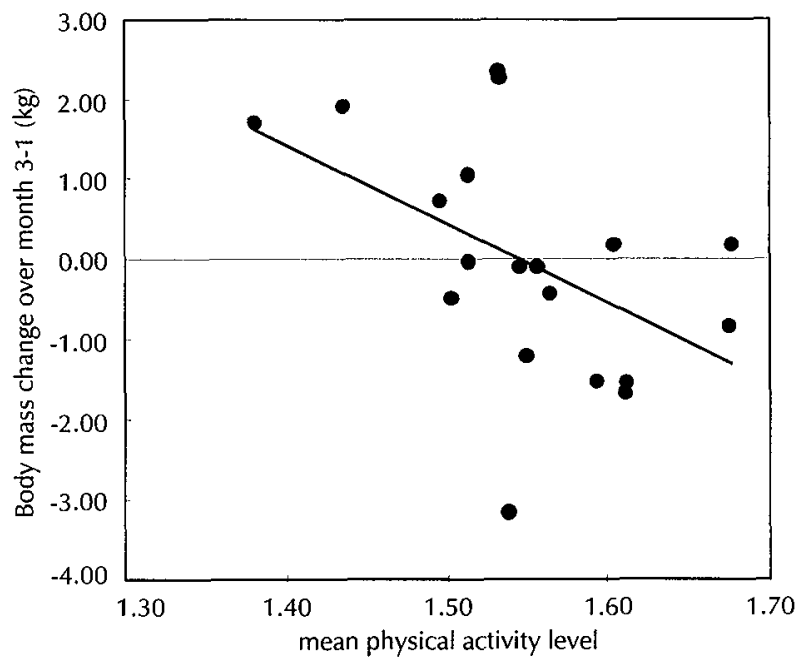

Figure 5.1 Body mass change from month one to month three plotted against the mean physical activity level $(n=19 ; r=-0.49, p=0.03)$ 


\section{Discussion}

The results show no clear changes in body mass for both groups. At 1 month after discharge, small differences in energy balance between the intervention and control group became visible. The positive energy balance in the intervention group resulted in a weight gain from month 1 to month 3 . However, after 3 months the intervention group did not have a higher body mass increase than the control group. Probably, the intervention group compensated for the nutritional supplements by reducing their other food intake. During the recording week the intervention group consumed on average $95 \pm 6 \%$ of the prescribed nutritional supplements at month 1 and $89 \pm 14 \%$ of the prescribed nutritional supplements at month 3. Not all prescribed supplements were consumed, which might also be a reason for the low weight increase in the intervention group. Furthermore it might be that the sample size was not sufficient to find an effect of supplementation on the energy balance. The power of the current study was calculated to elucidate the influence of physical activity on energy balance, as this was the main focus of this study.

The physical activity level of about 1.56 in this group of out-patients with COPD was lower than measured in COPD patients in a rehabilitation center ${ }^{9}$ and lower than measured in a group of healthy elderly men and women. ${ }^{14}$ In the rehabilitation center patients followed a daily program including physical exercises, which might be the reason for the higher physical activity level. Additionally, the physical activity level of the COPD patients in the rehabilitation center, was calculated from energy expenditure measured with the doubly labeled water method and basal metabolic rate measured with the ventilated hood. Thus, the activity-related energy expenditure included also energy needed for the decreased mechanical efficiency in COPD patients. ${ }^{9}$ Here, physical activity was estimated with a triaxial accelerometer for movement registration and an eventually lower mechanical efficiency was not taken into account.

At home physical exercise is probably limited in COPD patients. However, a temporarily lower physical activity level is not per se negative in weight-losing or depleted COPD patients. COPD patients with a lower physical activity level were able to eat sufficient for their energy needs and remained in energy balance or even gained weight (figure 5.1). A high physical activity level must be accompanied with a higher energy intake to maintain at least energy balance. This was probably difficult for the depleted COPD patients with a high physical activity level, because they lost weight. In a controlled setting, a rehabilitation center, patients with a high physical activity level were still able to maintain their body weight or even gained weight. ${ }^{2}$ More research is needed, to target physical activity and food intake to depleted out-patients with COPD. Our results indicate that some of the depleted patients might even temporarily require enteral tube feeding. 
The food intake was reported accurately and the patients did not change their diet while food recording. The patients were motivated to report their food intake accurately and had probably sufficient time to record everything, because they were mostly at home. Results on reported food intake could therefore be used to compare the energy balance between the intervention and control group.

The water balance technique can give an indication whether subjects recorded their food intake accurately. A good recording of water intake does not necessarily imply that the same holds for the recording of food intake. Most foodstuffs contain a certain amount of water and therefore if a individual records his/her water intake accurately it is expected that they record their whole food intake accurately. Also a good recording does not say anything about a change in diet while food recording and body mass changes over the recording period must be measured. Earlier studies showed that the water-balance method was able to measure misreporting of food intake on the group level. The sum of a change in diet and misreporting as assessed with the water balance method was equal to the total amount of misreporting as measured with the doubly labeled water method. ${ }^{10,11}$ A good reporting of food intake in free-living subjects is not very common as most subjects tend to misreport their food intake or change their diet while food recording. ${ }^{10}$

In summary, the weight change from month 1 to month 3 was negatively associated with the energy requirement for physical activity. These preliminary results suggests, that knowledge about the individual physical activity level is necessary for the estimation of the energy need of the patient and to give an appropriate advise about food intake and the use of supplements. However, more research is needed to find out which combination of oral or enteral supplementation and physical activity results in the highest weight gain and functional improvement in depleted COPD patients at home. 


\section{References}

1. Schols AM, Soeters PB, Mostert R, Saris WH, Wouters EF. Energy balance in chronic obstructive pulmonary disease. Am Rev Respir Dis 1991;143:1248-52.

2. Creutzberg EC, Wouters EF, Mostert R, Weling-Scheepers CA, Schols AM. Efficacy of nutritional supplementation therapy in depleted patients with chronic obstructive pulmonary disease. Nutrition 2003;19:120-7.

3. Mostert R, Goris AH, Weling-Scheepers CA, Wouters EF, Schols AM. Tissue depletion and health related quality of life in patients with chronic obstructive pulmonary disease. Respir Med 2000;94:859-67.

4. Schols AM, Slangen J, Volovics L, Wouters EF. Weight loss is a reversible factor in the prognosis of chronic obstructive pulmonary disease. Am J Respir Crit Care Med 1998;157:1791-7.

5. Wilson DO, Rogers RM, Wright EC, Anthonisen NR. Body weight in chronic obstructive pulmonary disease. The National Institutes of Health Intermittent PositivePressure Breathing Trial. Am Rev Respir Dis 1989;139:1435-8.

6. Schols AM, Soeters PB, Mostert R, Pluymers RJ, Wouters EF. Physiologic effects of nutritional support and anabolic steroids in patients with chronic obstructive pulmonary disease. A placebo- controlled randomized trial. Am J Respir Crit Care Med 1995;152:1268-74.

7. Efthimiou J, Fleming J, Gomes C, Spiro SG. The effect of supplementary oral nutrition in poorly nourished patients with chronic obstructive pulmonary disease. Am Rev Respir Dis 1988;137:1075-82.

8. Lewis MI, Belman MJ, Dorr Uyemura L. Nutritional supplementation in ambulatory patients with chronic obstructive pulmonary disease. Am Rev Respir Dis 1987;135:1062-8.

9. Baarends EM, Schols AM, Pannemans DL, Westerterp KR, Wouters EF. Total free living energy expenditure in patients with severe chronic obstructive pulmonary disease. Am J Respir Crit Care Med 1997;155:549-54.

10. Goris AH, Westerterp KR. Underreporting of habitual food intake is explained by undereating in highly motivated lean women. J Nutr 1999;129:878-82.

11. Goris AH, Meijer EP, Kester A, Westerterp KR. Use of a triaxial accelerometer to validate reported food intakes. Am J Clin Nutr 2001;73:549-53.

12. Fjeld $\mathrm{CR}$, Brown $\mathrm{KH}$, Schoeller DA. Validation of the deuterium oxide method for measuring average daily milk intake in infants. Am J Clin Nutr 1988;48:671-9.

13. Westerterp KR, Kayser B, Brouns F, Herry JP, Saris WH. Energy expenditure climbing Mt. Everest. J Appl Physiol 1992;73:1815-9.

14. Meijer EP, Goris AH, Wouters L, Westerterp KR. Physical inactivity as a determinant of the physical activity level in the elderly. Int J Obes Relat Metab Disord $2001 ; 25: 935-9$. 
Chapter 6

Effects of an acute exacerbation on nutritional and metabolic profile of patients with chronic obstructive pulmonary disease

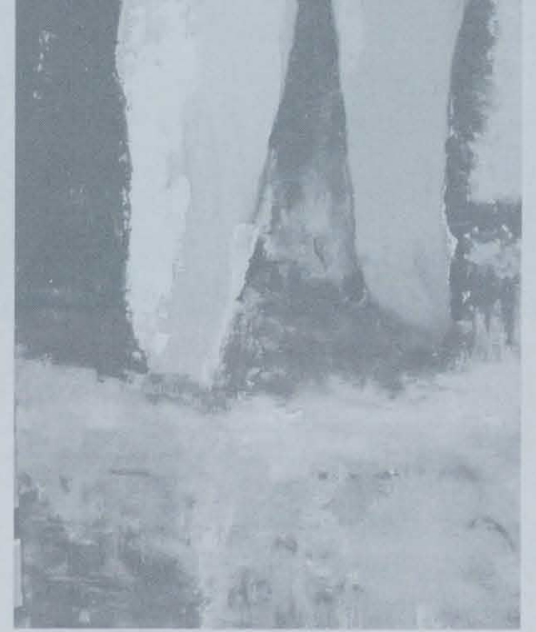

MAP Vermeeren, AMWJ Schols, EFM Wouters

European Respiratory Journal 1997; 10: 2264-2269 


\section{Abstract}

\section{Introduction}

In this study, we investigated the influence of an acute disease exacerbation on the nutritional and metabolic status of patients with chronic obstructive pulmonary disease (COPD).

\section{Methods}

The study group consisted of 23 patients acutely admitted to the hospital for standardized medical treatment. Dietary intake (dietary records and diet history), resting energy expenditure (ventilated hood), body composition (bio-electrical impedance spectroscopy) and disease symptoms (visual analogue scale) were assessed on admission, daily throughout the hospitalization period, at discharge and 3 months thereafter in stable clinical condition.

\section{Results}

Dietary intake, since aggravation of disease symptoms, prior to admission, $(5.64 \pm 2.67 \mathrm{MJ})$ was significantly lower than habitual intake $(7.86 \pm 2.00 \mathrm{MJ})$. The balance between dietary intake with measured resting energy expenditure and estimated diet-induced thermogenesis was severely impaired during the first 3 days of hospitalization, stabilizing thereafter to $145 \pm 24$ at discharge. Resting energy expenditure decreased from $6.81 \pm 0.90 \mathrm{MJ}(123 \pm 11 \%)$ on admission to $6.19 \pm 0.79 \mathrm{MJ}(113 \pm 14 \%)$ on discharge $(p<0.001)$. During treatment, no significant shift in water compartments, fat-free mass and body weight was seen. Follow-up data were obtained from 10 out of 23 patients. Three months after admission, dietary intake was not significantly different from usual dietary intake ( $8.51 \pm 2.29$ and $8.41 \pm 2.60 \mathrm{MJ}$, respectively), resting energy expenditure was similar to the value at discharge, and a significant body weight gain was seen.

\section{Conclusions}

We conclude that an acute exacerbation of chronic obstructive pulmonary disease is accompanied by an impaired energy balance due to a decreased dietary intake and an increased resting energy expenditure. 


\section{Introduction}

Tissue depletion frequently occurs in patients with chronic obstructive pulmonary disease (COPD). Reported (prevalence) rates range from $20 \%$ in clinically stable out-patients ${ }^{1}$ up to $50 \%$ in patients with acute respiratory failure. ${ }^{2}$ Weight loss and, in particular, loss of fat-free mass (FFM) have been shown to adversely influence functional performance and survival, independently of the compromised lung function. ${ }^{3-5}$ Wasting of FFM is related to weakening of respiratory and peripheral skeletal muscles and to an impaired exercise performance. ${ }^{1,3,4}$ Dysfunction of the respiratory muscles is furthermore related to the patient's sensation of dyspnoea ${ }^{6}$.

Weight loss results from an imbalance between dietary intake and energy expenditure. In the majority of COPD patients, weight loss appears to develop gradually, while they are in an otherwise stable clinical condition. Previous studies using diet histories found a normal to elevated dietary intake in COPD patients when compared to normal values. ${ }^{7,8}$ A within-group comparison, however, showed a significantly lower dietary intake in weight-losing than in weight-stable patients, both in absolute terms and when expressed as percentage of measured resting energy expenditure (REE). ${ }^{8}$ Several studies have shown an increased REE, in addition to a relatively decreased dietary intake, in clinically stable COPD patients, the cause of which is unclear. ${ }^{9,10}$

Retrospective data suggest that, in a subgroup of patients, weight loss follows a stepwise pattern related to acute disease exacerbations. However, limited data are available on dietary intake and energy metabolism in COPD during an acute disease exacerbation. The aim of the present study was, therefore, to investigate the effect of an acute exacerbation on the nutritional and metabolic profile of patients with COPD.

\section{Subjects and methods}

\section{Patients}

Patients admitted to the respiratory unit of the University Hospital Maastricht with an acute exacerbation of COPD were considered for inclusion in the study. COPD was defined according to the criteria of the American Thoracic Society. ${ }^{11}$ All patients were current or ex-smokers. None had evidence of significant reversibility ( $>15 \%$ of predicted baseline) of airflow limitation after $500 \mu \mathrm{g}$ of terbutaline inhalation. An acute exacerbation was defined as a recent increase in dyspnoea, cough and sputum production of sufficient severity to warrant hospital admission. Patients suffering from concomitant diseases such as diabetes mellitus, lung 
carcinoma, thyroid and cardiovascular disease were excluded from the study. Inhospital treatment consisted of parenteral corticosteroids and theophylline in addition to nebulized beta-agonists and ipratropium bromide and broad spectrum antibiotic therapy, in case of bacterial infection confirmed by clinical data and sputum culture. The daily $500 \mathrm{~mL}$ infusion solution contained $5 \%$ glucose, which is equivalent to $0.42 \mathrm{MJ} /$ day. This value is incorporated in the calculations of the energy balance during hospitalization, but not in the calculations of "spontaneous" dietary intake.

Measurements were performed during hospitalization period, and all patients were invited for a follow-up consultation 3 months after discharge when they were in stable clinical condition. The study was approved by the medical Ethics Committee of the University Hospital Maastricht. Informed consent was obtained from all subjects.

\section{Dietary intake}

Habitual dietary intake, dietary intake prior to admission since aggravation of dyspnoea and other disease symptoms, as well as dietary intake during the followup consultation were evaluated using the diet history method with cross-check. ${ }^{12}$ All interviews were performed by the same trained dietician. During hospitalization, dietary intake was registered daily using dietary records and an automated food distribution system. Patients were not receiving nutritional support during their hospitalization, but they had the opportunity to choose their menus. Food composition data were coded for computer energy and nutrient analysis. The database was derived from the Dutch food composition tables. ${ }^{13}$

\section{Resting energy expenditure}

REE was measured the day after admission, at discharge and during the outpatient follow-up by indirect calorimetry using a ventilated hood system (Oxycon$\beta$, Mijnhardt, Bunnik, The Netherlands). ${ }^{14}$ Standardized measurements of volume of oxygen utilization $\left(\mathrm{V}^{\prime} \mathrm{O}_{2}\right)$ and carbon dioxide output $\left(\mathrm{V}^{\prime} \mathrm{CO}_{2}\right)$ were performed in the early morning in the fasting state (between 08.30 and $09.30 \mathrm{~h}$ ) approximately $3 \mathrm{~h}$ after the patients had received their regular medication. If patients were on oxygen therapy, the oxygen was withdrawn temporarily $30 \mathrm{~min}$ prior to the measurement and, in these patients, oxygen saturation was measured continuously during the measurement. The patients did not experience a worsening of dyspnoea after withdrawal of the oxygen. In a subgroup of nine patients, REE was measured daily to assess the variability and course of REE during hospitalization.

\section{Diet-induced thermogenesis}

Diet-induced thermogenesis (DIT) was estimated as $10 \%$ of dietary intake.

\section{Body composition}

During hospitalization, fasting body weight was assessed daily using a digital weighing chair. Body composition was measured the day after admission, at 
discharge and during the out-patient follow-up by bio-electrical impedance spectroscopy (Xitron 4000B; Xitron Technologies Inc., San Diego, CA. USA).$^{15}$ The principle of this method is based on the conductivity of an electrical sinusoidal alternating current through body fluids. Conductivity is higher in FFM, which contains all body fluids and electrolytes, than in fat mass. The resistance of the body can be measured at a spectrum of frequencies (ranging $5-500 \mathrm{kHz}$ ). At low frequency $(<50 \mathrm{kHz})$, the conductivity is mainly through the extracellular part, while at higher frequency conductivity takes place through total body water. Resistance of intracellular and extracellular water was measured by extrapolation of the measured resistance and reactance according to the Cole-Cole model. ${ }^{16}$

\section{Disease symptoms}

Disease symptoms were scored using a visual analogue scale (VAS) on admission, on day 5 of hospitalization, at discharge and during the follow-up consultation. The following symptoms were evaluated: loss of appetite; dyspnoea at rest and while eating; early satiety; nausea; obstipation; dry mouth; problems with chewing and swallowing; diarrhoea; flatulence; nervousness; fatigue; and disturbed sleeping.

\section{Statistics}

Groups were compared by analysis of variance or by the Mann-Whitney U-test, where appropriate. The Chi-squared test was used to compare categorical variables. Changes within the patient were compared using a paired $t$-test. Results are presented as mean \pm SD unless stated otherwise. A p-value of less than 0.05 was considered statistically significant. The statistical analyses were performed using the Statistical Products and Service Solutions (SPSS; Chicago, IL, USA) for Windows package ${ }^{17}$.

\section{Results}

Twenty three consecutive patients were studied. Characteristics of the total group, as well as the subgroup of 10 patients that participated in the follow-up consultation, are given in table 6.1.

Mean forced expiratory volume in one second $\left(\mathrm{FEV}_{1}\right)$ amounted to $37 \pm 12$ \%predicted. Mean body mass index (BMI) was $23 \mathrm{~kg} / \mathrm{m}^{2}$, ranging from 16$29 \mathrm{~kg} / \mathrm{m}^{2}$. Based on BMl $\leq 21 \mathrm{~kg} / \mathrm{m}^{2}$, eight patients were underweight. Five patients were admitted with acute respiratory failure (arterial oxygen tension $\left(\mathrm{PaO}_{2}\right)<7.3$ $\mathrm{kPa}$ and/or arterial carbon dioxide tension $\left.\left(\mathrm{PaCO}_{2}\right)>6.0 \mathrm{kPa}\right)$. Fifteen patients were treated with antibiotics. 
Table 6.1 Baseline characteristics of the total study group and the subgroup that participated in the follow-up

\begin{tabular}{lcc}
\hline & $\begin{array}{c}\text { Total group } \\
\mathrm{n}=23\end{array}$ & $\begin{array}{c}\text { Follow-up } \\
\mathrm{n}=10\end{array}$ \\
\hline Male/female & $12 / 11$ & $7 / 2$ \\
Age, years & $63 \pm 8$ & $65 \pm 9$ \\
$\mathrm{IVC}, \%$ predicted & $70 \pm 22$ & $81 \pm 23$ \\
$\mathrm{FEV}_{1}, \%$ predicted & $37 \pm 12$ & $41 \pm 9$ \\
$\mathrm{PaO}_{2}, \mathrm{kPa}$ & $8.8 \pm 2.3$ & $9.9 \pm 2.9$ \\
$\mathrm{PaCO}_{2}, \mathrm{kPa}$ & $5.0 \pm 0.9$ & $4.6 \pm 0.7$ \\
$\mathrm{Habitual}$ weight, $\mathrm{kg}$ & $63.5 \pm 12.0$ & $67.2 \pm 12.2$ \\
Weight on admission, $\mathrm{kg}$ & $63.4 \pm 11.9$ & $67.5 \pm 12.2$ \\
$\mathrm{BMI}, \mathrm{kg} / \mathrm{m}^{2}$ & $23.0 \pm 3.2$ & $24.4 \pm 2.5$ \\
\hline
\end{tabular}

Values are mean $\pm \mathrm{SD}$, or absolute number for sex. None of the differences between the total group and the follow-up group were significant. IVC, inspiratory vital capacity; $F E V_{1}$, forced expiratory volume in one second; $\mathrm{PaO}_{2}$, arterial oxygen tension; $\mathrm{PaCO}_{2}$, arterial carbon dioxide tension; $\mathrm{BMI}$, body mass index.

\section{Dietary intake}

Dietary intake in the period prior to admission amounted to $5.64 \pm 2.67 \mathrm{MJ} /$ day and was significantly $(p<0.001)$ than habitual dietary intake $(7.86 \pm 2.00 \mathrm{MJ} /$ day $)$. Dietary intake increased substantially during hospitalization from $4.46 \pm 2.29$ $\mathrm{MJ} /$ day at day 1 to $9.04 \pm 2.49 \mathrm{MJ} /$ day at day 4 , after which it remained stable. Dietary intake at discharge was significantly higher than habitual dietary intake $(9.54 \pm 2.68 \mathrm{MJ} /$ day and $7.86 \pm 2.00 \mathrm{MJ} /$ day, respectively, $\mathrm{p}<0.01)$. Protein, fat and carbohydrate intake in absolute terms and expressed as a percentage of total energy intake is shown in table 6.2a and 6.2b. Protein intake was low prior to hospitalization, gradually increasing thereafter. Fat intake was low prior to and on admission, but increased thereafter by a greater proportion than carbohydrate intake. Figure 6.1a shows the daily dietary intake pattern of the subgroup of nine patients in which resting energy expenditure was also measured daily. This figure showed a similar pattern as described for the total group.

Table 6.2a Macronutrient intake (habitual and pre-admission intake)

\begin{tabular}{lcc}
\hline & & Dietary history \\
& Habitual & Pre-admission \\
\hline Protein, $\mathrm{g}$ & $64.3 \pm 19.4$ & $49.2 \pm 23^{\circ}$ \\
Protein, $\mathrm{g} / \mathrm{kg}$ & $1.03 \pm 0.32$ & $0.78 \pm 0.33^{\circ}$ \\
Protein, en\% & $14.9 \pm 3.1$ & $14.1 \pm 12.2$ \\
Fat, g & $80.6 \pm 23.5$ & $58.2 \pm 27.7^{\circ}$ \\
Fat, en\% & $40.5 \pm 10.0$ & $38.9 \pm 7.7$ \\
$\mathrm{CHO}, \mathrm{g}$ & $217.3 \pm 74.8$ & $155.7 \pm 91.7^{\circ}$ \\
$\mathrm{CHO}, \mathrm{en} \%$ & $44.1 \pm 12.1$ & $46 \pm 9.6$ \\
\hline
\end{tabular}

Data are mean $\pm \mathrm{SD} ; \mathrm{CHO}$, carbohydrates, $\mathrm{p}<0.005$ comparison between habitual and pre-admission. 
Table 6.2b Macronutrient intake during hospitalization

\begin{tabular}{|c|c|c|c|c|c|c|}
\hline & \multicolumn{6}{|c|}{ Dietary records } \\
\hline & Day 1 & Day 2 & Day 3 & Day 4 & Day 5 & Discharge \\
\hline Protein, $\mathrm{g}$ & $37.4 \pm 20.6$ & $61 \pm 25.4$ & $69.7 \pm 27.9$ & $74.4 \pm 24.2$ & $73.7 \pm 24^{\circ}$ & $81 \pm 27.1^{\cdots \cdots}$ \\
\hline Protein, $\mathrm{g} / \mathrm{kg}$ & $0.59 \pm 0.33$ & $0.6 \pm 0.33$ & $0.96 \pm 0.4$ & $1.12 \pm 0.53$ & $1.22 \pm 0.42^{*}$ & $1.32 \pm 0.5^{\cdots}$ \\
\hline Protein, en\% & $14.1 \pm 2.5$ & $14.9 \pm 3.7$ & $14.1 \pm 3.2$ & $13.7 \pm 3.0$ & $14.2 \pm 2.9$ & $14.1 \pm 2.7$ \\
\hline Fat, $g$ & $40.2 \pm 23.7$ & $67.9 \pm 38.5$ & $90.4 \pm 33.2$ & $94.7 \pm 33.8$ & $89.2 \pm 27.9^{*}$ & $103.5 \pm 32.5^{\cdots \cdots}$ \\
\hline Fat, en $\%$ & $32.9 \pm 10.1$ & $35.7 \pm 9.2$ & $41.7 \pm 6.8$ & $38.8 \pm 6.9$ & $38.2 \pm 5.2^{\circ}$ & $40.5 \pm 6.7^{\cdots}$ \\
\hline $\mathrm{CHO}, \mathrm{g}$ & $140 \pm 74.4$ & $204.7 \pm 83.6$ & $217.8 \pm 77.6$ & $253.9 \pm 71.6$ & $251 \pm 84.3^{\circ}$ & $258 \pm 83^{\cdots \cdots}$ \\
\hline $\mathrm{CHO}$, en\% & $53.1 \pm 15.0$ & $49.4 \pm 10.5$ & $44.2 \pm 8.1$ & $47.5 \pm 7.0$ & $47.7 \pm 6.6$ & $45.4 \pm 7.5^{\cdots}$ \\
\hline
\end{tabular}

Values are mean $\pm \mathrm{SD} ; \mathrm{CHO}$, carbohydrates, ${ }^{*} \mathrm{p}<0.05, " \mathrm{p}<0.01$, day 5 compared to day $1 ;{ }^{\cdots *} \mathrm{p}<0.05$, .... $p<0.01$, discharge compared to day 1 .

\section{Resting energy expenditure}

REE amounted to $6.81 \pm 0.90 \mathrm{MJ} /$ day on admission and decreased significantly $(p<0.001)$ to $6.19 \pm 0.79 \mathrm{MJ} /$ day at discharge. In the patients in whom resting energy expenditure was measured daily, REE remained elevated during the first 4 days after which it decreased until discharge (figure 6.1b).

a

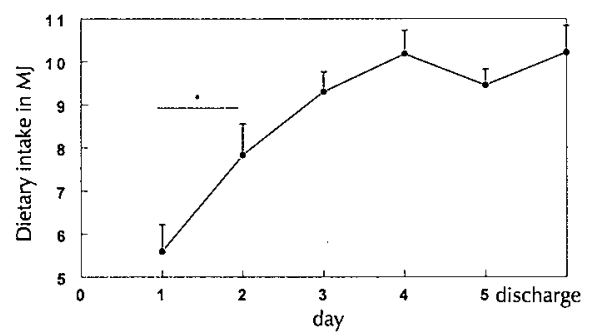

b

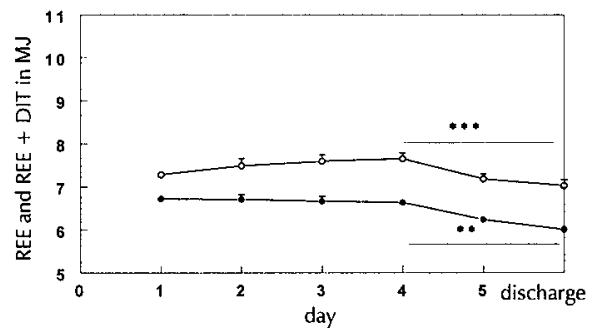

Figure 6.1 Daily course of dietary intake, 6.1a; daily course of measured resting energy expenditure (REE), 6.1b during hospitalization in nine COPD patients; closed circles, REE; open circles, REE and diet-induced thermogenesis (DIT). * $p=0.002,{ }^{* *} p=0.001, * * *$ $p=0.0004$

Changes in REE were not related to changes in body temperature. Respiratory quotient increased significantly $(p<0.001)$ from $0.77 \pm 0.05$ on admission to $0.85 \pm 0.01$ at discharge. Measured REE was also compared to the commonly used prediction formulas by Harris and Benedict. ${ }^{18}$ REE was $123 \pm 11 \%$ the day after admission and $113 \pm 14 \%$ at discharge $(p<0.001)$. On basis of a REE $>110 \%$ predicted at discharge, 10 patients were still hypermetabolic at discharge. The day after admission, REE in the hypermetabolic patients at discharge was also significantly higher than in the normometabolic patients at discharge $(130 \pm 12 \%$ versus $124 \pm 12 \%$, respectively, $p<0.05$ ), but did not decrease significantly during hospitalization. The hypermetabolic group at discharge was furthermore characterized by a significantly lower BMI $\left(20.9 \pm 2.8\right.$ versus $24.7 \pm 2.5 \mathrm{~kg} / \mathrm{m}^{2}$, respectively, $p<0.05$ ). Prevalence of bronchial infection between the subgroups of 
hyper- ( 7 out of 10) and ( 8 out of 13) normometabolic patients at discharge was not different.

\section{Energy intake compared to REE (and estimated DIT)}

During the first days after admission, a negative energy balance was seen. Energy intake (including intravenous glucose) the day after admission, expressed as percentage of REE and DIT, amounted to $68 \pm 28 \%$. In the subgroup of patients in whom a daily REE measurement was performed, it was shown that the negative balance quickly improved from $69 \pm 32 \%$ on day 1 , and $109 \pm 24 \%$ on day 2 , to $136 \pm 18 \%$ on day 4 , further increasing to $145 \pm 24 \%$ at discharge.

\section{Body composition}

No significant weight change was seen during the hospitalization period. Mean body weight was $63.4 \pm 12 \mathrm{~kg}$ on admission and $62.9 \pm 11 \mathrm{~kg}$ at discharge. FFM did not change either in this period $(42.9 \pm 7.8$ and $43.2 \pm 7.5 \mathrm{~kg}$, respectively). Furthermore, no significant change in the ratio between the resistance of intracellular and extracellular water was detected $(2.1 \pm 0.4$ and $2.2 \pm 0.5$, respectively).

\section{Disease symptoms}

Figure 6.2 displays the VAS score of those disease symptoms that changed significantly during hospitalization. Symptoms that did not change were "bloating", "nausea", "vomiting", "difficulties with chewing and swallowing", "obstipation" and "diarrhoea". On day 5, most symptoms had improved significantly compared to admission, except for symptoms "dyspnoea while eating", "loss of appetite" and "early satiety". At discharge, the score of these three symptoms was also significantly improved.

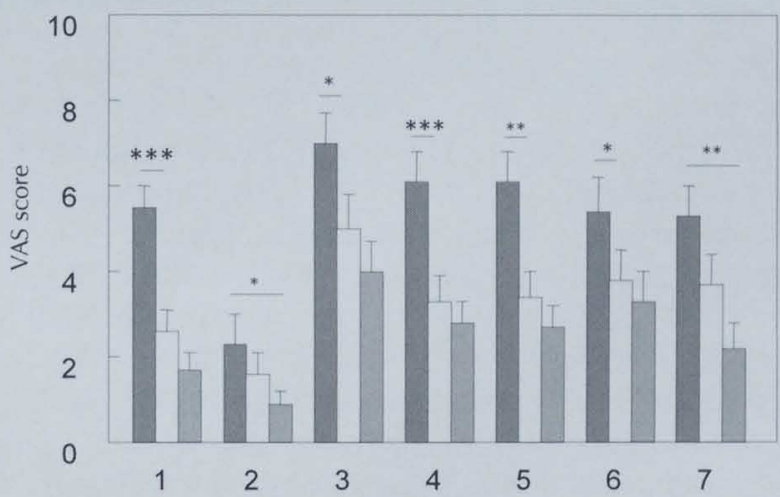

Figure 6.2 Disease symptoms (VAS scores) on admission (dark grey bars), at day 5 (open bars) and at discharge from the hospital (grey bars). Symptoms: 1, dyspnoea; 2, loss of appetite; 3, disturbed sleeping; 4 , fatigue; 5 , dry mouth; 6 , nervousness; 7 , early satiety; ${ }^{*} p<0.05$, ** $p<0.01,{ }^{* * *} p<0.001$ 
A significant relationship ( $r=0.52, p=0.004)$ between the changes in REE and the changes in dyspnoea at rest was observed (figure 6.3).

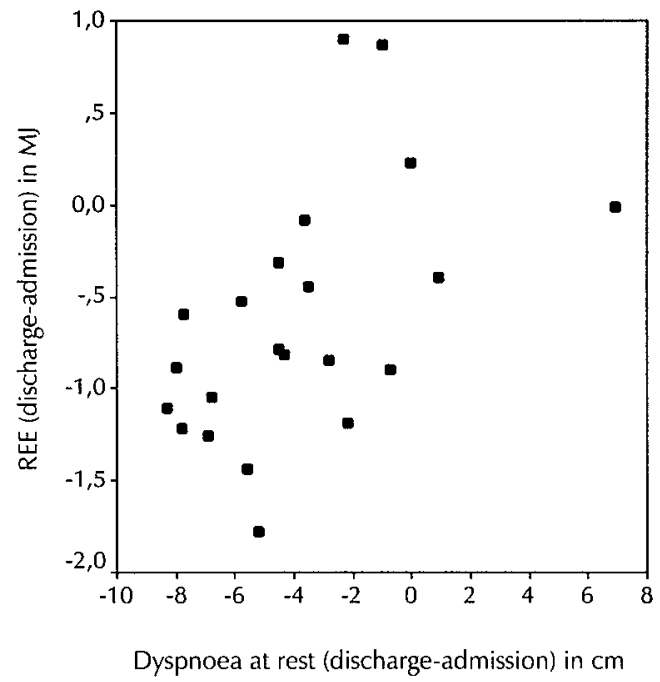

Figure 6.3 Significant relationship between the changes in REE and dyspnoea sensation during the total hospitalization period $(r=0.52, p=0.004)$

\section{Follow-up consultation}

All patients were asked for a voluntary follow-up consultation 3 months after discharge from the hospital. A minority of the group (43\%) responded. Although the follow-up group tended to have a better lung function and weighed more than the patients that were not followed after 3 months, no significant difference in baseline characteristics was found between these subgroups (table 6.1). Figure 6.4 shows the course of dietary intake, using the diet history method, of the follow-up patients. The pattern during hospitalization was comparable with the total group. Three months after discharge, dietary intake was similar to habitual dietary intake $(8.51 \pm 2.29$ and $8.41 \pm 2.60 \mathrm{MJ} /$ day, respectively). REE also showed a similar decrease during hospitalization, as was seen in the total group, from $6.93 \pm 1.24$ $(121 \pm 8 \%)$ to $6.28 \pm 0.96 \mathrm{MJ} / \mathrm{day}(110 \pm 9 \%), p=0.01$. REE amounted to $6.48 \pm 1.63 \mathrm{MJ} /$ day $(112 \pm 11 \%)$ at follow-up and was not significantly different from the value at discharge. Subsequently energy balance changed from $75 \pm 35 \%$ on admission to $133 \pm 43 \%$ at discharge, decreasing to $118 \pm 34 \%$ at follow-up. Although body weight did not change either during hospitalization, a significant $(p<0.05)$ mean increase in body weight of $1.6 \pm 2.1 \mathrm{~kg}$ was seen at follow-up. No significant changes were detected in the ratio between intracellular and extracellular water. Furthermore, no clear changes were observed in symptomatology since discharge from the hospital. 


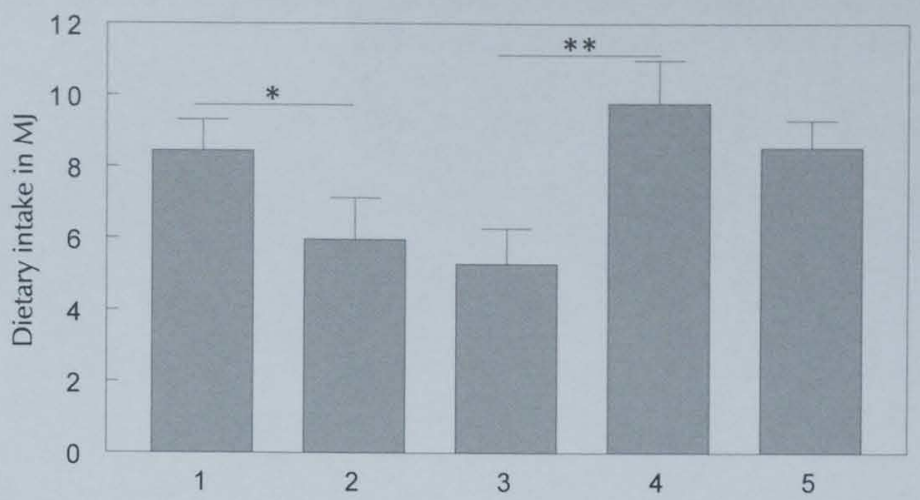

Figure 6.4 Course of dietary intake in 10 patients prior to and during hospitalization for an acute exacerbation and 3 months afterwards in stable clinical condition; 1 , habitual dietary intake; 2 , pre-admission dietary intake; 3 , dietary intake on admission; 4 , dietary intake at discharge; 5 , dietary intake at follow-up; ${ }^{*} \mathrm{p}<0.01,{ }^{* *} \mathrm{p}<0.001$

\section{Discussion}

Nutritional depletion is a common but possibly reversible problem in patients with COPD. From a therapeutic perspective, it is important to know the course of and contributing factors to weight loss. It is still unclear whether weight loss progresses gradually in patients who are otherwise in a stable clinical condition, or if it follows a stepwise pattern related to acute disease exacerbations. At present, only anecdotal reports have addressed this issue. In the present study, therefore, we assessed the nutritional and metabolic profile of a group of COPD patients suffering from an acute disease exacerbation, on admission to, during the treatment period in, and at discharge from the hospital. In a subgroup of patients, this profile was additionally studied 3 months afterwards in a stable clinical condition.

Several studies of clinically stable patients showed that dietary intake was equivalent to, or exceeded, estimated daily requirements. ${ }^{7,8}$ In the present study the majority of patients, however, reported a decreased appetite prior to, and a very low dietary intake during the first 3 days of hospitalization for an acute exacerbation. Thereafter, dietary intake improved quickly during the remaining hospital period. Based on the course of the symptoms VAS scores, multiple factors appear to be related to changes in dietary intake. Taking also the baseline values into consideration, it is hypothesized that it was not so much a decreased appetite, but more the "inability" to eat more due to dyspnoea and fatigue that was related to the very low intake in the first days after admission. In qualitative terms, protein intake was low prior to and during the first days of hospitalization, restored thereafter but remained rather low in order to optimize protein synthesis. Furthermore, it is of interest to note that a low appetite and a decreased dietary intake were reflected in a very low fat intake, which could be related to the early 
feeling of satiety during these days. This spontaneous response in macronutrient intake is in contrast to a long-held but not yet scientifically confirmed belief that COPD patients would benefit from a high fat, low carbohydrate meal, particularly during acute metabolic stress. When comparing the diet histories prior to admission, at discharge and at the follow-up consultation, the data clearly indicate that at discharge, dietary intake was significantly higher than habitual intake. This could be a compensation related to improvement of symptoms such as dyspnoea, appetite and fatigue, possibly related to reduced resting oxygen consumption and related ventilation and/or inflammation. Another suggested explanation could be an appetite-stimulating effect of high-dosage corticosteroid treatment. Remarkably, energy intake was highest during the tapering-off phase of parenteral corticosteroid treatment.

Several studies measured REE in clinically stable COPD patients with standard methods of indirect calorimetry and found an average increase in REE of $10-20 \%$ higher than predicted from age, weight, height and gender using the Harris and Benedict equations. ${ }^{9,10}$ Limited data are available on the course of REE during an exacerbation. Expressed as percentage of predicted values, REE was enhanced in all patients on admission to the hospital and decreased gradually towards the end of the hospitalization period.

Several factors could contribute to a temporary (further) increase in metabolic rate during an exacerbation. An increased oxygen cost of ventilation related to an increase in elastic and resistive work of breathing, metabolic effects of theophyllines and $\beta_{2}$-agonists, or a systemic inflammatory response. ${ }^{19-21}$ The oxygen cost of ventilation was not measured in the present study. The significant relationship between changes in REE and changes in the VAS score for dyspnoea at rest, however, provides indirect evidence for a contribution of the oxygen cost of ventilation to REE during an acute exacerbation. Recently, VanderhovenAugustin et $\mathrm{a}^{22}$ investigated, in a group of patients hospitalized for an acute exacerbation, the influence of theophylline on REE and found no relationship between (changes in) REE and (changes in) theophylline dose or plasma theophylline levels. Since $\beta_{2}$-agonists are commonly given as part of the pharmacological therapy during an acute exacerbation, Creutzberg et $\mathrm{al}^{23}$ studied, as part of the present study, the acute effects of $5 \mathrm{mg}$ salbutamol hemisulphate $0.5 \%$ and $1 \mathrm{~mL}$ sodium chloride $0.9 \%$ on REE in COPD patients recovering from an acute exacerbation. Mean REE was raised by $4.2 \%$ up to $45 \mathrm{~min}$ after salbutamol administration, but was not significantly different from a healthy agematched control group. Using the same dose, Burdet et $\mathrm{al}^{24}$ even found a slightly greater thermogenic effect of salbutamol in clinically stable COPD patients, which lasted for several hours. Since patients received both salbutamol by nebulizer and by inhalation during their hospitalization period, we were not able to calculate an average daily dose for subsequent comparison with REE. Two studies have recently reported a significantly enhanced level of tumor necrosis factor $\alpha$ (TNFa) in plasma of weight-losing COPD patients. ${ }^{25,26}$ Acute administration of TNFa in men causes an increase in acute-phase proteins, provokes an elevation of REE, promotes proteolysis and lipolysis and causes anorexia. ${ }^{27}$ In clinically stable COPD patients with elevated REE and depletion of FFM, Schols et al ${ }^{21}$ reported increased 
serum levels of acute phase reactant proteins and soluble tumor necrosis factor (sTNF) receptors suggestive of a relationship between metabolic derangements factor and a systemic inflammatory response in a subset of COPD patients. Further research is needed to investigate if the relationship between metabolic derangements and inflammation involves a sustained systemic effect of acute inflammatory exacerbations or merely reflects a chronic inflammatory state.

In this group of mostly bed-rested or sedentary patients, it is conceivable to assume that the energy expenditure of activities is not very high and that the other components (REE and DIT) are a good estimate of total daily energy expenditure. Several studies have shown that DIT is normal in patients with COPD, amounting to approximately $10 \%$ of dietary intake. Analysis of the balance between REE and dietary intake revealed a negative balance on admission, which soon restored to normal. Further evidence for a temporary state of negative energy balance was seen in changes in respiratory quotient from close to 0.7 to 0.8 . In view of the sensibility of the bio-electrical impedance spectroscopy measurement and duration of hospitalization, the energy imbalance was probably too short to be reflected in body weight and body composition data. The improvement in energy balance was accompanied by a significant improvement in symptoms such as dyspnoea and fatigue. These results imply that an (acute) disease exacerbation can indeed temporarily affect both dietary intake and REE in patients with COPD, but that if a patient responds adequately to the medical treatment, aggressive nutritional support is not indicated in a temporarily unstable clinical condition.

In qualitative terms, our data indicate that protein intake should be increased $(1.5 \mathrm{~g} / \mathrm{kg} /$ day $)$ in order to provide optimal conditions form a nutritional point of view, for protein synthesis in the recovery period. Despite insignificant changes in body weight during hospitalization, improved body weight in the subgroup of patients that were studied 3 months afterwards suggests the presence of a preexisting period of energy imbalance in association with the acute exacerbation. To provide more insight in this period, dietary consultation and metabolic evaluation of patients with chronic obstructive pulmonary disease, suffering from an acute exacerbation should include a (retrospective) evaluation of the period prior to hospitalization and be expanded from the in-hospital period to the out-patient recovery period immediately afterwards. The conclusions of this study apply only to patients with acute exacerbation of moderate severity and further studies are needed in patients with severe respiratory failure, especially those requiring mechanical ventilation. 


\section{References}

1. Engelen MP, Schols AM, Baken WC, Wesseling GJ, Wouters EF. Nutritional depletion in relation to respiratory and peripheral skeletal muscle function in out-patients with COPD. Eur Respir J 1994;7:1793-7.

2. Driver AG, McAlevy MT, Smith JL. Nutritional assessment of patients with chronic obstructive pulmonary disease and acute respiratory failure. Chest 1982;82:568-71.

3. Rochester D, Braun N. Determinants of maximal inspiratory pressure in chronic obstructive pulmonary disease. Am Rev Respir Dis 1985;132:42-7.

4. Schols AM, Mostert R, Soeters PB, Wouters EF. Body composition and exercise performance in chronic obstructive pulmonary disease. Thorax 1991;46:695-9.

5. Wilson DO, Rogers RM, Wright EC, Anthonisen NR. Body weight in chronic obstructive pulmonary disease. The National Institutes of Health intermittent PositivePressure Breathing Trial. Am Rev Respir Dis 1989;139:1435-8.

6. Breslin EH. Dyspnoea-limited response in chronic obstructive pulmonary disease: reduced unsupported arm activities. Rehabil Nurs 1992;17:12-20.

7. Hunter AM, Carey MA, Larsh HW. The nutritional status of patients with chronic obstructive pulmonary disease. Am Rev Respir Dis 1981;124:376-81.

8. Schols AM, Soeters PB, Saris WH, Wouters EF. Energy balance in patients with chronic obstructive pulmonary disease. Am Rev Respir Dis 1991;143:1248-52.

9. Goldstein S, Askanazi J, Weissman C, Thomashow B, Kinney JM. Energy expenditure in patients with chronic obstructive pulmonary disease. Chest 1987;91:222-4.

10. Schols AM, Fredrix EW, Soeters PB, Westererp KP, Wouters EF. Resting energy expenditure in patients with chronic obstructive pulmonary disease. Am J Clin Nutr 1991;54:983-7.

11. ATS. Standards for the diagnosis and care of patients with chronic obstructive pulmonary disease (COPD) and astma. Am Rev Respir Dis 1987;134:239-43.

12. Black G. A review of validations of dietary assessment methods. AM J Epidemiology 1982;115:492-505.

13. NEVO tabel. Stichting Nederlands Voedingsstoffenbestand. s'Gravenhage: Voorlichtingsbureau voor de Voeding. 1986.

14. Schols AM, Schoffelen PF, Ceulemans J, Wouters EF, Saris WH. Measurement of resting energy expenditure in patients with chronic obstructive pulmonary disease in a clinical setting. J Par Ent Nutr 1992;16:364-8.

15. Jenin $\mathrm{P}$, Lenoir J, Roullet $\mathrm{C}$, Thomasset $\mathrm{AL}$, Ducrot $\mathrm{H}$. Determination of body fluid compartments by electrical impedance measurements. Aviat Space Environ Med 1975;46:152-5.

16. Cole KS, Cole RH. Dispersion and absorption in dieletrics. I. Alternating current characteristics. J Chem Phys 1941;9:341-9.

17. SPSS for windows. MJ Norusis/SPSS Inc, Chicago. 1993.

18. Harris JA, Benedict EG. A biometric study of basal metabolism. Washington: Carnegie Institute of Washington; 1919. 
19. Dash A, Agrawal A, Venkat N, Moxham J, Ponte J. Effect of oral theophylline on resting energy expenditure in normal volunteers. Thorax 1994;49:1116-20.

20. Amoroso P, Wilson SR, Moxham J, Ponte J. Acute effects of inhaled salbutamol on the metabolic rate of normal subjects. Thorax 1993;48:882-5.

21. Schols AM, Buurman WA, Staal van den Brekel AJ, Dentener MA, Wouters EF. Evidence for a relation between metabolic derangements and increased levels of inflammatory mediators in a subgroup of patients with chronic obstructive pulmonary disease. Thorax 1996;51:819-24.

22. Vanderhoven-Augustin IM, Schols AM, Smeets HJ, Wouters EF. The influence of disease exacerbation on metabolism and lung function. Eur Respir J 1996;9:123s.

23. Creutzberg EC, Schols AM, Bothmer-Quaedvlieg FC, Wesseling G), Wouters EF. Acute effects of nebulized salbutamol on resting energy expenditure in patients with chronic obstructive pulmonary disease and in healthy subjects. Respiration 1998;65:375-80.

24. Burdet L, de Muralt B, Schutz Y, Fitting JW. Thermogenic effect of bronchodilators in patients with chronic obstructive pulmonary disease. Thorax 1997;52:130-5.

25. Francia MD, Barbier D, Mege JL, Orehek J. Tumor necrosis factor-alpha levels and weight loss in chronic obstructive pulmonary disease. Am J Respir Crit Care Med 1994;150:1453-5.

26. de Godoy I, Donahoe M, Calhoun WJ, Mancino J, Rogers RM. Elevated TNF-alpha production by peripheral blood monocytes of weight- losing COPD patients. Am J Respir Crit Care Med 1996;153:633-7.

27. Fong $Y$, Moldawer LL, Marano M, Wei H, Barber A, Manogue K, Tracey KJ, Kuo G, Fischman DA, Cerami A, Lowry SF. Cachectin/TNF or IL-1 alpha induces cachexia with redistribution of body proteins. Am J Physiol 1989;256:R659-65. 


\section{Chapter 7}

Nutritional support in patients with chronic obstructive pulmonary disease during hospitalization for an acute exacerbation; a randomized controlled feasibility trial

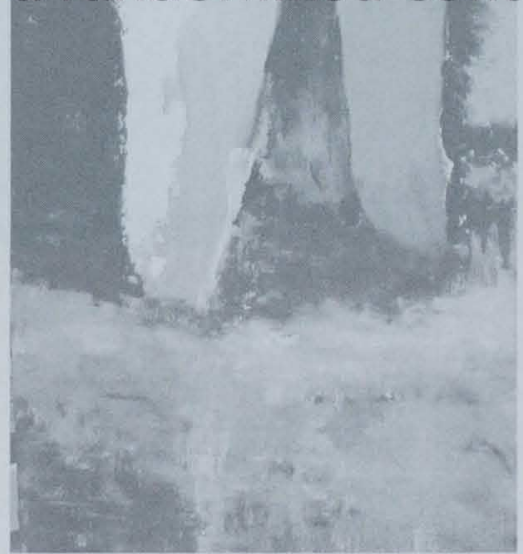

MAP Vermeeren, EFM Wouters, AJW Geraerts-Keeris, AMWJ Schols

Clinical Nutrition in press 


\section{Abstract}

\section{Background \& aims}

Previous studies reported a severely impaired energy balance in COPD patients during the first days of an acute exacerbation, mainly due to a decreased energy and protein intake. The aim of the study was to investigate the feasibility and effectiveness of energy- and protein-rich nutritional supplements during hospitalization for an acute exacerbation in nutritionally depleted COPD patients.

\section{Methods}

In a randomized double-blind, placebo-controlled two-center trial, 56 COPD patients were randomized and 47 patients completed the study. Nutritional intervention consisted of $3 \mathrm{x}$ $125 \mathrm{ml}(2.38 \mathrm{MJ} /$ day) and the placebo group received similar amounts of a non-caloric fluid. Medical therapy and dietetic consultation were standardized and dietary intake was measured daily. Body composition, respiratory and skeletal muscle strength, lung function and symptoms were measured on admission and on days 4 and 8 of hospitalization.

\section{Results}

Forty-seven percent of the patients had experienced recent involuntary weight loss prior to admission. The degree of weight loss was inversely related to resting arterial oxygen tension $(r=0.31 ; p<0.05)$. Nutritional intervention resulted in a significant increase in energy ( $16 \%$ versus placebo) and protein intake (38\% versus placebo). Mean duration of hospitalization was $9 \pm 2$ days. Relative to usual care, no additional improvements in lung function or muscle strength were seen after nutritional intervention.

\section{Conclusions}

Oral nutritional supplementation during hospitalization for an acute exacerbation is feasible in nutritionally depleted COPD patients and does not interfere with normal dietary intake. 


\section{Introduction}

Weight loss frequently occurs in patients with moderate to severe chronic obstructive pulmonary disease (COPD), and is associated with increased morbidity and mortality. ${ }^{1.3}$ It has been suggested that in a subgroup of COPD patients weight loss follows a stepwise pattern, related to acute exacerbations of the lung disease. ${ }^{4}$ Connors and associates found that besides disease severity and age, also body mass index (BMI) was independently related to survival time after an acute exacerbation of COPD. ${ }^{5}$ Low BMI and weight loss during hospitalization were furthermore indicators for early re-admission in patients with COPD. ${ }^{2}$ In two earlier studies we described a disturbed energy balance during the first days of hospitalization due to an acute exacerbation. ${ }^{6,7}$ Both a decreased dietary intake and an increased resting energy expenditure (REE) were shown during this period. A low ratio between dietary intake and REE was related to increased symptoms and to elevated levels of systemic inflammatory markers. ${ }^{6,7}$ Besides a disturbed energy balance, COPD patients may be at increased risk for a negative nitrogen balance during an acute exacerbation, due to an enhanced systemic inflammatory response, high dose of systemic glucocorticoids, immobility and low protein intake. Only two studies have yet measured nitrogen balance in hospitalized COPD patients with an acute exacerbation. ${ }^{8,9}$ Both studies reported a negative nitrogen balance. In addition, Saudny and coworkers ${ }^{8}$ showed a negative correlation between high dose of methylprednisolone and nitrogen balance $(r=-0.73, p=0.0048)$. The efficacy of nutritional support during a period of negative nitrogen balance in terms of functional improvement depends on whether predominantly protein synthesis is decreased or whether there is accelerated protein breakdown. Protein supplementation will theoretically increase protein synthesis but not affect protein breakdown. During periods of acute protein breakdown this type of nutritional intervention will therefore not be able to induce a positive protein balance, but could limit the catabolic state. To our knowledge only one study has described in a controlled design the effectiveness of nutritional intervention during an acute exacerbation of COPD until now. No significant improvement was found in body weight, inspiratory and peripheral muscle strength, but a trend was observed in improvement in wellbeing score. ${ }^{8}$ Although nutritional status was not an inclusion criterion in this study, one could speculate that particularly underweight or weight-losing patients might benefit from nutritional intervention.

The aim of our study was therefore to investigate the feasibility and the effectiveness of oral nutritional supplementation to improve protein and energy intake during hospitalization for an acute exacerbation in nutritionally depleted patients with COPD. 


\section{Subjects and methods}

\section{Study group}

The study group consisted of patients acutely admitted to the hospital for an exacerbation of COPD. The diagnosis COPD was based on the GOLD criteria. ${ }^{10,11}$ Criteria for hospitalization were a recent increase in breathlessness, cough and sputum production of sufficient severity to warrant hospital admission, judged by an independent chest physician. Inclusion criteria for nutritional intervention were a $\mathrm{BMI} \leq 22 \mathrm{~kg} / \mathrm{m}^{2}$ or a $\mathrm{BMI} \leq 25 \mathrm{~kg} / \mathrm{m}^{2}$ and $>5 \%$ weight loss in one month, or $>10 \%$ weight loss in 6 months prior admission to the hospital. Patients with diabetes mellitus type 1, patients with thyroid or intestinal diseases and patients with carcinoma were excluded from the study.

\section{Study design}

A randomized double-blind, placebo-controlled two-center trial was performed in the University Hospital Maastricht, and the regional hospital 'Maxima Medical Center' in Veldhoven, the Netherlands. Randomization took place on the first day of hospitalization.

Nutritional intervention was implemented in the standardized usual care management of these patients. Medical therapy (bronchodilator therapy and systemic glucocorticoids) was standardized, but slightly different between the two centers. In the University Hospital Maastricht, methylprednisolone was given during the first seven days in dosage of $0.4 \mathrm{mg} / \mathrm{kg}$ body weight, from day 8 on as $0.2 \mathrm{mg} / \mathrm{kg}$ body weight. Theophylline was given in doses of $7-10 \mathrm{mg} / \mathrm{kg}$ body weight during the study period. In Maxima Medical Center the medical therapy was $40 \mathrm{mg}$ methylprednisolone/day for the first three days, then $30 \mathrm{mg}$ methylprednisolone/day for day $4 / 5 / 6$ and $20 \mathrm{mg}$ methylprednisolone/day from day 7 onwards. The dose of theophylline was $400 \mathrm{mg}$ theophylline/day in underweight patients and $600 \mathrm{mg}$ theophylline/day in normal weight COPD patients. Mean methylprednisolone intake was similar between both hospitals. Oxygen therapy was given if indicated based on resting arterial blood gas measurements.

The study was approved by the medical ethical committee of the University Hospital Maastricht and of Maxima Medical Center. All subjects gave written informed consent.

\section{Nutritional intervention}

The intervention (I) consisted of $3 \times 125 \mathrm{ml}$ Respifor ${ }^{\circledast} /$ day (Nutricia, Zoetermeer, The Netherlands); $2.38 \mathrm{MJ} /$ day, 20 energy\% protein, 20 energy\% fat and 60 energy\% carbohydrate. The control group received placebo $(\mathrm{P}), 3 \times 125 \mathrm{ml}$ vanilla flavored water with $0 \mathrm{MJ} /$ day. All supplements were given in white packages and 
were offered from the first day of hospitalization. Supplementation was given three times daily during daytime between main meals. Besides the supplementation, all the patients had the opportunity to select their own menus from a standardized hospital form. Dietetic consultation was standardized during the study period.

\section{Measurements}

During hospitalization, dietary intake and body weight were assessed daily. Muscle function, lung function and symptoms were measured on the day after admission, on day 4 and day 8 . Day 4 was chosen because previous studies showed that generally the acute phase of an exacerbation lasted 3 days and day 8 was chosen because mean hospital duration was 9 days in both hospitals. Measurement of all these outcome variable was standardized in the morning.

\section{Energy balance}

Habitual dietary intake, dietary intake prior to admission since aggravation of dyspnoea and other disease symptoms were assessed using the dietary history method with cross check. ${ }^{12}$ All interviews were performed by two trained dieticians. During hospitalization dietary intake was recorded daily with dietary records and using an automated food distribution system. Dietary records were reported by the patients with support of the nursing staff. The dietary records were verified within one day by the two trained dieticians. The obtained food composition data from the dietary history and records were coded for computer nutrient analysis. The nutrient database was derived from the Dutch food composition tables. ${ }^{13}$ Energy intake was expressed as total energy intake $(\mathrm{kJ} /$ day), as cumulative energy intake during total study period and as $\mathrm{kJ} / \mathrm{kg}$ body weight/day. Total protein intake was also expressed as gram $/ \mathrm{kg}$ body weight/day. Carbohydrate and fat intake were presented as proportions of total energy intake (energy\%).

The daily $500-\mathrm{ml}$ infusion solution contained $5 \%$ glucose, which is equivalent to $420 \mathrm{~kJ} /$ day. This amount of energy was incorporated in the calculations of the daily dietary intake during hospitalization.

\section{Body composition}

Body height was determined to the nearest $0.5 \mathrm{~cm}$ (WM $715^{\circledast}$, Lameris, Breukelen, The Netherlands) with subjects standing barefoot. Body weight was assessed with a beam scale to the nearest $0.1 \mathrm{~kg}$ (SECA ${ }^{\circledR}$, Hamburg, Germany) with subjects standing barefoot and in light clothing. Body composition was estimated using single frequency $(50 \mathrm{kHz})$ bio-electrical impedance analysis (Xitron technologies Inc., San Diego, CA, USA) while subjects were in supine position. Fat-free mass (FFM) was calculated from COPD- and gender specific regression equations. ${ }^{14}$ FFM depletion was defined as FFM index (FFMI: FFM in $\mathrm{kg} /$ height in $\mathrm{m}^{2}$ ) $\leq 15$ (females) or $\leq 16$ (males) $\mathrm{kg} / \mathrm{m}^{2}$. 


\section{Lung function}

Forced expiratory volume in one second ( $\mathrm{FEV}_{1}$ ), inspiratory vital capacity (IVC) were calculated from the flow volume curve using a portable spirometer (Jaeger, Würzburg, Germany). Results of lung function parameters were expressed as percentage of the predicted normal values. ${ }^{15}$ Respiratory muscle function was assessed by measuring maximal inspiratory mouth pressure (Pi-max) according to the method of Black and Hyatt. ${ }^{16}$ The best of three attempts was taken for analysis. Pi-max values were noted as positive values.

\section{Disease severity}

Disease severity was defined according to the GOLD guidelines. ${ }^{10,11}$ The classification of severity of COPD is stage 0 , at risk: normal spirometry, chronic symptoms; stage 1, mild COPD: $\mathrm{FEV}_{1} \geq 80 \%$ predicted and with or without chronic symptoms; stage 2, moderate COPD: $50 \% \leq \mathrm{FEV}_{1}<80 \%$ predicted and with or without symptoms; stage 3, severe COPD: $30 \% \leq \mathrm{FEV}_{1}<50 \%$ predicted and with or without symptoms and stage 4, very severe COPD: FEV $1 \leq 30 \%$ predicted or $\mathrm{FEV}_{1}<50 \%$ predicted plus chronic respiratory failure. This classification is based on post bronchodilator $\mathrm{FEV}_{1}$.

\section{Arterial blood gases}

Blood was drawn on admission from the brachial artery while the patients were breathing room air. Arterial oxygen tension $\left(\mathrm{PaO}_{2}\right)$ and carbon dioxide tension $\left(\mathrm{PaCO}_{2}\right)$ were analyzed on a blood gas analyzer (Radiometer, ABL 330,

94 Copenhagen, Denmark).

\section{Quadriceps strength}

Isometric quadriceps strength was measured using a Cybex II+ dynamometer (Lumex, New York). Peak torque in newton-meters $(\mathrm{Nm})$ was measured at the dominant side, during a maximal isometric knee extension maneuver with the hip in $90^{\circ}$ flexion and the knee in $60^{\circ}$ flexion. At least three attempts were performed. The highest value of three measurements was taken.

\section{Handgrip strength}

Handgrip strength was assessed with use of a handgrip dynamometer (Yamar ${ }^{\boxplus}$, Preston, Jackson, MI, U.S.A.). The isometric grasp was determined by measuring the maximally developed strength of the flexors of the right and left hand respectively. The highest value of three maneuvers was used. The average of the maximal left and right handgrip strength was taken for analysis.

\section{Disease symptoms}

Disease symptoms, including dyspnoea at rest and while eating, loss of appetite, early satiety, bloating and fatigue were scored using a visual analogue scale (VAS), ranging from 0 to $100 \mathrm{~mm}$ and evaluated during hospitalization. 


\section{Statistics}

The differences in the baseline characteristics between the groups of the two hospitals were compared using a Student's t-test for independent samples.

For evaluating the feasibility and effectiveness of the intervention only the data of COPD patients who completed the study period were analyzed.

For comparison between the intervention group and control group, analysis of variance (ANOVA) was used with the day 8 value of the outcome parameter as the dependent variable, with intervention as a fixed factor, with institution and disease severity (GOLD stages) as random factor and the corresponding baseline value was used as a covariate.

A p-value of less than 0.05 was considered statistically significant. Data were expressed as mean $\pm \mathrm{SD}$ in the text and tables and as mean $\pm \mathrm{SEM}$ in the graphs.

The statistical analyses were performed using the Statistical Product and Service Solutions (SPSS, version 10.0 for Windows, SPSS Inc., Chicago, IL).

\section{Results}

Fifty-six COPD patients were randomized in the study (29l, 27P). Forty-seven patients completed the study $(231,24 \mathrm{P})$. The dropouts were caused by medical problems $(n=4)$, alcohol withdrawal delirium $(n=1)$ and 4 patients experienced nausea after supplementation (3I, 1P). The baseline characteristics of the total study population are summarized in table 7.1 .

There were no differences in BMI and FFMI between the hospital populations. Also between the intervention and control group there were no significantly differences in BMI and FFMI at baseline. Thirty-three of 56 patients received antibiotic therapy in case of a bacterial infection confirmed by positive sputum cultures, and there were no differences in response on the nutritional intervention. Mean duration of hospitalization was equal between the two centers: $9 \pm 2$ days. Mean intake of methylprednisolone during hospitalization was also similar in both groups, namely $25 \pm 5 \mathrm{mg} /$ day.

The COPD patients, who experienced involuntary weight loss prior to admission, were characterized by a significant lower arterial oxygen tension ( $7.8 \pm 1.4$ versus $8.7 \pm 1.1 \mathrm{kPa}, \mathrm{p}=0.035)$ but a comparable $\mathrm{FEV}_{1},(35 \pm 11$ versus $34 \pm 15$ $\%$ predicted). In figure 7.1 a significant correlation is shown between the change in body weight prior to admission and arterial oxygen tension on admission $(r=0.31$; $\mathrm{p}<0.05$ ). 
Table 7.1 The baseline characteristics of the total study population

\begin{tabular}{|c|c|c|c|c|c|}
\hline & \multirow{2}{*}{$\begin{array}{c}\text { University } \\
\text { Hospital } \\
n=28\end{array}$} & \multirow{2}{*}{$\begin{array}{c}\text { Regional } \\
\text { Hospital } \\
n=28\end{array}$} & \multicolumn{3}{|c|}{ Study population } \\
\hline & & & $\begin{array}{l}\text { I-group } \\
n=23\end{array}$ & $\begin{array}{c}\text { P-group } \\
n=24\end{array}$ & $\begin{array}{c}\text { Drop-outs } \\
n=9\end{array}$ \\
\hline Male / female & $18 / 10$ & $19 / 9$ & $14 / 9$ & $18 / 6$ & $5 / 4$ \\
\hline Age, years & $65 \pm 9$ & $68 \pm 7$ & $66 \pm 8$ & $65 \pm 10$ & $72 \pm 3$ \\
\hline Weight, kg & $58.6 \pm 12.5$ & $59.2 \pm 8$ & $57.1 \pm 12.5$ & $59.6 \pm 8.5$ & $58 \pm 9.9$ \\
\hline Height, $\mathrm{cm}$ & $167 \pm 10$ & $164 \pm 11$ & $167 \pm 12$ & $166 \pm 10$ & $163 \pm 11$ \\
\hline $\mathrm{BMI}, \mathrm{kg} / \mathrm{m}^{2}$ & $21.0 \pm 2.7$ & $21.9 \pm 2.0$ & $20.4 \pm 2.7$ & $21.4 \pm 2.3$ & $21.9 \pm 2.3$ \\
\hline FFMI, $\mathrm{kg} / \mathrm{m}^{2}$ & $15.4 \pm 2.0$ & $16.1 \pm 1.9$ & $15.6 \pm 2.2$ & $15.8 \pm 1.9$ & $15.7 \pm 1.7$ \\
\hline $\mathrm{PaO}_{2}, \mathrm{kPa}$ & $7.8 \pm 1.1^{\circ}$ & $9.0 \pm 1.4$ & $8.0 \pm 1.2$ & $8.5 \pm 1.4$ & $8.9 \pm 1.4$ \\
\hline $\mathrm{PaCO}_{2}, \mathrm{kPa}$ & $6.3 \pm 1.3^{*}$ & $5.5 \pm 0.9$ & $6.0 \pm 1.2$ & $5.7 \pm 0.7$ & $6.3 \pm 2.1$ \\
\hline Disease severity, stages $1 \mathrm{I} / \mathrm{II} / \mathrm{IV}$ & $0 / 12 / 16^{\circ}$ & $5 / 21 / 2$ & $2 / 11 / 10$ & $1 / 16 / 7$ & $2 / 6 / 1$ \\
\hline $\mathrm{FEV}_{1}, \%$ predicted & $29 \pm 8^{\circ}$ & $42 \pm 13$ & $32 \pm 12$ & $34 \pm 12$ & $43 \pm 12$ \\
\hline IVC, \%predicted & $66 \pm 19$ & $77 \pm 21$ & $67 \pm 13$ & $73 \pm 23$ & $64 \pm 19$ \\
\hline $\mathrm{FEV}_{1} / \mathrm{IVC}, \%$ predicted & $43 \pm 12$ & $56 \pm 16$ & $48 \pm 17$ & $47 \pm 11$ & $54 \pm 18$ \\
\hline PEF, \%predicted & $34 \pm 9^{\circ}$ & $45 \pm 16$ & $38 \pm 16$ & $41 \pm 13$ & $38 \pm 8$ \\
\hline $\mathrm{Pi}$-max, $\mathrm{cm} \mathrm{H} \mathrm{H}_{2} \mathrm{O}$ & $48 \pm 13$ & $60 \pm 24$ & $54 \pm 16$ & $53 \pm 22$ & $58 \pm 22$ \\
\hline Mean handgrip strength, kg & $27 \pm 9$ & $29 \pm 10$ & $28 \pm 10$ & $28 \pm 9$ & $25 \pm 8$ \\
\hline Weight loss/weight stable & $16 / 12^{*}$ & $7 / 21$ & $10 / 13$ & $12 / 12$ & $1 / 8^{* *}$ \\
\hline
\end{tabular}

" $p<0.05$, baseline characteristics are compared between the study group of the university hospital and the regional hospital; " $p<0.05$, baseline characteristics are compared between the intervention group, placebo group and the dropouts.

$\mathrm{BMI}$, body mass index; FFMI, fat-free mass index; $\mathrm{FEV}_{1}$, forced expiratory volume in one second; IVC, inspiratory vital capacity; PEF, peak expiratory flow; Pi-max, maximal inspiratory mouth pressure.

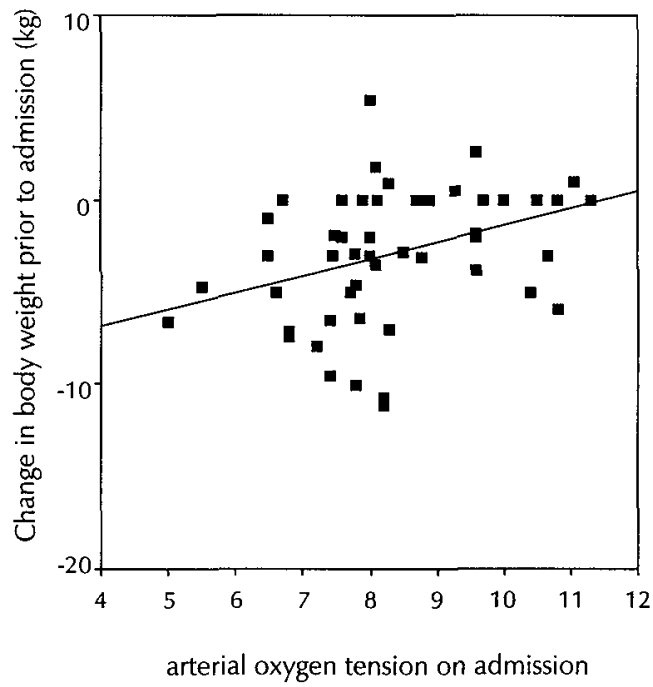

Figure 7.1 The correlation between change in body weight prior to admission and arterial oxygen tension on admission, $r=0.31, p<0.05$

Nine patients with COPD (4I, 5P) were readmitted at the pulmonary ward within 3 months. These patients were characterized by a lower FEV 1 compared with those patients, who were not readmitted, $27 \pm 10 \%$ predicted FEV $_{1}$ and $36 \pm 13$ 
\%predicted $\mathrm{FEV}_{1}(\mathrm{p}=0.08)$ respectively. 5 of those patients $(2 \mathrm{I}, 3 \mathrm{P})$ experienced involuntary weight loss on readmission, of which $4(2 \mathrm{l}, 2 \mathrm{P})$ had also lost weight prior to the first admission.

\section{Dietary intake prior to admission}

Twenty-four COPD patients (51\%) reported a decrease in habitual dietary intake prior to admission from $9.53 \pm 2.64 \mathrm{MJ} /$ day to $6.07 \pm 2.25 \mathrm{MJ} /$ day $(p<0.01)$. Also protein intake per $\mathrm{kg}$ body weight was decreased in this group from $1.3 \pm 0.3 \mathrm{~g} / \mathrm{kg}$ body weight to $0.7 \pm 0.2 \mathrm{~g} / \mathrm{kg}$ body weight, $\mathrm{p}<0.01$. The mean period of decreased dietary intake was $3 \pm 1$ months.

\section{Dietary intake during hospitalization}

Over the period of hospitalization the mean energy intake in the intervention group (I) was significantly higher compared to the placebo group (P), 10.89 \pm 2.01 $\mathrm{MJ} /$ day versus $9.40 \pm 2.54 \mathrm{MJ} /$ day, $\mathrm{p}<0.05$. Cumulative energy intake during hospitalization was significantly higher in the intervention group relative to the control group $(89.9 \pm 17.9$ versus $77.1 \pm 18.3 \mathrm{MJ}, \mathrm{p}<0.05)$. Expressed in $\mathrm{kJ} / \mathrm{kg}$ body weight, the mean energy intake was $194 \pm 50 \mathrm{~kJ} / \mathrm{kg}$ body weight (l) compared to $159 \pm 42 \mathrm{~kJ} / \mathrm{kg}$ body weight $(P)(p=0.022)$. Mean protein intake was $38 \%$ higher in the intervention group, $1.8 \pm 0.4 \mathrm{~g} / \mathrm{kg}$ body weight $(\mathrm{I})$ versus $1.3 \pm 0.3 \mathrm{~g} / \mathrm{kg}$ body weight $(P)(p<0.01)$. See figure 7.2a and 7.2b for the pattern of daily energy intake and protein intake during hospitalization. The mean carbohydrate intake during hospitalization was $54 \pm 4$ energy\% (I) versus $47 \pm 5$ energy\% carbohydrate (P) $(p<0.01)$. Mean fat intake was $27 \pm 3$ energy\% (I) versus $33 \pm 4$ energy\% fat $(P)$ $(\mathrm{p}<0.01)$.

The proportion of oral supplementation that was ingested during hospitalization was carefully monitored by the nurses and amounted to $98 \pm 2 \%$. The dotted line in figure $7.2 \mathrm{a}$ and $7.2 \mathrm{~b}$ shows that dietary intake without supplements was comparable between the treatment and the placebo group.

a

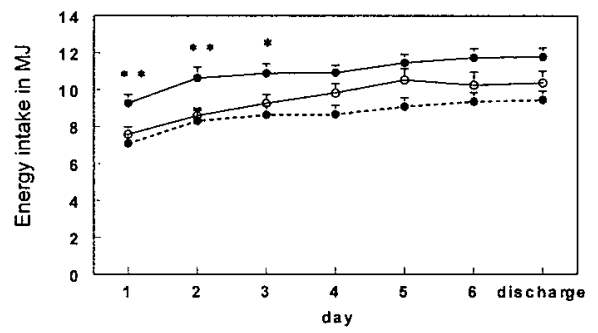

b

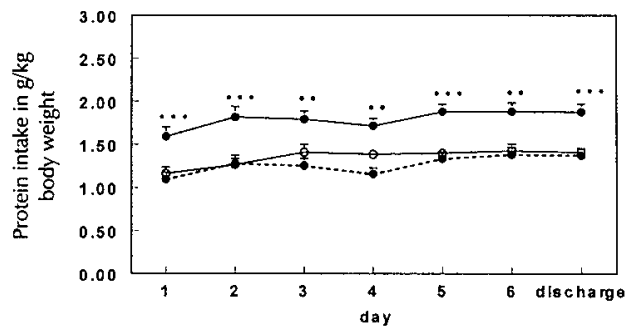

Figure 7.2 Pattern of energy intake during hospitalization, 7.2a, pattern of protein intake during hospitalization, $7.2 \mathrm{~b}$. Closed circles and solid line, the intervention group; closed circles with dashed line, the spontaneously intake of the intervention group without the supplementation; open circles and solid line, the placebo group. ${ }^{*} p=0.05,{ }^{* *} p \leq 0.01$, $* * * p \leq 0.001$ 


\section{Body weight and body composition}

In both groups body weight improved significantly and comparably during hospitalization (table 7.2). The change in body weight during hospitalization, expressed as percentage weight change was not significantly different between the groups, $2.6 \pm 2.5 \%(\mathrm{I})$ and $2.0 \pm 2.2 \%(\mathrm{P})$. Twenty-two patients $(47 \%)$ experienced involuntary weight loss prior to admission. Their usual body weight was similar to that of weight-stable COPD patients $(n=25)$, namely $61.4 \pm 11 \mathrm{~kg}$ and $61.5 \pm 10 \mathrm{~kg}$. The weight-losing patients lost on average $5.9 \pm 2.4 \mathrm{~kg}(10 \pm 4 \%$ weight loss) in $3 \pm 1$ months before hospital admission. Weight gain during hospitalization in the weight-losing patients tended to be higher than in the weight-stable patients, $1.5 \pm 1.3 \mathrm{~kg}$ and $0.9 \pm 1.1 \mathrm{~kg}(\mathrm{p}=0.08)$, respectively or $3.1 \pm 2.4 \%$ compared to $1.6 \pm 2.1 \%$ in the weight stable patients $(p=0.05)$. There were no significantly changes in FFM in both groups. FM increased significantly in both groups during hospitalization (see also table 7.2).

\section{Lung function, muscle function and symptoms}

In table 7.2 the changes in lung function, inspiratory muscle strength, handgrip strength and symptoms are shown. FEV 1 and IVC improved slightly but significantly in the total group. All symptoms improved significantly in the total group during hospitalization, but no differences were observed between the treatment and control group.

The majority of patients were unable to perform a valid quadriceps strength test on day 1. Therefore quadriceps strength measurements were compared only between days 4 and 8 . There was no significant change in muscle strength between these days and also no difference between the intervention and control group.

Table 7.2 Changes in outcome parameters from admission to discharge

\begin{tabular}{|c|c|c|c|c|}
\hline & \multicolumn{2}{|c|}{ Intervention } & \multicolumn{2}{|r|}{ Placebo } \\
\hline & $n$ & & $\mathbf{n}$ & \\
\hline Weight, kg & 23 & $1.37 \pm 1.3^{*}$ & 24 & $1.12 \pm 1.2^{*}$ \\
\hline Fat-free mass, $\mathrm{kg}$ & 21 & $-0.5 \pm 2.6$ & 22 & $-0.4 \pm 2.7$ \\
\hline Fat mass, kg & 21 & $1.7 \pm 2.5^{*}$ & 22 & $1.5 \pm 2.5^{*}$ \\
\hline $\mathrm{FEV}_{1}, \%$ predicted & 23 & $5 \pm 6^{*}$ & 23 & $5 \pm 9^{*}$ \\
\hline IVC, \%predicted & 23 & $7 \pm 12^{*}$ & 23 & $10 \pm 17^{*}$ \\
\hline Pi-max, $\mathrm{cm} \mathrm{H} \mathrm{H}_{2} \mathrm{O}$ & 20 & $3 \pm 10$ & 23 & $3 \pm 13$ \\
\hline Mean handgrip strength, $\mathrm{kg}$ & 20 & $0 \pm 3$ & 22 & $0 \pm 3$ \\
\hline Quadriceps strength, $\mathrm{Nm}^{\mathrm{a}}$ & 20 & $3 \pm 8$ & 23 & $2 \pm 9$ \\
\hline Score of dyspnoea at rest & 23 & $-3.8 \pm 2.5^{*}$ & 24 & $-4.3 \pm 3.2^{*}$ \\
\hline Score of dyspnoea while eating & 23 & $-4.2 \pm 2.5^{*}$ & 24 & $-4.7 \pm 3.3^{*}$ \\
\hline Score of loss of appetite & 23 & $-2.7 \pm 3.2^{*}$ & 24 & $-2.6 \pm 2.9^{*}$ \\
\hline Score of early satiety & 23 & $-3.2 \pm 3.3^{*}$ & 24 & $-2.5 \pm 3.3^{*}$ \\
\hline Score of bloating & 23 & $-2.4 \pm 3.4^{*}$ & 24 & $-3.0 \pm 2.8^{*}$ \\
\hline Score of fatigue & 23 & $-4.2 \pm 3.7^{*}$ & 24 & $-3.9 \pm 3.5^{*}$ \\
\hline
\end{tabular}

a change in quadriceps strength is compared between day 4 and day 8

' $p<0.05 ; F V_{1}$, forced expiratory volume in one second; IVC, inspiratory vital capacity. 


\section{Discussion}

This study shows that nutritional supplementation is feasible and able to increase energy intake and particularly protein intake in nutritionally depleted COPD patients during hospitalization for an acute exacerbation. There were however no significant differences in body weight gain and functional improvement between the treated and control group.

The following considerations were made in the nutritional support strategy. In contrast to the earlier study by Saudny et $a l^{8}$ who did not use nutritional status as inclusion criterium, we focused on COPD patients at risk of malnutrition and normal weight patients with recent involuntary weight loss. Indeed $47 \%$ of the patients had experienced weight loss prior to hospitalization, during a period of 24 months. The caloric support was moderate $(2.38 \mathrm{MJ} /$ day $)$ and primarily aimed at maintaining body weight during the average 9 days hospitalization, because we previously reported that a low BMI and weight loss during hospitalization was an independent predictor of early hospital readmission. ${ }^{2}$ The group with recent weight loss tended to increase weight during hospitalization while this was not observed in the weight-stable patients. Based on the observation, we speculate that these results indicate that recent weight loss may be a more appropriate criterion for nutritional intervention during hospitalization for an acute exacerbation than BMI.

During hospitalization COPD patients are at risk for protein catabolism due to several factors including systemic glucocorticoid treatment, a flare up of the systemic inflammatory response, inactivity and hypoxia. Optimizing protein intake may reduce this catabolic response, even when anabolism will not be reached. A protein intake of $1.5 \mathrm{~g} / \mathrm{kg}$ body weight has been identified to optimize protein synthesis in several acute and chronic conditions. ${ }^{17}$ No specific protein requirements are available for COPD, but already in clinical stable condition whole body protein turnover is increased. ${ }^{18}$ This study clearly shows that the normal hospital diet alone was unable to reach the requirement of $1.5 \mathrm{~g} / \mathrm{kg}$ body weight but that the supplements increased daily protein intake to $1.8 \mathrm{~g} / \mathrm{kg}$ body weight. The protein-rich supplementation however was not reflected in an improvement in FFM. Since both treatment and control group showed an increase in $\mathrm{FM}$, it is likely that body compositional response occur independently from the nutritional intervention. Theoretically, the maintenance of FFM does not exclude actual loss of muscle mass and FFM could be masked by water retention. Previous studies showed that systemic glucocorticoid treatment is associated with a negative nitrogen balance in a dose dependent way. ${ }^{8}$ In addition Spruit et al recently reported peripheral skeletal muscle weakness in COPD patients during hospitalization for an acute exacerbation. ${ }^{19}$ Interestingly our muscle function measurements were not dramatically low compared to the clinical stable condition $^{20}$ and patients did not show any further decline in muscle function 
during hospitalization. This may be related to the relatively low mean daily dose of glucocorticosteroids that patients received in this study ( $25 \mathrm{mg} / \mathrm{kg}$ body weight) compared to previous studies. ${ }^{6,8,19}$ To assess more specifically protein requirements in COPD patients during an acute exacerbation, further research is indicated.

Some nutritional intervention studies have shown that nutritional supplements may cause a drop in normal dietary intake so that the effectiveness of the treatment is limited. ${ }^{21}$ This could particularly be a problem during acute exacerbations because we previously reported severe dyspnoea and a low spontaneous dietary intake during the first day of hospitalization. ${ }^{6}$ In an earlier study we analyzed the acute effect of different portion sizes and macronutrient composition on symptoms and functional capacity in clinically stable COPD patients. We noticed that although on average patients could tolerate supplements up to $2092 \mathrm{~kJ}$, severely underweight patients experienced a dramatic drop in postprandial exercise capacity after $2092 \mathrm{~kJ}$ relative to $1046 \mathrm{~kJ}$. In the same study we also reported that a fat-rich supplement caused a postprandial increase in dyspnoea sensation while no effect was seen after a carbohydrate-rich supplement. ${ }^{22}$ The current protein-rich and carbohydrate-rich supplement was well tolerated, even in patients with acute respiratory failure. Portion size was limited to $125 \mathrm{ml}$ instead of the commonly used $200 \mathrm{ml}$ and was indeed well tolerated and taken additionally instead of replacing normal dietary intake. In a subgroup of patients $(12 \mathrm{I}, 10 \mathrm{P}) \mathrm{PaCO}_{2}$ was routinely measured not only on admission, but also on day 4 of hospitalization. There were no significantly differences in $\mathrm{PaCO}_{2}$ between the intervention group and the placebo group. So the increase of carbohydrate consumption over the day during the acute phase of the exacerbations had no adverse effects.

Remarkably in contrast to our two earlier studies, spontaneous energy intake, particularly during the first days of hospitalization was higher both in the treatment and in the placebo group. Perhaps participation to a clinical trial per se including more regular and standardized dietetic consultation as well as the placebo drink may have increased patient's awareness to eat well.

We confirmed that a high proportion of patients reported recent involuntary weight loss prior to hospitalization which was inversely related to resting arterial oxygen tension. In general acute hypoxia leads to weight loss and loss of appetite ${ }^{22-25}$, irrespective of hypobaric hypoxia. At high altitude, a rapid increase in satiety reduces meal size and obviously dietary intake ${ }^{25}$, which might be similar during an acute exacerbation of COPD. Furthermore it is known that the systemic inflammatory response in depleted patients with COPD which in itself may affect appetite and dietary intake ${ }^{7,26}$ can also be triggered by hypoxia. ${ }^{27}$ Nevertheless, this study clearly shows that after normalization of the arterial blood gases by oxygen therapy, this subgroup of patients shows a comparable response to nutritional support than normoxemic patients.

We recognize that a mean hospital stay of 9 days is very short to show effectiveness of nutritional intervention on functional outcome measures which 
was indeed not observed. A more appropriate outcome measure would have been for instance hospital readmission rate. Nine patients were readmitted within 3 months after discharge of whom again $56 \%$ had suffered involuntary weight loss. Besides optimizing nutritional screening and support during hospitalization, these figures indicate that more attention should also be paid to home care during the first weeks immediately after hospitalization.

In summary nutritional supplementation is feasible and recommended protein intake could only be reached in the treatment group.

\section{Acknowledgements}

The authors are grateful to AF Lenssen, LCAM Wijnen and C vd Wetering for their assistance. The study was supported by Numico Research BV, The Netherlands. 


\section{References}

1. Landbo C, Prescott E, Lange P, Vestbo J, Almdal TP. Prognostic value of nutritional status in chronic obstructive pulmonary disease. Am J Respir Crit Care Med 1999;160:1856-61.

2. Pouw EM, Ten Velde GP, Croonen BH, Kester AD, Schols AM, Wouters EF. Early nonelective readmission for chronic obstructive pulmonary disease is associated with weight loss. Clin Nutr 2000;19:95-9.

3. Schols AM, Slangen J, Volovics L, Wouters EF. Weight loss is a reversible factor in the prognosis of chronic obstructive pulmonary disease. Am J Respir Crit Care Med 1998;157:1791-7.

4. Rogers RM, Donahoe $M$, Costantino J. Physiologic effects of oral supplemental feeding in malnourished patients with chronic obstructive pulmonary disease. A randomized control study. Am Rev Respir Dis 1992;146:1511-7.

5. Connors AF, Jr., Dawson NV, Thomas C, Harrell FE, Jr., Desbiens N, Fulkerson W], Kussin P, Bellamy P, Goldmand L, Knaus WA. Outcomes following acute exacerbation of severe chronic obstructive lung disease. The SUPPORT investigators (Study to Understand Prognoses and Preferences for Outcomes and Risks of Treatments). Am J Respir Crit Care Med 1996;154:959-67.

6. Vermeeren MA, Schols AM, Wouters EF. Effects of an acute exacerbation on nutritional and metabolic profile of patients with COPD. Eur Respir J 1997;10:2264-9.

7. Creutzberg EC, Wouters EF, Vanderhoven-Augustin IM, Dentener MA, Schols AM. Disturbances in leptin metabolism are related to energy imbalance during acute exacerbations of chronic obstructive pulmonary disease. Am J Respir Crit Care Med 2000;162:1239-45.

8. Saudny-Unterberger H, Martin JG, Gray-Donald K. Impact of nutritional support on functional status during an acute exacerbation of chronic obstructive pulmonary disease. Am J Respir Crit Care Med 1997;156:794-9.

9. Thorsdottir I, Gunnarsdottir I. Energy intake must be increased among recently hospitalized patients with chronic obstructive pulmonary disease to improve nutritional status. J Am Diet Assoc 2002;102:247-9.

10. Pauwels RA, Buist AS, Calverley PM, Jenkins CR, Hurd SS. Global strategy for the diagnosis, management, and prevention of chronic obstructive pulmonary disease. NHLBI/WHO Global Initiative for Chronic Obstructive Lung Disease (GOLD) Workshop summary. Am J Respir Crit Care Med 2001;163:1256-76.

11. GOLD newsletter. www.goldcopd.com august 2003.

12. Black G. A review of validations of dietary assessment methods. AM J Epidemiology 1982;115:492-505.

13. NEVO tabel. Stichting Nederlands Voedingsstoffenbestand. s'Gravenhage: Voorlichtingsbureau voor de Voeding. 1986.

14. Steiner MC, Barton RL, Singh S], Morgan MD. Bedside methods versus dual energy Xray absorptiometry for body composition measurement in COPD. Eur Respir J 2002;19:626-31.

15. Quanjer PH. Standardized lung function testing. Official statement of the European Respiratory Society. Eur Respir ] 1993;6(Suppl 16):1-100. 
16. Black LF, Hyatt RE. Maximal respiratory pressure: normal values and relationship to age and sex. Am Rev Respir Dis 1969;99:696-702.

17. Shaw $\mathrm{JH}$, Wildbore $\mathrm{M}$, Wolfe RR. Whole body protein kinetics in severely septic patients. The response to glucose infusion and total parenteral nutrition. Ann Surg 1987;205:288-94.

18. Engelen MP, Deutz NE, Mostert R, Wouters EF, Schols AM. Response of whole-body protein and urea turnover to exercise differs between patients with chronic obstructive pulmonary disease with and without emphysema. Am J Clin Nutr 2003;77:868-74.

19. Spruit MA, Gosselink R, Troosters T, Kasran A, Gayan-Ramirez G, Bogaerts P, Bouillon $\mathrm{R}$, Decramer $M$. Muscle force during an acute exacerbation in hospitalised patients with COPD and its relationship with CXCL8 and IGF-I. Thorax 2003;58:752-6.

20. Gosker HR, Lencer NH, Franssen FM, Van Der Vusse GJ, Wouters EF, Schols AM. Striking similarities in systemic factors contributing to decreased exercise capacity in patients with severe chronic heart failure or COPD. Chest 2003;123:1416-24.

21. Stratton RJ, Green CJ, Elia M. Disease-related malnutrition: an evidence-based approach to treatment: CABI Publishing; 2003.

22. Vermeeren MA, Wouters EF, Nelissen LH, van Lier A, Hofman Z, Schols AM. Acute effects of different nutritional supplements on symptoms and functional capacity in patients with chronic obstructive pulmonary disease. Am J Clin Nutr 2001;73: 295-301.

23. Schols AM, Westerterp KR. Hypoxia, nitrogen balance and body weight. Eur Respir J 2002;20:252-3.

24. Westerterp KR, Meijer EP, Rubbens M, Robach P, Richalet JP. Operation Everest III: energy and water balance. Pflugers Arch 2000;439:483-8.

25. Westerterp-Plantenga MS. Effects of extreme environments on food intake in human subjects. Proc Nutr Soc 1999;58:791-8.

26. Schols AM, Creutzberg EC, Buurman WA, Campfield A, Saris WH, Wouters EF. Plasma leptin concentration is related to pro-inflammatory status and dietary intake in patients with COPD. Am J Respir Crit Care Med 1999;160:1220-6.

27. Takabatake $N$, Nakamura $H$, Abe $S$, Inoue $S$, Hino T, Saito $H$, Yuki $H$, Kato S, Tomoiki $H$. The relationship between chronic hypoxemia and activation of the tumor necrosis factor-alpha system in patients with chronic obstructive pulmonary disease. Am J Respir Crit Care Med 2000;161:1179-84. 
Chapter 8

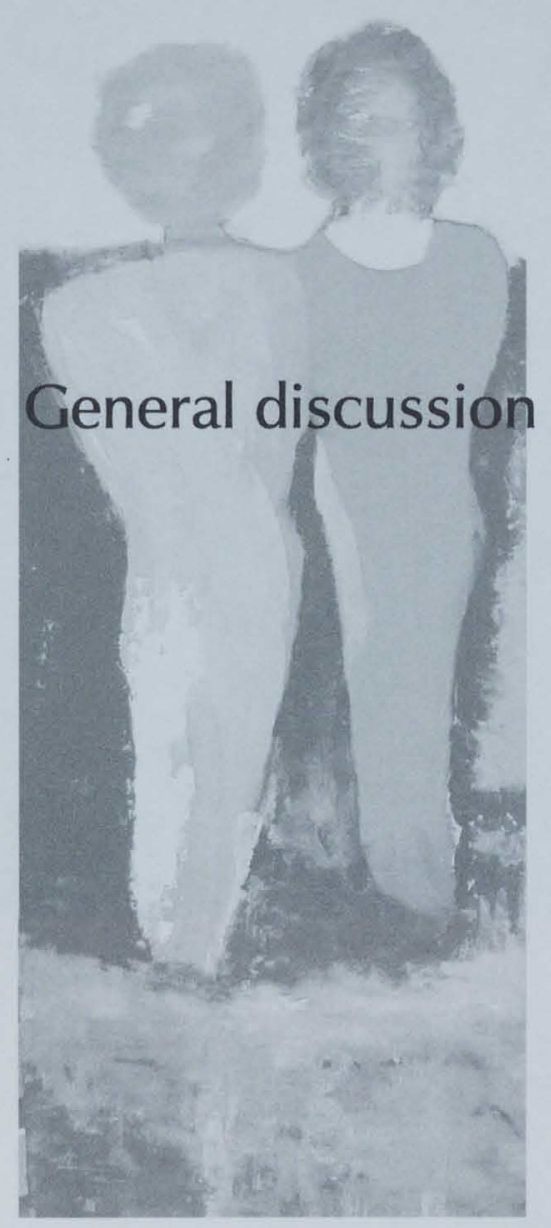


Chapter 8 


\section{General discussion}

The studies in this thesis aimed to gain more insight into the nutritional profile of patients with COPD under acute and stable conditions in order to improve the efficacy of nutritional support.

The rationale for nutritional support in COPD is based on the concept that COPD is a systemic disorder ${ }^{1}$; besides lung impairment, progressive impairment in respiratory and skeletal muscle function and exercise capacity occurs. ${ }^{2-4}$ Recently a multidimensional grading system with four independent predictors of outcome in COPD patients was developed and validated. ${ }^{5}$ This so called BODE-index includes body mass index (B), the degree of airway obstruction (O), dyspnoea (D) and exercise capacity (E). COPD-patients with a higher score of the BODE-index were at higher risk of death. ${ }^{5}$ The score of each predictor alone did not predict outcome better, which supports the concept of COPD as a multicomponent systemic disease that requires an integrated management approach.

Impaired nutritional status is an important determinant of decreased physical capacity and prognosis in COPD patients. In nutritionally depleted patients physical impairment is partly reversible when weight gain is achieved by nutritional support. ${ }^{6,7}$ Unfortunately not all studies were able to reach weight gain after dietetic intervention or nutritional supplementation. Therefore the research as outlined in this thesis aimed to improve not only outcome but also proper implementation of dietetic intervention.

\section{Nutritional assessment}

In order to identify patients who will benefit from nutritional intervention, nutritional status should be incorporated in the diagnostic work-up.

Measurement of body weight (changes) or body mass index (BMI) alone has its limitations, since it provides no qualitative information on specific body tissues. In clinical practice, there is no standard method for assessment of body composition. Generally a two compartment model is applied distinguishing fat mass (FM) and fat-free mass (FFM). Bio-electrical impedance analysis (BIA) performed at a frequency of $50 \mathrm{kHz}$ is a valid and reproducible method to assess FM and FFM in clinical stable COPD patients. ${ }^{8-11}$ In general, loss of FFM is the critical component related to increased disability risk in chronic disease..$^{12}$ In chapter 2 we assessed the prevalence and pattern of nutritional depletion (defined on the basis of both $\mathrm{BMI}$ and FFMI) in a large COPD out-patient population. $27 \%$ of the patients were considered depleted (low BMI and/or low FFMI). Most remarkable was a high prevalence of hidden loss of FFM, with preservation of body weight $(15 \%)$. Furthermore this proportion was substantially higher in normal weight women than in normal weight men with COPD, $25 \%$ versus $11 \%$ respectively. Hidden loss 
of FFM is only detectable by assessment of body composition. FFM depletion is related to decreased peripheral skeletal muscle function and affects respiratory muscle function as well as exercise performance. ${ }^{13,14}$ This study clearly indicates that it is essential during out-patient screening of COPD patients to assess body composition, even in normal weight COPD patients.

When fluid shifts occur, for instance during acute disease, assessment of body composition requires measurement or estimation of the distribution of intracellular water (ICW) and extracellular water (ECW) compartments. Bioelectrical impedance spectroscopy (BIS) performed at frequencies from 5 to $500 \mathrm{kHz}$ not only measures total body water (TBW) but also extracellular water (ECW). During an acute exacerbation it is thought that fluid shifts may occur in hospitalized COPD patients. Therefore, in chapter 6 we applied BIS to measure body compositional changes during an inventarisation of the nutritional and metabolic profile of COPD patients hospitalized for an acute exacerbation and at three months after discharge in clinically stable condition. No significant changes in the ratio between the volume of ICW and ECW were found during hospitalization in the total study group and after discharge. This suggests that no major fluid shifts were present during the acute phase of COPD in our study population. However in another study, when acute exacerbation resulted in acute respiratory failure requiring mechanical ventilation, indeed a higher $\mathrm{ECW} / \mathrm{ICW}$ volume ratio was found..$^{15}$ This suggests that fluid shifts may be more pronounced related to the severity of COPD exacerbation.

108 As described earlier, a remarkably high prevalence of hidden loss of FFM was found in an out-patient population (chapter 2). Also many hospitalized COPD patients appeared to be characterized by hidden loss of FFM (chapter 6), as was confirmed in another group of hospitalized COPD patients. ${ }^{16}$ These observations suggest an association between loss of FFM and exacerbation frequency. Hidden loss of FFM may be indicative of specific alterations in protein metabolism in COPD patients which may be particularly pronounced during acute COPD exacerbations. Besides, an increased whole-body protein synthesis and breakdown were found in weight-stable COPD patients. ${ }^{17}$ Protein turnover refers to a dynamic flux in protein metabolism whereby proteins are degraded and synthesized simultaneously. Protein rates may differ considerably depending on function and specific needs. A potential explanation for this elevated protein turnover $^{17}$ is thought to be enhanced acute phase protein synthesis, associated with acute or low-grade inflammation. This is balanced by an increased amino acid release from the skeletal muscle compartment resulting in net muscle protein breakdown. Previously Pouw et al indeed observed an inverse relationship between the acute phase protein LPS binding protein and the total sum of plasma amino acid levels in COPD patients. ${ }^{18}$ In another study COPD patients with an acute phase response and elevated resting metabolic rate, were characterized by selective depletion of FFM. ${ }^{19}$ More studies are needed, however, to confirm this hypothesis using advanced techniques to measure (acute phase) protein synthesis and breakdown at the whole body level and across skeletal muscle. These studies 
are important because they highlight that maintenance of homeostatic regulation of metabolic processes in COPD under certain circumstances is an unstable equilibrium. Evoked in inflammatory conditions the acute phase response includes the hepatic synthesis of large quantities of proteins with a wide variety of functions to clear tissue debris. This is an energy-intensive process with high rates of hepatic protein synthesis requiring large quantities of essential amino acids. The need for essential amino acids drives the loss of skeletal muscle. The trade off may be viewed as a shift in the body's priorities from offensive to defensive. ${ }^{20}$ This adaptation is effective over the short term because skeletal muscle is replaced rapidly as recovery is completed. Because skeletal muscle depletion significantly contributes to morbidity and mortality, problems ensue when the process is chronic, related to continuous low grade inflammation or frequent acute (infectious) exacerbations.

\section{Treatment of weight loss}

Weight loss will occur if energy demands exceeds dietary intake over a period of time. Not only decreased dietary intake, but also increased energy expenditure can be present in COPD. These impairments of energy balance can simultaneously be present, but can also act alone.

\section{Clinical stable condition}

In some of the clinically stable COPD patients an increased REE was found ${ }^{21-23}$, which was related to markers of systemic inflammation such as C-reactive protein, LPS-binding protein and TNF-alpha. ${ }^{19,24}$ This association has also been observed in many other chronic wasting conditions ${ }^{25,26}$ and REE can therefore be considered as a metabolic marker of systemic inflammation. However unrelated to (increased) $\mathrm{REE}^{27}$, total energy expenditure (TEE) can be increased in stable patients with severe COPD. Potential factors involved in an elevated TEE are a decreased efficiency of skeletal muscle energy metabolism and an increased oxygen cost of breathing. ${ }^{28-30}$

The most variable component of TEE is energy requirement for physical activity. In chapter 5, measurement of physical activity was done by a tri-axial accelerometer for movement registration in stable COPD patients at home; the range of physical activity level (PAL) was wide, varying from 1.40 to 2.44. In COPD patients with a high PAL, it was difficult to reach a positive energy balance (chapter 5). Recently a study was published, using doubly labeled water technique for measuring TEE in COPD patients in the community. ${ }^{31}$ Here also a great range in PAL (1.15 to 1.80) was found and TEE varied between 5.2 MJ and $11.1 \mathrm{MJ}$. These studies confirm that physical activity is very variable in COPD patients in the community and that it is important to measure PAL. While accelerometers are not (yet) readily 
available for clinical practice, a validated method for physical activity assessment in COPD patients in the community is advisable. A more accurate establishment of physical activity will certainly improve indication and efficacy of nutritional intervention. Furthermore, measurement of physical activity additional to measured or estimated REE, can also be used for validity of reported energy intake. ${ }^{32}$ More research is certainly needed in this area to provide dieticians with more objective tools to guide and evaluate treatment.

At the other part of the energy balance, dietary intake can be disturbed in COPD patients. Dietary intake can be influenced by several symptoms likewise dyspnoea and fatigue; these symptoms are particularly pronounced during acute exacerbations as outlined in chapter 6 . Also anxiety or severe psychiatric disorders such as depression or depressive symptoms can adversely influence dietary intake. ${ }^{33}$ The presence of these psychiatric symptoms is high in COPD patients ${ }^{34}$ especially in severely oxygen dependent COPD patients. ${ }^{35}$ Furthermore, patients with severe COPD are at increased risk of developing depression. ${ }^{36}$ It can be hypothesized that adequate treatment of depressive symptoms in depleted COPD patients will also improve dietary intake in quantitative and qualitative terms and thereby improve the efficacy of nutritional support. Attention must be paid to these depressive disorders by care givers in a multidisciplinary setting and perhaps questionnaires could be used under certain circumstances (for instance in difficult to treat patients) by the dietician.

Altered appetite regulation results in a decreased dietary intake and this process was related to higher levels of inflammatory markers including TNF receptors and leptin. ${ }^{37-39}$ Recently, ghrelin, a novel peptide, has been developed and there is growing evidence that indicates that ghrelin is involved in appetite regulation. Ghrelin stimulates growth hormone secretion and influences appetite and hunger, resulting in improved dietary intake. Furthermore the action of leptin can be antagonized by ghrelin, as it has been shown in rats that leptin-induced inhibition of food intake was reversed by ghrelin injections. ${ }^{40}$ Ghrelin has been demonstrated to stimulate food intake ${ }^{41}$ and acts as a meal initiator in humans. ${ }^{42}$ In weight-losing persons and in cachectic patients with chronic heart failure increased circulating levels of ghrelin were reported. ${ }^{43,44}$ Future studies are required to establish the role of ghrelin in the pathogenesis of a dysregulation of energy balance in COPD patients.

Pharmacologic modulation of appetite-regulation, by use of substances such as megestrol acetate (MA) or ghrelin, may develop as a supplemental method to promote appetite and anabolism in depleted COPD patients. Recently the progestational appetite stimulant megestrol acetate, was investigated in underweight stable COPD patients ${ }^{45}$ in a randomized double-blind placebocontrolled study. Megestrol acetate induced an improved appetite and weight gain. However, mainly an increase in FM was found with no progression in health status or functional performance. ${ }^{45} \mathrm{MA}$ treatment was initiated as a single intervention, while the results of the study clearly indicate that pharmacological modulation of appetite must be accompanied by an anabolic stimulus. These studies indicate the need for a multidisciplinary approach to wasting in severe COPD. 


\section{Nutritional intervention in clinically stable condition}

The efficacy of nutritional support in COPD patients was recently reviewed in a meta-analysis. ${ }^{46}$ It was concluded that nutritional supplementation had no effect on improving anthropometry or functional exercise capacity in COPD patients. However in this review, no distinction between failure to intervene and failure of intervention was made. Nutritional therapy in studies often corresponds to an energy supplement of $0.84-2.1 \mathrm{MJ} /$ day, which does not automatically mean that total energy intake increases accordingly, since individual differences exist in total daily energy and protein requirements. In some studies the prescribed dietary supplementation was used to replace regular meals and was not additional to habitual intake $e^{47,48}$, and so nutritional intervention fails to achieve an increase in energy intake. Furthermore, in some studies nutritional supplementation was given in addition to habitual intake. When total energy requirement is not (accurately) established, it is possible that even with additional supplements, a positive energy balance is not reached, because of a (very) low habitual dietary intake at baseline. In the studies, where a positive energy balance was reached, weight gain and functional improvements were found. ${ }^{49,50}$ In chapter 5 energy balance was studied in COPD patients at 1 and 3 months after discharge from the hospital or rehabilitation center. All COPD patients received dietary counseling aimed to improve dietary intake according to estimated total energy requirements. The supplemented group used additional nutritional supplementation and they had a positive energy balance already at 1 month after discharge. The control group however reached a positive energy balance later on, namely at 3 months, which indicates that nutritional supplementation can improve energy balance sooner than by changes in habitual dietary intake alone.

The efficacy of nutritional supplementation was found to improve when nutritional support was incorporated in a multidisciplinary rehabilitation program. ${ }^{51,52}$ Improvements in body weight, body composition, muscle strength and exercise performance were found, but also health status improved in COPD patients..$^{52}$ If nutritional support results in weight gain during a rehabilitation program, even an improved survival was reported. ${ }^{6}$

Even in a controlled environment such as an in-patient pulmonary rehabilitation center, some COPD patients do not respond to nutritional intervention. In addition to non-compliance to therapy, an inadequate energy intake relative to energy requirements and the inability of the patients to ingest the extra energy, inadequate metabolic handling may contribute to poor treatment response. The interaction between nutritional depletion and systemic inflammation as well as an inverse association between systemic inflammation and response to nutritional supplementation ${ }^{37}$ have drawn attention to the potential beneficial effects of anticatabolic agents in specific modulation of the systemic inflammatory response. 
The efficacy of anti-catabolic nutritional modulation like n-3 polyunsaturated fatty acids requires further investigation.

\section{Acute exacerbation of COPD}

An impaired energy balance was found in COPD patients during the first days of hospitalization for an acute exacerbation (chapter 6), mainly due to an increased REE and a temporarily decreased dietary intake. The change in REE was significantly correlated with the change in dyspnoea score during the period of hospitalization. Besides a low dietary intake during hospitalization, also a decreased dietary intake prior to admission was reported in a substantial part of nutritionally depleted patients who were studied in chapter 7 .

Little is known on the pattern of body weight decline in COPD patients. It is possible that weight loss occurs steadily or it may be related to acute phases of the disease like exacerbations. In chapter 6 we found in well nourished COPD patients that during the hospitalization period weight could be maintained and that at 3 months after discharge the patients on average gained weight. This latter may suggest that there was some weight loss prior to admission. In the depleted COPD study population (chapter 7), the prevalence of involuntary weight loss prior to admission was high $(47 \%)$. Involuntary weight loss was reported over a period of 1-4 months and negatively correlated with resting arterial oxygen tension. It has indeed been described that hypoxemic conditions, such as during 112 high altitude climbing, lead to weight loss. ${ }^{38,53-56}$ Besides, alterations in intermediary metabolism can further aggravate weight loss and muscle wasting during acute exacerbation, as described earlier. These data indicate that nutritional deterioration is aggravated during exacerbations of the disease and is caused by several metabolic and inflammatory changes, which influence dietary intake negatively during the exacerbation or even before the exacerbation is manifested.

\section{Efficacy of nutritional intervention in acute conditions}

Until now only one study has described the efficacy of nutritional intervention during an acute exacerbation of COPD in a controlled design. No significant improvement was found in body weight, inspiratory and peripheral muscle strength, but a trend was observed in improvement in well-being score. ${ }^{57}$ Although nutritional status was not an inclusion criterion in this study, one could speculate that particularly underweight or weight-losing patients might benefit from nutritional intervention. Therefore in chapter 7 we investigated the feasibility and the efficacy of oral nutritional supplementation to improve protein and energy intake during hospitalization for an acute exacerbation in nutritionally depleted patients with COPD. Surprisingly, nutritional supplementation was feasible and 
well tolerated. Furthermore, it was able to increase energy intake and particularly protein intake in nutritionally depleted COPD patients during hospitalization for an acute exacerbation. However, the mean hospital stay of 9 days was very short to show efficacy of nutritional intervention on functional outcome measures, which was indeed not observed.

\section{Possible adverse effects of nutritional intervention}

As described earlier, dietary intervention with sip feeding could lead to reduced habitual dietary intake as a result of (acute) adverse postprandial effects on appetite, satiety or metabolism. To gain more insight into these possible adverse effects of nutritional supplementation, different nutritional experiments were conducted in stable COPD patients (chapter 3). Besides symptoms like appetite, satiety and dyspnoea, the acute effect of food ingestion was studied on energy metabolism, lung function and exercise performance. Food ingestion leads to an increase in oxygen consumption $\left(\mathrm{V}^{\prime} \mathrm{O}_{2}\right)$ and carbon dioxide production $\left(\mathrm{V}^{\prime} \mathrm{CO}_{2}\right)$ secondary to nutrient processing. As $\mathrm{V}^{\prime} \mathrm{CO}_{2}$ will raise, ventilation will be stimulated. Especially in COPD patients with limited ventilatory reserves, it can be hypothesized that the composition of nutrition may play a prominent role, as it is known that carbohydrate ingestion results in higher $\mathrm{V}^{\prime} \mathrm{CO}_{2}$. Indeed, adverse effects of carbohydrate-rich drinks have been reported in COPD patients. ${ }^{58,59}$ These effects were however reported after a very high energy load, namely 3.86 $\mathrm{MJ}$. In chapter 3, we could not confirm these findings even in severe COPD patients after a more physiological energy load. No differences in metabolic response and exercise performance were found after a fat-rich supplement and an isocaloric carbohydrate-rich supplement $(1.04 \mathrm{MJ}$ in $200 \mathrm{ml})$. These findings indicate that the energy load influences the metabolic response more than the food composition and this was confirmed by a more pronounced metabolic response after a higher energy load, namely 2.09 MJ versus 1.04 MJ (chapter 3 ). In chapter 7, we studied the efficacy of nutritional support in hospitalized patients for an acute exacerbation of COPD. The nutritional supplements that were used were not only protein and energy-rich, but also carbohydrate-rich. Especially during acute exacerbations of COPD, it could be suggested that more carbohydrates would influence outcome negatively, since ventilation will be more limited and $\mathrm{V}^{\prime} \mathrm{CO}_{2}$ excretion more difficult. However, no differences in arterial blood gases $\left(\mathrm{PaO}_{2}\right.$ and $\left.\mathrm{PaCO}_{2}\right)$ were found between the intervention and placebo group during admission and day 4 of hospitalization (chapter 7). Probably the small size of carbohydrates per portions ( 28 gram) given at three times during the day, will have little impact on ventilatory load. Furthermore, the compliance was high during hospitalization indicating good feasibility of the used nutritional supplementation (chapter 7). The nutritional supplementation consisted of 3 packages of a small portion size $(2.38 \mathrm{MJ} /$ day), namely $125 \mathrm{ml}$ instead of the commonly used $200 \mathrm{ml}$. A recent study by our group surprisingly showed that 
nutritional support with a smaller portion size and lower energy content ( $3 \times 125$ $\mathrm{ml} ; 2.38 \mathrm{MJ} /$ day) can result in more weight gain than nutritional support with a larger portion size and even higher energy content $(3 \times 200 \mathrm{ml} ; 3.36 \mathrm{MJ} /$ day $) .{ }^{60}$ The macronutrient composition of both nutritional regimens was similar in the study, namely 60 energy\% carbohydrates, 20 energy\% protein and 20 energy\% fat. Besides smaller portion size, also a better timing of nutritional supplementation can improve the efficacy of nutritional support in COPD patients. Differences in macronutrient composition of meals or supplements may also have differential effects on gastric emptying and on (the release of biomarkers of) satiety. ${ }^{61}$ Previously it was reported that nutritional supplementation with a higher fat content resulted in a delayed gastric emptying in COPD patients. ${ }^{62}$ In chapter 4 we investigated gastric emptying rate and postprandial changes after two solid meals with different macronutrient composition, namely fat-rich versus carbohydrate-rich. The protein content was similar in both meals, because it has been suggested that satiety is influenced by protein. ${ }^{63}$ Besides gastric emptying rate, physiologic and subjective measures of satiety were incorporated in this study. Remarkably gastric emptying rate after both meals was not different in COPD patients as well as in healthy control subjects and this was similar for satiety perception during the experiment. Unrelated to gastric emptying rate, the actual food intake at the next eating episode tended to be lower after the fat-rich meal in COPD patients. This suggests that the effect of different food ingredients enhances satiety on longer term and thereby reduces appetite at the subsequent eating moment, which was supported by postprandial increased level of glucagonlike peptide- 1 after the fat-rich meal in COPD patients (chapter 4).

\section{To a more behavioral approach of dietary management}

Nutritional intervention studies in COPD patients were mainly pointed to additional oral supplementation to improve habitual dietary intake. Efficacy of dietary management might be improved by combining medically prescribed nutritional supplementation with a more behavioral approach aimed at long term changes in eating behavior and dietary intake.

Health promotion programs can be useful in COPD patients in every stage of the disease as recently reviewed by Brug et al.$^{64}$ In the development of such a health promotion program including planned dietary change interventions, three phases can be identified: problem analysis, behavior analysis, and behavioral determinants analysis. ${ }^{64}$ So the first step is an analysis of health or quality of life problems, to identify whether a health issue is important enough to spend time, money and other resources on attempts to reduce it. The following step is to identify important and potentially changeable causes of the health problem. The last step is the identification of the determinants of the risk behavior. Three categories of important as well as changeable determinants of dietary behavior have been identified: attitudes (weighing expected or perceived pros and cons), 
social influences and perceived control. These factors are assumed to influence eating behavior mostly by behavioral intentions. ${ }^{65}$

Education programs of healthy life style and self-management in COPD patients may improve the benefits of nutritional intervention, especially if it is initiated at less advanced stage of the disease. Weight loss is easily detectable, so COPD management should be aimed at early detection and treatment of weight loss. However prevention of involuntary weight loss will be even better.

Suggestions have been made that diet, besides a role in disease progression, also is implicated in the early onset of COPD. Not only dietary habits, but also a low $\mathrm{BMI}$ may be related to the risk of COPD. ${ }^{66}$ Thereby nutrition may play a role in the primary prevention of COPD. Recently, associations of the intake of n-3 fatty acids, antioxidants, fruit and vegetables and the risk of COPD have been suggested. ${ }^{67}$ However, the available evidence is not substantial enough to specify dietary advice aimed at preventing COPD. In general, the preventive dietary habits like consumption of fatty fish and fruit are in line with the guidelines of healthy nutrition. More studies are needed to address the benefits of healthy nutrition and improvements in eating behavior in patients with COPD.

Nevertheless the currently available evidence suggests that nutrition plays a pivotal role in the total disease management of COPD, from early onset until endstage disease. 


\section{References}

1. Wouters EF. Chronic obstructive pulmonary disease. 5: systemic effects of COPD. Thorax 2002;57:1067-70.

2. Nishimura $Y$, Tsutsumi $M$, Nakata $H$, Tsunenari T, Maeda $H$, Yokoyama $M$. Relationship between respiratory muscle strength and lean body mass in men with COPD. Chest 1995;107:1232-6.

3. Gosselink R, Troosters T, Decramer M. Peripheral muscle weakness contributes to exercise limitation in COPD. Am J Respir Crit Care Med 1996;153:976-80.

4. Palange $P$, Forte $S$, Felli A, Galassetti P, Serra P, Carlone S. Nutritional state and exercise tolerance in patients with COPD. Chest 1995;107:1206-12.

5. Celli BR, Cote CG, Marin JM, Casanova C, Montes de Oca M, Mendez RA, Pinto Plata $\mathrm{V}$, Cabral HJ. The body-mass index, airflow obstruction, dyspnoea, and exercise capacity index in chronic obstructive pulmonary disease. $N$ Engl J Med 2004;350:1005-12.

6. Schols AM, Slangen J, Volovics L, Wouters EF. Weight loss is a reversible factor in the prognosis of chronic obstructive pulmonary disease. Am J Respir Crit Care Med 1998;157:1791-7.

7. Prescott E, Almdal T, Mikkelsen KL, Tofteng CL, Vestbo J, Lange P. Prognostic value of weight change in chronic obstructive pulmonary disease: results from the Copenhagen City Heart Study. Eur Respir J 2002;20:539-44.

8. Schols AM, Wouters EF, Soeters PB, Westerterp KR. Body composition by bioelectrical-impedance analysis compared with deuterium dilution and skinfold anthropometry in patients with chronic obstructive pulmonary disease. Am J Clin Nutr 1991;53:421-4.

9. Schols AM, Dingemans AM, Soeters PB, Wouters EF. Within-day variation of bioelectrical resistance measurements in patients with chronic obstructive pulmonary disease. Clinical Nutrition 1990;9:266-71.

10. Steiner MC, Barton RL, Singh S], Morgan MD. Bedside methods versus dual energy Xray absorptiometry for body composition measurement in COPD. Eur Respir J 2002;19:626-31.

11. Kilduff LP, Fuld JP, Neder JA, Pitsiladis YP, Carter R, Stevenson R, Ward SA. Clinical relevance of inter-method differences in fat-free mass estimation in chronic obstructive pulmonary disease. Respiration 2003;70:585-93.

12. Janssen I, Baumgartner RN, Ross R, Rosenberg IH, Roubenoff R. Skeletal muscle cutpoints associated with elevated physical disability risk in older men and women. Am J Epidemiol 2004;159:413-21.

13. Engelen MP, Schols AM, Does JD, Wouters EF. Skeletal muscle weakness is associated with wasting of extremity fat- free mass but not with airflow obstruction in patients with chronic obstructive pulmonary disease. Am J Clin Nutr 2000;71:733-8.

14. Baarends EM, Schols AM, Mostert R, Wouters EF. Peak exercise response in relation to tissue depletion in patients with chronic obstructive pulmonary disease. Eur Respir J 1997;10:2807-13.

15. Faisy C, Rabbat A, Kouchakji B, Laaban JP. Bioelectrical impedance analysis in estimating nutritional status and outcome of patients with chronic obstructive pulmonary disease and acute respiratory failure. Intensive Care Med 2000;26:518-25. 
16. Creutzberg EC, Schols AM, Bothmer-Quaedvlieg FC, Wouters EF. Prevalence of an elevated resting energy expenditure in patients with chronic obstructive pulmonary disease in relation to body composition and lung function. Eur / Clin Nutr 1998;52:396-401.

17. Engelen MP, Deutz NE, Wouters EF, Schols AM. Enhanced levels of whole-body protein turnover in patients with chronic obstructive pulmonary disease. Am J Respir Crit Care Med 2000;162:1488-92.

18. Pouw EM, Schols AM, Deutz NE, Wouters EF. Plasma and muscle amino acid levels in relation to resting energy expenditure and inflammation in stable chronic obstructive pulmonary disease. Am J Respir Crit Care Med 1998;158:797-801.

19. Schols AM, Buurman WA, Staal - van den Brekel AJ, Dentener MA, Wouters EF. Evidence for a relation between metabolic derangements and increased levels of inflammatory mediators in a subgroup of patients with chronic obstructive pulmonary disease. Thorax 1996;51:819-24.

20. Kotler DP. Cachexia. Ann Intern Med 2000;133:622-34.

21. Schols AM, Fredrix EW, Soeters PB, Westerterp KR, Wouters EF. Resting energy expenditure in patients with chronic obstructive pulmonary disease. Am J Clin Nutr 1991;54:983-7.

22. Goldstein S, Askanazi J, Weissman C, Thomashow B, Kinney JM. Energy expenditure in patients with chronic obstructive pulmonary disease. Chest 1987;91:222-4.

23. Creutzberg EC, Schols AM, Bothmer-Quaedvlieg FC, Wesseling G, Wouters EF. Acute effects of nebulized salbutamol on resting energy expenditure in patients with chronic obstructive pulmonary disease and in healthy subjects. Respiration 1998;65:375-80.

24. Nguyen LT, Bedu M, Caillaud D, Beaufrere B, Beaujon G, Vasson M, Coudert J, Ritz P. Increased resting energy expenditure is related to plasma TNF-alpha concentration in stable COPD patients. Clin Nutr 1999;18:269-74.

25. Walsmith J, Roubenoff R. Cachexia in rheumatoid arthritis. Int J Cardiol 2002;85:8999.

26. Garcia-Lorda $P$, Serrano $P$, Jimenez-Exposito $M J$, Fraile J, Bullo $M$, Alonso $C$, Bonada $A$, Viciana $P$, Luna PP, Salas-Salvado J. Cytokine-driven inflammatory response is associated with the hypermetabolism of AIDS patients with opportunistic infections. J Parenter Enteral Nutr 2000;24:317-22.

27. Baarends EM, Schols AM, Pannemans DL, Westerterp KR, Wouters EF. Total free living energy expenditure in patients with severe chronic obstructive pulmonary disease. Am J Respir Crit Care Med 1997;155:549-54.

28. Baarends EM, Schols AM, Akkermans MA, Wouters EF. Decreased mechanical efficiency in clinically stable patients with COPD. Thorax 1997;52:981-6.

29. Mannix ET, Manfredi F, Farber MO. Elevated O2 cost of ventilation contributes to tissue wasting in COPD. Chest 1999;115:708-13.

30. Gosker HR, Schrauwen P, Hesselink MK, Schaart G, van der Vusse G), Wouters EF, Schols AM. Uncoupling protein-3 content is decreased in peripheral skeletal muscle of patients with COPD. Eur Respir J 2003;22:88-93.

31. Slinde F, Ellegard L, Gronberg AM, Larsson S, Rossander-Hulthen L. Total energy expenditure in underweight patients with severe chronic obstructive pulmonary disease living at home. Clin Nutr 2003;22:159-65. 
32. Goris $A H$, Meijer EP, Kester A, Westerterp KR. Use of a triaxial accelerometer to validate reported food intakes. Am J Clin Nutr 2001;73:549-53.

33. Plata-Salaman CR. Central nervous system mechanisms contributing to the cachexiaanorexia syndrome. Nutrition 2000;16:1009-12.

34. van Ede L, Yzermans CJ, Brouwer HJ. Prevalence of depression in patients with chronic obstructive pulmonary disease: a systematic review. Thorax 1999;54:688-92.

35. Lacasse Y, Rousseau L, Maltais F. Prevalence of depressive symptoms and depression in patients with severe oxygen-dependent chronic obstructive pulmonary disease. J Cardiopulm Rehabil 2001;21:80-6.

36. van Manen JG, Bindels PJ, Dekker FW, CJ IJ, van der Zee JS, Schade E. Risk of depression in patients with chronic obstructive pulmonary disease and its determinants. Thorax 2002;57:412-6.

37. Creutzberg EC, Schols AM, Weling-Scheepers CA, Buurman WA, Wouters EF. Characterization of nonresponse to high caloric oral nutritional therapy in depleted patients with chronic obstructive pulmonary disease. Am J Respir Crit Care Med $2000 ; 161: 745-52$.

38. Schols AM, Creutzberg EC, Buurman WA, Campfield LA, Saris WH, Wouters EF. Plasma leptin is related to proinflammatory status and dietary intake in patients with chronic obstructive pulmonary disease. Am J Respir Crit Care Med 1999;160:1220-6.

39. Creutzberg EC, Wouters EF, Vanderhoven-Augustin IM, Dentener MA, Schols AM. Disturbances in leptin metabolism are related to energy imbalance during acute exacerbations of chronic obstructive pulmonary disease. Am J Respir Crit Care Med 2000;162:1239-45.

40. Shintani $M$, Ogawa $Y$, Ebihara $K$, Aizawa-Abe $M$, Miyanaga $F$, Takaya $K$, Hayashi $T$, Inoue $G$, Hosoda K, Kojima M, Kangawa K, Nakao K. Ghrelin, an endogenous growth hormone secretagogue, is a novel orexigenic peptide that antagonizes leptin action through the activation of hypothalamic neuropeptide $\mathrm{Y} / \mathrm{Y} 1$ receptor pathway. Diabetes 2001;50:227-32.

41. Wren AM, Seal LJ, Cohen MA, Brynes AE, Frost GS, Murphy KG, Dhillo WS, Ghatei MA, Bloom SR. Ghrelin enhances appetite and increases food intake in humans. J Clin Endocrinol Metab 2001;86:5992.

42. Cummings DE, Purnell JQ, Frayo RS, Schmidova K, Wisse BE, Weigle DS. A preprandial rise in plasma ghrelin levels suggests a role in meal initiation in humans. Diabetes 2001;50:1714-9.

43. Cummings DE, Weigle DS, Frayo RS, Breen PA, Ma MK, Dellinger EP, Purnell JQ. Plasma ghrelin levels after diet-induced weight loss or gastric bypass surgery. $\mathrm{N}$ Engl J Med 2002;346:1623-30.

44. Nagaya $N$, Uematsu $M$, Kojima $M$, Date $Y$, Nakazato $M$, Okumura $H$, Hosoda $H$, Shimizu W, Yamagishi $M$, Oya $H$, Koh H, Yutani C, Kangawa K. Elevated circulating level of ghrelin in cachexia associated with chronic heart failure: relationships between ghrelin and anabolic/catabolic factors. Circulation 2001;104:2034-8.

45. Weisberg J, Wanger J, Olson J, Streit B, Fogarty C, Martin T, Casaburi R. Megestrol acetate stimulates weight gain and ventilation in underweight COPD patients. Chest 2002;121:1070-8.

46. Ferreira IM, Brooks D, Lacasse $Y$, Goldstein RS. Nutritional support for individuals with COPD: a meta-analysis. Chest 2000;117:672-8. 
47. Lewis MI, Belman MJ, Dorr Uyemura L. Nutritional supplementation in ambulatory patients with chronic obstructive pulmonary disease. Am rev respir dis 1987;135:1062-8.

48. Knowles JB, Fairbarn MS, Wiggs BJ, Chan Yan C, Pardy RL. Dietary supplementation and respiratory muscle performance in patients with COPD. Chest 1988;93:977-83.

49. Efthimiou J, Fleming J, Gomes C, Spiro SG. The effect of supplementary oral nutrition in poorly nourished patients with chronic obstructive pulmonary disease. Am Rev Respir Dis 1988;137:1075-82.

50. Rogers RM, Donahoe $M$, Costantino J. Physiologic effects of oral supplemental feeding in malnourished patients with chronic obstructive pulmonary disease. A randomized control study. Am Rev Respir Dis 1992;146:1511-7.

51. Schols AM, Soeters PB, Mostert R, Pluymers RJ, Wouters EF. Physiologic effects of nutritional support and anabolic steroids in patients with chronic obstructive pulmonary disease. A placebo- controlled randomized trial. Am J Respir Crit Care Med 1995;152:1268-74.

52. Creutzberg EC, Wouters EF, Mostert R, Weling-Scheepers CA, Schols AM. Efficacy of nutritional supplementation therapy in depleted patients with chronic obstructive pulmonary disease. Nutrition 2003;19:120-7.

53. Schols AM, Westerterp KR. Hypoxia, nitrogen balance and body weight. Eur Respir J 2002;20:252-3.

54. Westerterp KR, Meijer EP, Rubbens M, Robach P, Richalet JP. Operation Everest III: energy and water balance. Pflugers Arch 2000;439:483-8.

55. Westerterp-Plantenga MS. Effects of extreme environments on food intake in human subjects. Proc Nutr Soc 1999;58:791-8.

56. Takabatake N, Nakamura $H$, Abe $S$, Inoue $S$, Hino T, Saito H, Yuki H, Kato S, Tomoike $H$. The relationship between chronic hypoxemia and activation of the tumor necrosis factor-alpha system in patients with chronic obstructive pulmonary disease. Am ) Respir Crit Care Med 2000;161:1179-84.

57. Saudny-Unterberger H, Martin JG, Gray-Donald K. Impact of nutritional support on functional status during an acute exacerbation of chronic obstructive pulmonary disease. Am J Respir Crit Care Med 1997;156:794-9.

58. Efthimiou J, Mounsey PJ, Benson DN, Madgwick R, Coles SJ, Benson MK. Effect of carbohydrate rich versus fat rich loads on gas exchange and walking performance in patients with chronic obstructive lung disease. Thorax 1992;47:451-6.

59. Frankfort JD, Fischer CE, Stansbury DW, McArthur DL, Brown SE, Light RW. Effects of high- and low-carbohydrate meals on maximum exercise performance in chronic airflow obstruction. Chest 1991;100:792-5.

60. Broekhuizen R, Creutzberg EC, Weling-Scheepers CA, Wouters EF, Schols AM. Optimizing oral nutritional supplementation in patients with chronic obstructive pulmonary disease. Submitted.

61. de Graaf C, Blom WA, Smeets PA, Stafleu A, Hendriks HF. Biomarkers of satiation and satiety. Am J Clin Nutr 2004;79:946-61.

62. Akrabawi SS, Mobarhan S, Stoltz RR, Ferguson PW. Gastric emptying, pulmonary function, gas exchange, and respiratory quotient after feeding a moderate versus high fat enteral formula meal in chronic obstructive pulmonary disease patients. Nutrition $1996 ; 12: 260-5$. 
63. Westerterp-Plantenga MS. The significance of protein in food intake and body weight regulation. Curr Opin Clin Nutr Metab Care 2003;6:635-8.

64. Brug J, Schols AM, Mesters I. Dietary change, nutrition education and chronic obstructive pulmonary disease. Patient Educ Couns 2004;52:249-57.

65. Schols AM, Brug J. Efficacy of nutritional intervention in chronic obstructive pulmonary disease. Eur Respir Mon 2003;24:142-52.

66. Harik-Khan Rl, Fleg $\mathrm{JL}$, Wise RA. Body mass index and the risk of COPD. Chest 2002;121:370-6.

67. Smit HA, Grievink L, Tabak C. Dietary influences on chronic obstructive lung disease and asthma: a review of the epidemiological evidence. Proc Nutr Soc 1999;58: 309-19. 
Chapter 9

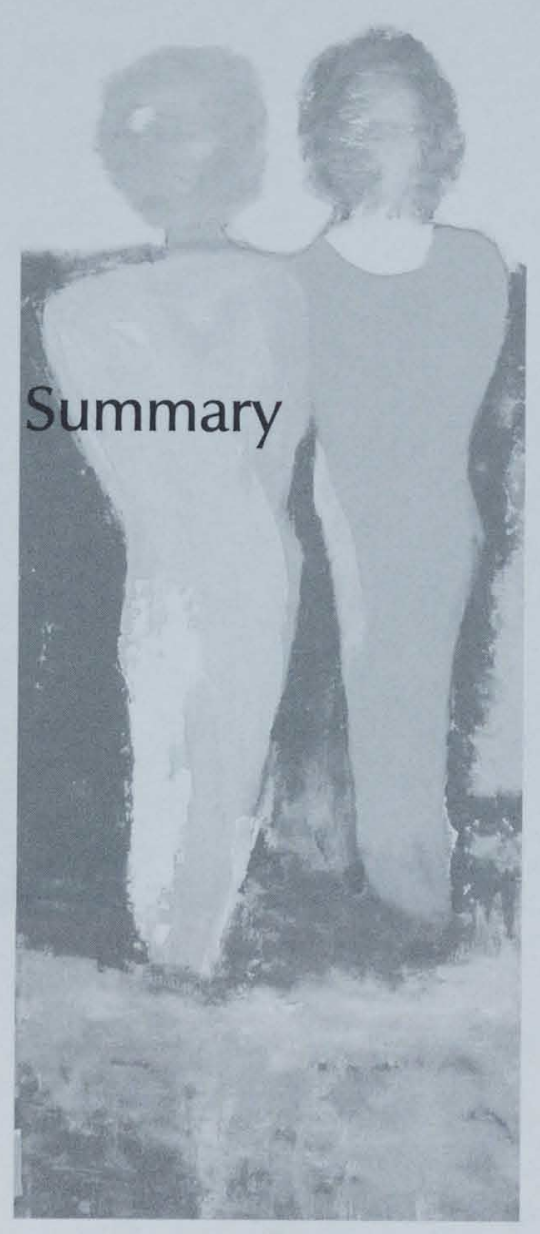


Chapter 9

122 


\section{Introduction}

The studies presented in this thesis aimed to gain more insight into dietary factors that adversely affect nutritional status in patients with chronic obstructive pulmonary disease. The following topics were addressed: 1) nutritional status characterized by body composition in an out-patient COPD population in the Netherlands, 2) potential acute postprandial adverse effects of supplemental nutrition in depleted COPD patients that may limit effectiveness and compliance of nutritional support and 3) the influence of hospitalization for an acute exacerbation on the nutritional profile as well as the feasibility of nutritional supplementation.

\section{Nutritional status}

Nutritional depletion and muscle dysfunction commonly occur in patients with COPD. Nutritional depletion is associated with adverse effects on respiratory and peripheral muscle function, exercise capacity and health status. In chapter 2 , the prevalence of nutritional depletion in relation to functional performance, airflow limitation, dyspnoea and health status is reported in a large multi-center outpatient population with moderate and severe COPD. Body composition was measured by bioelectrical impedance analysis in 389 COPD patients in the Netherlands. Nutritional depletion was defined as body mass index (BMI) $\leq 21 \mathrm{~kg} / \mathrm{m}^{2}$ and/or fat-free mass index (FFMl) $\leq 15$ (females) or $\leq 16$ (males) $\mathrm{kg} / \mathrm{m}^{2}$.

Nutritional depletion was present in $27 \%$ of the patients. The prevalence of nutritional depletion was not different between patients with moderate and severe COPD. Surprisingly, the prevalence of nutritional depletion was higher in female compared to male COPD patients. Furthermore, a high prevalence of (hidden) loss of FFM was found in $15 \%$ of the total COPD population. In $25 \%$ of the female COPD-patients FFM depletion with body weight preservation occurred, which was significantly higher than in males (11\%). Furthermore, comparison between depleted and non-depleted COPD patients revealed no differences in FEV $\%$ predicted, dyspnoea score and health status. Besides FFM depletion, age and especially gender were found as independent predictors of muscle weakness in COPD measured by handgrip strength.

These data indicate that for diagnostic purpose, assessment of body composition is useful to assess systemic disease severity, not only in patients with severe COPD, but also in those with mild to moderate disease. 


\section{Adverse effects}

When optimal adaptation of dietary habits fails to improve dietary intake to reverse weight loss, nutritional supplementation is commonly indicated. Implementation of nutritional supplements in COPD patients requires careful balancing between positive effects on outcome and possible acute adverse effects on metabolism and exercise performance. Therefore, in chapter 3 the acute effects of different liquid oral nutritional supplements on lung function, symptoms and exercise capacity were investigated. In part 1 of the study, the effects of supplements with a different energy load (placebo: $209 \mathrm{~kJ}, 1046 \mathrm{~kJ}, 2092 \mathrm{~kJ}$ ) and a normal macronutrient distribution were measured in 14 COPD patients. In the second part of the study, the effects of a fat-rich versus a carbohydrate-rich supplement $(1046 \mathrm{~kJ})$ were studied in 11 COPD patients.

In general this study did not show significant adverse effects of the studied nutritional supplements on the ventilatory system. A higher energy load (2092 kJ) resulted in a significantly higher metabolic and ventilatory response and in a higher satiety sensation, but was not reflected in a decreased exercise capacity for the total study group. A remarkable observation in part 1 of the study was the dramatically decreased endurance capacity after $2092 \mathrm{~kJ}$ in 3 COPD patients compared to $1046 \mathrm{~kJ}$ and placebo. These patients were exactly the ones in great need for nutritional support, since they were characterized as being severely cachectic with a low BMI, low FFMI and a low maximal exercise capacity.

The suggestion that carbohydrate-rich supplements would induce a higher ventilation due to a higher respiratory quotient was not confirmed in the second part of this study. Differences in fat versus carbohydrate content of supplements were not reflected in differences in endurance capacity in COPD patients. In contrast, shortness of breath increased postprandial more after ingestion of the fat-rich supplement than after the carbohydrate-rich supplement. These combined findings indicate that in clinically stable COPD patients, when given in moderate size amounts, a carbohydrate-rich drink is preferable to a fat-rich drink.

We hypothesized that delayed gastric emptying might be present in depleted COPD patients with lung hyperinflation relative to healthy control subjects due to different macronutrient content. Furthermore a more pronounced effect of different macronutrient content on gastric emptying might be seen in these patients that might need to be accounted for during dietary management. In Chapter 4 the effect of two isocaloric solid meals, different in macronutrient content, on gastric emptying and related parameters were investigated in 10 depleted COPD patients and 9 healthy control subjects. The meals were provided as breakfast. Gastric emptying rate was measured by ${ }^{13} \mathrm{C}$ octanoid acid breath test. Other measurements included lung function, oxygen saturation, symptoms and dietary intake. In addition, the biochemical markers, glucose, insulin, 
cholecystokinin and glucagon-like peptide-1 (GLP-1) were measured. The two different test meals were served in a randomized cross-over fashion.

No differences in gastric emptying rate after the two different meals were found in COPD patients and in control subjects and between both groups. Reported symptoms, like dyspnoea and satiety, were not different between both meals. Postprandial glucose and insulin response after the two meals were comparable in COPD patients and in healthy controls. A postprandial increase in GLP-1, a marker of satiety, after a fat-rich meal was found only in COPD patients. Furthermore, spontaneous dietary intake at lunch-time tended to be lower after a fat-rich meal in comparison with a carbohydrate-rich meal in depleted COPD patients. Therefore a potential adverse effect of a fat-rich meal seems more pronounced in perceived satiety sensation and subsequent caloric intake in depleted COPD patients with severe hyperinflation.

More insight into the energy balance of depleted ambulatory COPD patients was achieved in chapter 5. Besides body weight and energy intake, energy expenditure was established in 20 clinically stable COPD patients. Besides measurement of resting energy expenditure (REE), a 7-day assessment of physical activity with a triaxial accelerometer for movement registration was performed. Assessments were done at one month and at three months after discharge from the hospital or from the pulmonary rehabilitation center. All patients were randomly assigned to an intervention or control group with regard to nutritional supplementation. In both groups body weight remained stable after 1 or 3 months. The supplemented patients achieved a positive energy balance at month 1 in contrast to the control group which achieved balance at month 3 . The range of physical activity level (PAL) found in this population was wide, varying from 1.40 to 2.44 and mean PAL was 1.56 . Weight change over the study period was negatively associated with PAL. In COPD patients with a higher PAL it appeared very difficult to reach a positive energy balance compared to COPD patients with a lower PAL as reflected in weight change during the study period. These results indicate that more insight about the individual level of physical activity is necessary for a more appropriate estimation of energy requirement and dietary advice in ambulatory COPD patients.

\section{Acute disease exacerbations}

In 23 COPD patients acutely admitted to the hospital, dietary intake, resting energy expenditure, body composition and disease symptoms were measured to investigate the influence of an acute disease exacerbation on the nutritional and metabolic profile (chapter 6 ). These assessments were done on admission, daily throughout the hospitalization period and at discharge. In a subgroup of 10 COPD patients these assessments were also done at 3 months after discharge from the hospital. Patients received no nutritional support during hospitalization, but had the opportunity to choose their own menus. 
Prior to admission, since aggravation of symptoms, dietary intake was decreased and amounted on average $72 \%$ of habitual dietary intake. The majority of the patients also reported a very low dietary intake during the first three days of hospitalization. During hospitalization protein intake improved but remained rather low given the low activity level of the patients and the high risk for increased protein requirements. Resting energy expenditure decreased during hospitalization, but a subgroup of patients remained hypermetabolic at discharge. Interestingly, these patients were characterized by a lower BMI. Changes in dyspnoea score during hospitalization were significantly related to changes in REE. Furthermore, at discharge dietary intake was significantly higher than habitual intake, which could be related to improvement of symptoms adversely affecting appetite and dietary intake, or induced by an appetite-stimulating effect of the high dose systemic glucocorticosteroid treatment. At three months after admission, a significant body weight gain was seen. Dietary intake at three months was comparable with habitual dietary intake and REE was similar to the value of REE at discharge.

In chapter 7 the feasibility and effectiveness of an energy- and protein-rich nutritional supplement during hospitalization for an acute exacerbation was investigated in depleted COPD patients. The study design was a randomized double blind, placebo controlled two-center trial. Besides dietary intake, body composition, respiratory and skeletal muscle strength, lung function and symptoms were measured during hospitalization.

A substantial part of the COPD patients reported recent involuntary weight loss 126 prior to admission. Weight loss was inversely related to resting arterial oxygen tension on admission. A significant higher increase in energy and protein intake was seen in the treatment group and the supplementation did not interfere with normal dietary intake. Only the treatment group achieved the required protein intake of $1.5 \mathrm{~g} / \mathrm{kg}$ body weight. No significant differences in body weight were found. Furthermore, no adverse effects of carbohydrate-rich supplementation during acute exacerbation of COPD were reported in this study. The oral nutritional supplements were well tolerated and compliance was high with only a small compensatory decrease in spontaneous dietary intake, even in patients with acute respiratory failure. In contrast to earlier reports by other groups, during hospitalization no decline in muscle function consequent to the acute exacerbation was found in all patients. Probably due to the short length of stay in the hospitalization, no additional improvements in muscle strength were seen in the treatment group.

Chapter 8 comprises the general discussion of the thesis and gives implication for further investigations. 


\section{Conclusion}

The studies described in this thesis demonstrate that assessment of nutritional status (body composition additional to body weight and height) is necessary in all COPD patients, not only in weight losing or severe COPD patients. Furthermore, previously suggested adverse effects of nutrition and nutritional supplements in COPD patients were not reported in the studies.

Nutritional support is indicated not only to treat clinically stable COPD patients, but also prevent weight loss and limit an impaired protein balance in COPD patients. Nutritional intervention during hospitalization for an acute exacerbation is feasible even in patients suffering from acute respiratory failure and able to increase energy intake, in particular protein intake. These results provide further argumentation to include dietary assessment and management in an integrated approach of COPD, from prevention to end of life care. 


\section{Chapter 10}

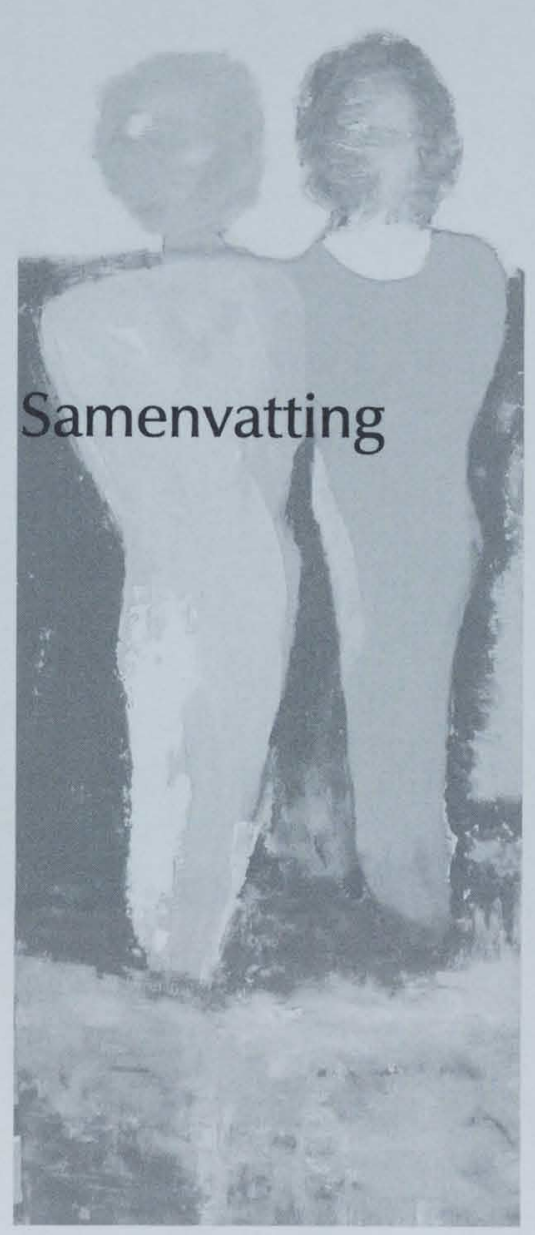


Chapter 10 


\section{Inleiding}

COPD is de engelse afkorting voor chronisch obstructieve longziekten en omvat de ziektebeelden longemfyseem en chronische bronchitis. De ziekte wordt gekenmerkt door een onomkeerbare vernauwing van de luchtwegen, die over een langere periode verergert. COPD is een invaliderende aandoening en treedt met name op bij personen van 50 jaar en ouder. Deze ziekte komt vooral voor bij mannen, maar vanwege veranderingen in het rookgedrag gedurende de afgelopen decennia neemt het aantal vrouwen met COPD sterk toe. De verwachting is dat in 2020 COPD de vierde plaats als oorzaak van sterfte zal innemen.

De prognose van de aandoening wordt bepaald door de ernst van de longfunctiestoornis op het moment dat de aandoening wordt vastgesteld en door de jaarlijkse afname van de longfunctie, maar ook door de body mass index.

De laatste jaren wordt COPD niet meer gezien als alleen een lokale orgaanstoornis, maar meer als een systeemaandoening waarbij lokale en systemische ontsteking, ontregelingen in het metabolisme, gewichtsverlies en spierzwakte een belangrijke rol spelen. De belangrijkste beperkingen die COPDpatiënten ondervinden zijn de kortademigheid en de beperkingen in het dagelijks functioneren. Het voorliggende proefschrift is met name gericht op de gewichtsproblematiek bij COPD.

\section{Doel van het onderzoek}

Het doel van het onderzoek is om de huidige tekortkomingen in de diëtistische kennis van COPD-patiënten na te gaan. De onderzoeken van het proefschrift zijn onder te verdelen in drie thema's:

1. bestudering van de omvang van een verstoorde voedingstoestand bij poliklinische COPD-patiënten.

2. bestudering van mogelijk nadelige effecten van voedingssupplementen en hieraan gerelateerde factoren op het klachtenpatroon van de patiënt die kunnen leiden tot een beperkte effectiviteit van voedingsinterventie.

3. onderzoek naar de invloed van acute opflakkeringen van de ziekte waarvoor patiënten moeten worden opgenomen in het ziekenhuis, op de voedingstoestand en daarmee samenhangend de toepasbaarheid en effectiviteit van voedingssuppletie gedurende deze periode. 


\section{Voedingstoestand}

Bij patiënten met COPD is aangetoond dat een verstoorde voedingstoestand nadelige gevolgen heeft voor het dagelijks functioneren, zoals een verminderde kracht van de ademhalingsspieren en skeletspieren, een verminderd inspanningsvermogen, verminderde kwaliteit van leven en zelfs een kortere overleving. Het is van belang om de voedingstoestand tijdig in kaart te brengen, om (verdere) verstoring van de voedingstoestand en daarmee samenhangende consequenties te voorkomen. In hoofdstuk 2 wordt de prevalentie van een verstoorde voedingstoestand, in relatie tot perifere spierkracht, luchtwegvernauwing, kortademigheid en kwaliteit van leven weergegeven. In 389 COPD-patiënten is de voedingstoestand bepaald met behulp van lengte, gewicht en lichaamssamenstelling. Het onderzoek heeft poliklinisch plaatsgevonden in 39 verschillende centra in Nederland. Een verstoorde voedingstoestand was gedefinieerd als een body mass index $(\mathrm{BMl}) \leq 21 \mathrm{~kg} / \mathrm{m}^{2}$ en/of vetvrije massa index (VVMI) $\leq 15$ (vrouwen) of $\leq 16$ (mannen) $\mathrm{kg} / \mathrm{m}^{2}$. In $73 \%$ van de totale groep van COPD-patiënten was er sprake van een goede voedingstoestand. In de resterende $27 \%$ was de voedingstoestand verstoord. Er werden geen verschillen gevonden tussen patiënten met matig COPD en patiënten met ernstig COPD. Verborgen verlies van vetvrije massa (VVM), met behoud van lichaamsgewicht, kwam voor bij $15 \%$ van de totale populatie en bij vrouwen was deze prevalentie hoger $(25 \%)$ 132 dan bij mannen (11\%). Er werden geen significante verschillen in longfunctie, kortademigheidscore en kwaliteit van leven tussen COPD-patiënten met een verstoorde voedingstoestand in vergelijking tot COPD-patiënten met een goede voedingstoestand gevonden. Niet alleen depletie van VVM was een onafhankelijke voorspeller van spierzwakte, maar ook leeftijd en geslacht. Met behulp van eenvoudig te bepalen klinische meetmethodieken, werd in deze studie dus de relatie tussen voedingstoestand en verminderde spierkracht bevestigd en deze correlatie was onafhankelijk van de ernst van de ziekte.

Aangezien depletie van VVM een belangrijke determinant is voor functionele capaciteit, is bepaling van de lichaamssamenstelling gewenst in de diagnosestelling en follow-up bij alle poliklinische COPD-patiënten.

\section{Nadelige effecten}

Voedingssuppletie is geïndiceerd, indien na optimalisatie van de voedselinname door aanpassing van de voedingsgewoonten gewichtsbehoud of gewichtstoename uitblijft. Implementatie van de voedingssupplementen in patiënten met COPD vraagt zorgvuldige afstemming van beoogde positieve effecten op functionele capaciteit en mogelijk nadelige effecten op ventilatie en metabolisme. In hoofdstuk 3 zijn de acute effecten van verschillende vloeibare 
voedingssupplementen op longfunctie, symptomen en inspanning beschreven. In het eerste deel van de studie, zijn de effecten van drie supplementen met een verschillende energiehoeveelheid (placebo: $209 \mathrm{~kJ}, 1046 \mathrm{~kJ}, 2092 \mathrm{~kJ}$ ) nagegaan bij 14 COPD-patiënten. In het tweede deel van de studie, is bij 11 COPD-patiënten gekeken naar de effecten van twee voedingssupplementen met een verschillende samenstelling van macronutriënten, namelijk vetrijk of koolhydraatrijk, maar met een gelijke hoeveelheid aan energie (1046 kJ).

Over het algemeen, zijn er geen nadelige effecten van de bestudeerde voedingssupplementen gevonden op de ventilatie. Een hogere energiehoeveelheid resulteerde wel in een hogere metabole en ventilatoire respons en een hoger verzadigingsgevoel, maar niet in een verminderde inspanningscapaciteit in de totale groep. Een opmerkelijke bevinding in het eerste deel van de studie was dat bij 3 COPD-patiënten de inspanningscapaciteit sterk verminderde na inname van het voedingssupplement van $2092 \mathrm{~kJ}$ terwijl deze verschillen niet gevonden waren na inname van placebo en $1046 \mathrm{~kJ}$. Deze drie patiënten hadden een lage BMI, VVMI en een lage maximale inspanningscapaciteit.

De suggestie dat een koolhydraatrijk supplement de ventilatie negatief beïnvloedt ten gevolge van een hoger respiratoir quotiënt, werd in deze studie niet bevestigd. De verschillende samenstelling van macronutriënten had geen invloed op de inspanningscapaciteit. Verder bleek de kortademigheid na inname van het vetrijke supplement significant meer toe te nemen dan na inname van het koolhydraatrijke supplement.

Een vertraagde maaglediging kan optreden bij deplete COPD-patiënten met hyperinflatie en mogelijk speelt de macronutriënten samenstelling van de voeding hierbij ook nog een rol. Hoofdstuk 4 beschrijft de maaglediging na twee vaste maaltijden met een gelijke energiehoeveelheid maar verschillend in macronutriënt samenstelling, vetrijk versus koolhydraatrijk. Deze studie is verricht bij 10 COPD patiënten met hyperinflatie en ondergewicht en bij 9 gezonde controle personen. De maaglediging was niet verschillend na beide maaltijden bij zowel COPDpatiënten als bij gezonde controle personen en tussen beide groepen. De klachten, kortademigheid en verzadiging waren vergelijkbaar na de verschillende maaltijden. Ten aanzien van de bloedparameters, werd alleen een significante toename van glucagon-like peptide-1 (een marker voor verzadiging) na de vetrijke maaltijd gevonden bij COPD-patiënten. Na voltooiing van het onderzoek, was de spontane voedselinname tijdens lunch na inname van de vetrijke maaltijd lager dan na inname van de koolhydraatrijke maaltijd. Hoewel dit verschil niet statisch significant was, duidt het resultaat mogelijk op een nadelig effect van een vetrijke maaltijd, in de perceptie van verzadiging voor of tijdens het volgende eetmoment.

Er zijn weinig gegevens beschikbaar over de energiebalans van COPD-patiënten in de thuissituatie (hoofdstuk 5). Bij 20 klinisch stabiele COPD-patiënten werd daarom lichaamsgewicht, energie-inname en het dagelijkse energiegebruik in de thuissituatie in kaart gebracht. Lichamelijke activiteit werd gemeten met behulp van een activiteitenmonitor, gedurende 7 dagen, 1 maand en 3 maanden na ontslag uit het ziekenhuis of het longrevalidatiecentrum. Door loting werd bepaald 
of een patiënt tot de interventiegroep of controlegroep behoorde. In beide groepen bleef het gewicht gelijk gedurende de studieperiode. Vergelijking tussen deze twee tijdstippen toonde echter dat de interventiegroep eerder in een positieve energiebalans kwam dan de controlegroep. Het niveau van lichamelijke activiteit varieerde van 1.40 tot 2.44 in deze onderzoekspopulatie. Gewichtsverandering gedurende de studieperiode was negatief gecorreleerd met het niveau van lichamelijke inspanning. Voor COPD-patiënten met een hoger niveau van lichamelijke activiteiten was het moeilijker om in gewicht aan te komen. Daarentegen namen patiënten met een lager niveau van activiteiten wel in gewicht toe tijdens de studie. Dit onderzoek toont de noodzaak voor diëtisten om het dieetadvies niet alleen af te stemmen op de voedingsanamnese of voedingsdagboekjes, maar op een objectieve meting van de lichamelijke activiteiten.

\section{Acute exacerbatie}

Om de invloed van een acute exacerbatie (opflakkering) van COPD op de voedingsstatus en het metabole profiel te onderzoeken werd in 23 COPDpatiënten, acuut opgenomen in het ziekenhuis, voedselinname, ruststofwisseling en lichaamssamenstelling gemeten (hoofdstuk 6). Deze metingen werden verricht bij opname, dagelijks tijdens het ziekenhuisverblijf en bij ontslag. In een subgroep van 10 COPD-patiënten zijn deze metingen 3 maanden na ontslag herhaald.

134 Patiënten hebben tijdens opname geen voedingsinterventie gekregen, maar zij hadden de mogelijkheid om hun eigen maaltijden samen te stellen.

De voedselinname voorafgaand aan de ziekenhuisopname was verminderd samenhangend met een toename van ziektesymptomen en bedroeg gemiddeld $72 \%$ van de gebruikelijke voedselinname. Het merendeel van de patiënten rapporteerde daarbovenop een erg lage voedselinname gedurende de eerste drie dagen van opname. Gedurende de ziekenhuisperiode verbeterde de energie- en eiwitinname, maar de eiwitinname bleef lager dan de aanbevolen hoeveelheid.

De ruststofwisseling was verhoogd gedurende de eerste dagen in het ziekenhuis, maar daalde tijdens het resterende ziekenhuisverblijf. In een subgroep van patiënten bleef het rustmetabolisme verhoogd bij ontslag. Opvallenderwijs waren deze patiënten gekarakteriseerd door een lage BMI. Veranderingen in de kortademigheidscore tijdens ziekenhuisopname waren significant gerelateerd aan veranderingen in de ruststofwisseling. Bij ontslag was de voedselinname significant hoger dan de gebruikelijke inname. Mogelijk ten gevolge van de negatieve balans was er sprake van een compensatie die samengaat met de verbetering van klachten of geïnduceerd kan zijn door het eetluststimulerende effect van de hoge dosis glucocorticosteroïden als medicamenteuze therapie. Drie maanden na ontslag vertoonde de subgroep van 10 COPD-patiënten een significante gewichtstoename. De voedselinname was drie maanden na ontslag vergelijkbaar met de gebruikelijke voedselinname en het rustmetabolisme was hetzelfde als bij ontslag. 
In hoofdstuk 7 zijn de toepasbaarheid en de effectiviteit van een energie- en eiwitrijk supplement tijdens de ziekenhuisopname voor een acute exacerbatie onderzocht in 56 deplete COPD-patiënten. De gerandomiseerde, dubbel-blinde, placebo-gecontroleerde studie werd verricht in twee ziekenhuizen, namelijk azM en MMC, locatie Veldhoven.

Een aanzienlijk deel van de COPD-patiënten rapporteerde recentelijk ongewenst gewichtsverlies voorafgaande aan de ziekenhuisopname. Gewichtsverlies was gerelateerd aan de zuurstofspanning in het bloed bij opname in het ziekenhuis; hoe lager de arteriële zuurstofspanning, hoe hoger het gewichtsverlies bij COPDpatiënten. De toename van de energie- en eiwitinname was significant groter in de groep met voedingssupplementen en de supplementen interfereerden niet met de normale voedselinname. Alleen de gesuppleerde groep patiënten bereikte de aanbevolen eiwitbehoefte van $1.5 \mathrm{~g} / \mathrm{kg}$ lichaamsgewicht. Geen significante verschillen in het verloop van het lichaamsgewicht traden op tussen de interventie groep en de controle groep. De voedingssupplementen werden goed getolereerd, een goede compliance met een kleine afname in de spontane voedselinname, ook in die patiëntengroep met acuut respiratoir falen. In tegenstelling met eerdere bevindingen door andere onderzoeksgroepen, werd er tijdens opname geen vermindering van de spierfunctie gevonden in alle patiënten. Waarschijnlijk ten gevolge van de korte duur van de ziekenhuisopname, werden er geen aanvullende verbeteringen in spierkracht gevonden in de interventiegroep.

Hoofdstuk 8 omvat de algemene discussie en een aanzet voor verder onderzoek.

\section{Conclusie}

De studies, beschreven in dit proefschrift, tonen het belang aan van het meten van de lichaamssamenstelling aanvullend op lichaamsgewicht en lengte tijdens diagnostiek en follow-up van alle poliklinische COPD-patiënten, en niet alleen bij patiënten die gewichtsverlies vertonen of met ernstig COPD. In tegenstelling tot suggesties uit de literatuur werden er geen acute nadelige effecten van voeding en voedingssupplementen gevonden op het klachtenpatroon, de ventilatie en de stofwisseling van COPD-patiënten.

Voedingsinterventie is geïndiceerd niet alleen om klinisch stabiele COPDpatiënten te behandelen, maar ook om gewichtsverlies te voorkomen en om de verstoorde eiwitbalans te beperken bij patiënten met COPD. Voedingsinterventie tijdens ziekenhuisopname voor een acute exacerbatie is toepasbaar, ook bij COPD-patiënten met acuut respiratoir falen, en resulteert in een verbetering van de energie-inname en in het bijzonder van de eiwitinname.

Deze resultaten bieden een verdere onderbouwing van de toepassing van nutritional assessment en management in een geïntegreerde benadering van $\mathrm{COPD}$, van preventie tot palliatieve zorg. 


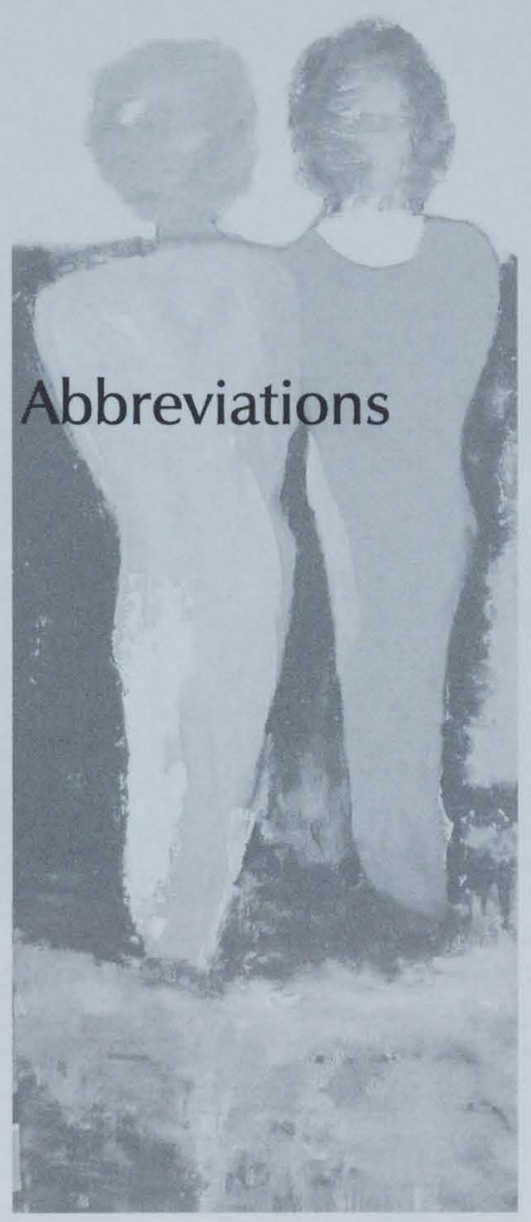


Appendices 


\section{Abbreviations}

$\begin{array}{ll}\text { \%FM } & \text { fat mass as percentage of body weight } \\ \% \text { predicted } & \text { percentage of predicted } \\ \text { ANOVA } & \text { analysis of variance } \\ \text { ATP/ADP ratio } & \text { adenosine triphosphate/adenosine diphosphate ratio } \\ \text { BIA } & \text { bioelectrical impedance analysis } \\ \text { BIS } & \text { bioelectrical impedance spectroscopy } \\ \text { BM } & \text { body mass } \\ \text { BMI } & \text { body mass index } \\ \text { BMR } & \text { basal metabolic rate } \\ \text { CCK } & \text { cholecystokinin } \\ \text { CHO } & \text { carbohydrates } \\ \text { COPD } & \text { chronic obstructive pulmonary disease } \\ \text { CRP } & \text { C-reactive protein } \\ \text { DIT } & \text { diet-induced thermogenesis } \\ \text { DIco } & \text { diffusing capacity for CO } \\ \text { DEXA } & \text { dual-energy x-ray absorptiometry } \\ \text { ECW } & \text { extracellular water } \\ \text { ECW/ICW ratio } & \text { extracellular/intracellular water ratio } \\ \text { EDTA } & \text { ethylene-diamine-tetraacetic acid } \\ \text { EE } & \text { energy expenditure } \\ \text { EI } & \text { energy intake } \\ \text { ELISA } & \text { enzyme-linked immunosorbent assay } \\ \text { en\% } & \text { energy\% } \\ \text { FEV } & \text { forced expiratory volume in one second } \\ \text { FFM } & \text { fat-free mass } \\ \text { FFMI } & \text { fat-free mass index } \\ \text { FM } & \text { fat mass } \\ \text { FVC } & \text { forced vital capacity } \\ \text { g } & \text { gram } \\ \text { GLP-1 } & \text { glucagon-like peptide-1 } \\ \text { GOLD } & \text { The Global Initiative for Chronic Obstructive Lung Disease } \\ \text { h } & \text { hour } \\ \text { HB } & \text { Harris and Benedict } \\ \text { ICW } & \text { intracellular water } \\ \text { IGF } & \text { insulin-like growth factor } \\ \text { IL } & \text { interleukin } \\ \text { ITGV } & \text { intrathoracic gas volume } \\ \text { IVC } & \text { inspiratory vital capacity } \\ \text { kg } & \text { kilogram } \\ \text { kJ } & \text { kilojoules } \\ \text { LPS } & \\ & \end{array}$




\begin{tabular}{|c|c|}
\hline $\mathrm{m}$ & meter \\
\hline MA & megesterol acetate \\
\hline MEF & mean expiratory flow \\
\hline MJ & megajoules \\
\hline $\min$ & minutes \\
\hline MRC & the Medical Research Council \\
\hline $\mathrm{mRNA}$ & messenger ribonucleic acid \\
\hline$n$ & number \\
\hline $\mathrm{Nm}$ & Newton meters \\
\hline NMR & nuclear magnetic resonance \\
\hline ns & not significant \\
\hline OCB & oxygen cost of breathing \\
\hline p (-value) & statistical significance \\
\hline $\mathrm{PaCO}_{2}$ & arterial carbon dioxide tension \\
\hline PA & physical activity \\
\hline PAL & physical activity level \\
\hline $\mathrm{PaO}_{2}$ & arterial oxygen tension \\
\hline Pe-max & maximal expiratory mouth pressure \\
\hline PEF & peak expiratory flow \\
\hline Pi-max & maximal inspiratory mouth pressure \\
\hline $\mathrm{r}$ & correlation coefficient \\
\hline Raw & airway resistance \\
\hline REE & resting energy expenditure \\
\hline $\mathrm{RQ}$ & respiratory quotient \\
\hline RV & residual volume \\
\hline $\mathrm{SaO}_{2}$ & arterial oxygen saturation \\
\hline $\mathrm{StO}_{2}$ & transcutaneous oxygen saturation \\
\hline $\mathrm{SD}$ & standard deviation \\
\hline SEM & standard error of the mean \\
\hline SGRQ & St. George's Respiratory Questionnaire \\
\hline SPSS & statistical product and service solutions \\
\hline$t_{1 / 2}$ & gastric emptying half-time \\
\hline$t_{\text {lag }}$ & lag phase \\
\hline TBW & total body water \\
\hline TEE & total energy expenditure \\
\hline TLC & total lung capacity \\
\hline TNF $\alpha$ & tumor necrosis factor $\alpha$ \\
\hline VAS & visual analogue scale \\
\hline $\mathrm{V}^{\prime} \mathrm{CO}_{2}$ & carbon dioxide production \\
\hline$V^{\prime} E$ & minute ventilation \\
\hline $\mathrm{V}^{\prime} \mathrm{O}_{2}$ & oxygen consumption \\
\hline Wmax & maximal exercise performance \\
\hline
\end{tabular}




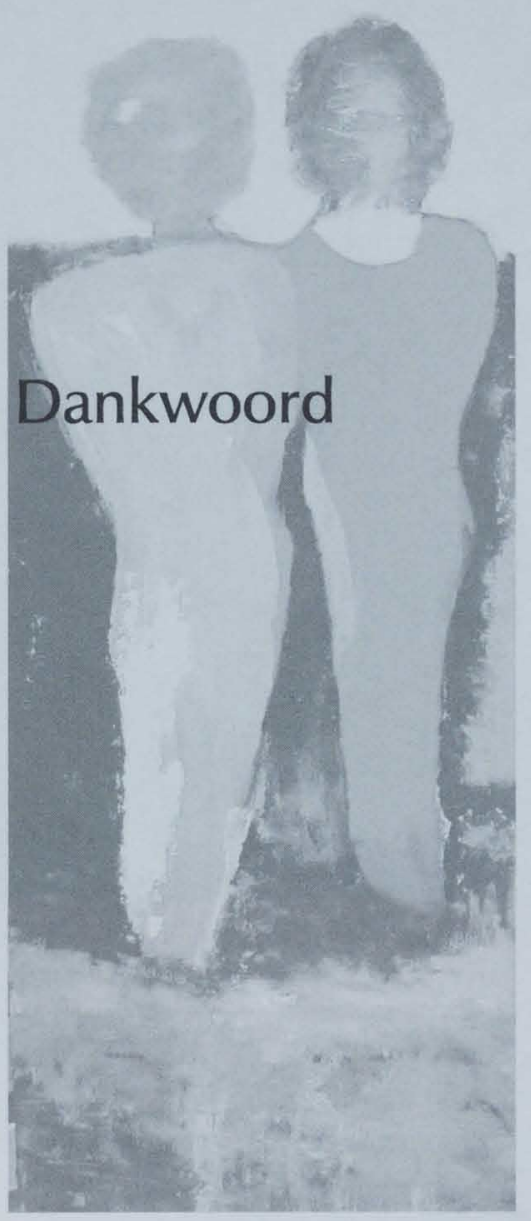


Appendices 


\section{Dankwoord}

Het dankwoord of ook wel het nawoord genoemd, het laatste deel van het proefschrift en een deel dat ik graag schrijf. Op deze wijze is het mogelijk om stil te staan bij de verschillende personen die in de afgelopen tijd medewerking verleenden, belangstelling en interesse toonden in de onderzoeksactiviteiten.

De twee personen, weergegeven in mijn proefschrift, zijn voor mij een weergave van een interactie of samenspel die kan plaatsvinden tussen personen. Het samenspel waarvoor meerdere personen nodig zijn, zo ook bij het tot stand komen van een proefschrift. Maar ook de interactie die plaats vindt tussen de diëtist en de patiënt om de dieetbehandeling tot een goed resultaat te brengen. Deze interactie tussen de verschillende personen kan heel divers plaatsvinden, kan zeer intrigerend zijn en maakt het geheel vaak interessant en boeiend. En hoe beter de interactie of het samenspel, hoe beter of mooier het resultaat.

Allereerst een woord van dank aan alle patiënten die deelgenomen hebben aan de diverse onderzoeken. Zeker de patiënten die tijdens een acute opname hebben deelgenomen, vaak zo kort van adem en toch meteen hun goedkeuring hebben gegeven voor deelname aan de studie. Bewonderenswaardig deze houding ten aanzien van de wetenschap. De huisbezoeken, de hartelijke ontvangst door jullie en de functie als taxivervoer vond ik heel bijzonder. Hoe dan ook, zonder jullie deelname had ik deze onderzoeken niet kunnen volbrengen. Natuurlijk, ook een woord van dank aan de gezonde controle personen.

Een speciaal woord van dank aan Prof. dr. EFM Wouters en Prof. dr. ir. AMWJ Schols, beide hebben het mij mogelijk gemaakt om voedingsonderzoek te verrichten bij COPD patiënten en om dit onderzoek af te sluiten met een promotie.

Prof. Wouters, de discussies rondom de onderzoeksactiviteiten waren boeiend en leerzaam. Verder ben ik er van overtuigd, dat als er in de toekomst een specialisatie voor "respiratory dietician" komt, u hier zeer zeker bij betrokken moet zijn.

Wanneer ik gestrand was in alle onderzoeksgegevens, wist jij, Annemie, weer structuur te brengen in het geheel. Op alle wetenschappelijke aspecten heb ik ondersteuning kunnen vinden in de afgelopen tijd, dat heb ik zeer gewaardeerd.

I $k$ wil de beoordelingscommissie onder leiding van Prof. dr. RJM Brummer en verder bestaande uit Prof. dr. PB Soeters, Prof. dr. JJ van Binsbergen, Prof. dr. WA van Staveren en dr. MS Westerterp-Plantenga, hartelijk bedanken voor het beoordelen van het proefschrift. 
Kijkende naar de afgelopen jaren in het azM, bedank ik Phil Geerlings voor de ondersteuning. Phil, fijn dat je mij de afgelopen jaren het vertrouwen en de ruimte hebt gegeven om dit alles tot een mooi einde te brengen.

Binnen de afdeling diëtetiek heb ik ook veel wetenschappelijke ondersteuning gevonden bij Nel Cox. Nel, de vele discussies met jou heb ik als heel prettig ervaren.

Verder natuurlijk een dankwoord aan alle collega's van de afdeling diëtetiek, Riëtte, Mariska, Christianne, Esther H, Esther M, Yvonne, Linda, Sandra, Liesbeth, Ingrid, José, Mieke, Corrie, Nicole H, Nicole P, Mariëlle, Anita, Angelique, Maike en Anke. Maar ook enkele ex-diëtetiek medewerkers, Carla en Rosita voor hun belangstelling en de gezellige invulling van de lunch in het azM.

Mijn vele vragen zijn door diverse collega's van de onderzoeksgroep altijd prima beantwoord. Heel erg bedankt, met name Eva, Erica B, Juanita, Ramon, Frits, Harry, Chris, Mieke, Mariëlle, Roelinka, Erica R, Kirsten, Evi, Marco, Jos, Astrid, Roy en Kim. In de afgelopen tijd is vooral met de 'oudere' onderzoekers het contact intensiever geweest, maar ook met de 'jongere' onderzoekers verloopt het contact prima. Bedankt voor jullie hulp.

Zonder de longartsen en arts-assistenten Longziekten was het niet mogelijk geweest om de patiënten te selecteren voor deelname aan het onderzoek. Maar ook voor het inbrengen van een infuusnaald of voor bloedafname, was hun medewerking nodig. Een ieder van jullie bedankt voor de medewerking.

Ook het secretariaat Longziekten heb ik geregeld belaagd met vragen, heel erg bedankt voor de hulp.

Natuurlijk ook een woord van dank aan Verpleegafdeling A3 in het azM, en in het bijzonder voor Lena, Camiel en Janine, bedankt voor jullie hulp en ondersteuning bij de voedingsinterventie studie.

Ingrid, Paul, Marie-José en alle medewerkers van de longfunctie wil ik hartelijk bedanken voor het verrichten van de diverse metingen bij de onderzoeken. Maar ook voor de gezelligheid gedurende de periode dat ik gebruik mocht maken van een werkruimte op de longfunctie.

Een speciaal woord van dank aan Hornerheide, voor de gastvrijheid die geboden werd en de mogelijkheden om onderzoek daar te verrichten. Clarie Weling, heel erg bedankt voor de organisatie en het includeren van de onderzoekspersonen. Rob Mostert, Herman Jan Pennings, Joan Does, Marianne en Kitty, Marco Akkermans, Annelies en collega's van het lab, de 'dames' van de afdelingskeuken en het verplegend personeel van Hornerheide. Bedankt allemaal, de samenwerking met jullie is prima verlopen.

Afdeling fysiotherapie azM voor de cybex-metingen, vooral Ton, Appie en ook Carlo hebben te allen tijde deze metingen verricht. Ondanks dat het vaak op zeer korte termijn gepland moest worden, was er altijd bereidwilligheid om de meting uit te voeren. Ik heb met veel plezier met jullie samengewerkt in de afgelopen tijd. 
Ook wil ik Robert-Jan Brummer, professor medische voeding en klinische dietetiek, bedanken voor zijn bijdrage. Robert-Jan, bedankt voor jouw ondersteuning en ik hoop dat we samen met de collega's diëtetiek de verdere onderbouwing van diëtetiek kunnen uitdragen.

Bij de studie naar de maaglediging heeft Michiel van Nieuwenhoven ook een bijdrage geleverd, Michiel, heel erg bedankt voor jouw aanvullingen en inbreng. Dr. PPCA Menheere en zijn lab, klinische chemie lab 5, hebben altijd klaar gestaan voor de diverse bepalingen, of het nu koffiepauze was of niet, de begroeting was altijd vriendelijk. Dr. Menheere, Jean-Marie en collega's, heel erg bedankt voor jullie hulpvaardigheid en vriendelijkheid.

Verder wil ik Prof. dr. DS Postma, dr. AC Roldaan, dr. WR Pieters, Prof. dr. KR Westerterp, Annelies Goris, Lotte Nelissen, Zandri Hofman, Annika van Lier, Gonnie Geraerts en Carel van de Wetering, bedanken voor hun medewerking aan de studies.

Mijn kamergenoten, Raymond, Gerry, Dorien en Wies, wil ik ook graag bedanken. In de afgelopen tijd zijn jullie zeer verdraagzaam geweest naar mij toe, ondanks het stressen. Dit waardeer ik zeer en ik vind het prettig om met jullie samen te werken. Ook 'de meisjes' van de poli, Anita, Mieke, Sonja, Willy en Margaret, wil ik bedanken, aangezien ik gebruik heb mogen maken van hun faciliteiten.

Tiny Wouters wil ik bedanken voor de ondersteuning bij de lay-out van het proefschrift en bij het zetten van de puntjes op de i. Tiny, mede dankzij jouw inzet is het zo'n mooi boekje geworden.

Zo zijn er nog vele personen geweest die ontspanning en afleiding hebben geboden naast de onderzoekswerkzaamheden, Marije en Rien, Yvonne, Monique, Maurice en Fanny (in de trein), Mireille en Ghislaine (culinair), Celeste (sportief). Maar ook de 'jonge moeders', Anita, Yvonne, Giovanni en Mariëlle, onze zonen worden dit jaar 10 jaar. Verder ook Rien en Nicole, die bij een afspraakje informeerden naar de stand van zaken. Ook jullie, bedankt voor de gezelligheid.

Het schilderij, voortgekomen uit de samenwerking tussen moeder en zoon, dient als omslag en illustraties van mijn proefschrift. Bedankt, Lenie en Walter.

Dan de paranimfen Marije en Jenny. Marije, het feit dat onze vriendschap gedurende de onderzoeksperiode gegroeid en versterkt is, geeft onze band weer. Een eenmalig bedankje is niet afdoende, dat weet je. Ik zal het regelmatig tegen je zeggen de komende tijd. Jenny, ik ben heel erg blij dat je deze rol wilt vervullen en dat jij naast mij staat.

Ma, samen met pa was je heel trots op mijn promotietraject. Helaas kan pa deze dag niet meer meemaken, hij had dit zo graag gewild. Fijn dat jij er wel bent. Maar ook fijn dat al mijn familieleden, Hans, Marja, Jenny, Joop, Karin, Jeroen, José en Yvon en Ruud aanwezig zijn. Bedankt een ieder van jullie. 
Als laatste 'mijn mannen', de drie grootste schatten in mijn leven. Allereerst mijn twee zonen, Bram en Timo. Ondanks dat ik veel tijd achter de pc heb doorgebracht, hebben jullie ook gezorgd voor een stuk ontspanning.

Paul, in de afgelopen tijd heb ik jouw ondersteuning heel erg gewaardeerd, ik weet dat je heel trots op mij bent. 


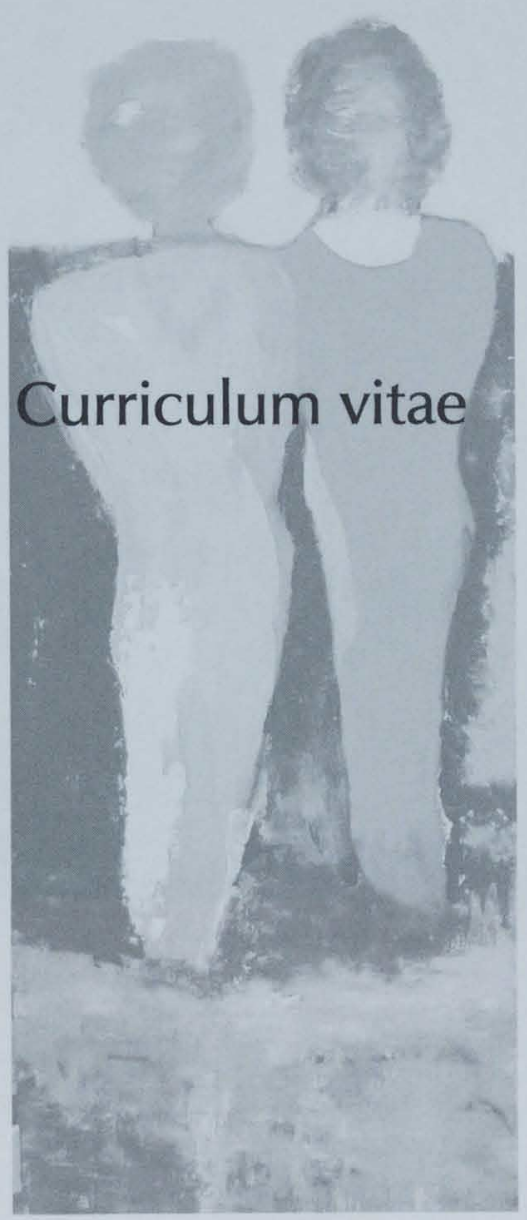


Appendices

148 


\section{Curriculum vitae}

Marja Vermeeren was born on August $30^{\text {th }}, 1964$ in Rijsbergen, The Netherlands. After she finished secondary school (Katholieke Scholengemeenschap Etten-Leur, The Netherlands) in 1982, she started education for Dietetics (Hogeschool Wachtendonck, Heerlen, The Netherlands) and she graduated in July 1986. From December 1986 until May 1990 she worked as dietitian in Sophia Hospital in Zwolle, The Netherlands. From 1989 - 1990 she attended a post-graduate course 'Research by Dieticians' (Hogeschool Voeding en Diëtetiek, Nijmegen, The Netherlands). The research conducted as an assignment of this course was her first experience with scientific research. Since July 1990 she has been working as a dietician in the Department of Dietetics at the University Hospital Maastricht. In 1992 she started working with patients with pulmonary disease, such as COPD. Since January 1998, she started with research activities concerning this thesis at the Department of Respiratory Medicine of the University Hospital of Maastricht. Firstly for one day in the week and after one year, for two days per week till now. The other days of the week she continued her dietetic activities. The research is especially directed towards optimal implementation of nutritional therapy in patients with COPD. 